\title{
LÍVIA FIORIN
}

EFEITO DE DIFERENTES PROTOCOLOS DE DESGASTE NAS

CARACTERÍSTICAS SUPERFICIAIS E COMPORTAMENTO MECÂNICO

DA ZIRCÔNIA (Y-TZP)

Ribeirão Preto

2017 

LÍVIA FIORIN

\title{
EFEITO DE DIFERENTES PROTOCOLOS DE DESGASTE NAS
}

\section{CARACTERÍSTICAS SUPERFICIAIS E COMPORTAMENTO MECÂNICO \\ DA ZIRCÔNIA (Y-TZP)}

\begin{abstract}
Dissertação apresentada à Faculdade de Odontologia de Ribeirão Preto da Universidade de São Paulo, para obtenção do título de Mestre pelo Programa de Pós-Graduação em Reabilitação Oral
\end{abstract}

Área de concentração: Reabilitação Oral

Orientadora: Prof. Dra. Renata Cristina Silveira Rodrigues Ferracioli

VERSÃO CORRIGIDA 
Autorizo a reprodução e divulgação total ou parcial deste trabalho, por qualquer meio convencional ou eletrônico, para fins de estudo e pesquisa, desde que citada a fonte.

FICHA CATALOGRÁFICA

Elaborada pela Biblioteca Central do Campus da USP - Ribeirão Preto

Fiorin, Lívia

Efeito de diferentes protocolos de desgaste nas características superficiais e comportamento mecânico da zircônia (Y-TZP). Ribeirão Preto, 2017.

119p. : il. ; $30 \mathrm{~cm}$

Dissertação de Mestrado, apresentada à Faculdade de Odontologia de Ribeirão Preto/USP. Área de concentração: Reabilitação Oral.

Versão corrigida da dissertação. A versão original se encontra disponível na unidade que aloja o programa.

Orientador: Prof. Dra. Renata Cristina Silveira Rodrigues Ferracioli

1. Zircônia, 2. Desgaste, 3. Propriedades mecânicas, 4. Fadiga. 


\section{FOLHA DE APROVAÇÃO}

FIORIN, L. Efeito de diferentes protocolos de desgaste nas características superficiais e comportamento mecânico da zircônia (Y-TZP).

Dissertação apresentada à Faculdade de Odontologia de Ribeirão Preto da Universidade de São Paulo, para obtenção do título de Mestre pelo Programa de Pós-Graduação em Reabilitação Oral.

Área de concentração: Reabilitação Oral

Aprovado em:

BANCA EXAMINADORA

Prof.(a) Dr.(a).:

Instituição:

Julgamento: Assinatura:

Prof.(a) Dr.(a).:

Instituição:

Julgamento: Assinatura:

Prof.(a) Dr.(a).:

Instituição:

Julgamento: Assinatura: 

Dedicatória 



\section{Dedico este trabalho,}

Aos meus pais, Edison e Marta. Com vocês conheci o amor, aprendi que a vida deve ser guiada por princípios e que deve haver uma luta diária para que os objetivos possam ser atingidos. Vê-los sempre lutando me impulsionou a traçar minhas metas e ir em busca dos meus sonhos. Vocês são minha grande inspiração e não existem palavras que possam traduzir toda a minha gratidão.

Ao meu irmão, Luís Gustavo, pelo amor, companheirismo e apoio. Tê-lo ao meu lado para compartilhar dos momentos de felicidade e até das situações mais difíceis, torna a caminhada da vida mais agradável.

Aos meus avós, Luís, Verônica, Maria e Orlando (in memorian), pelo amor, carinho e cuidado. O conforto do abraço de vocês revigoram minhas energias.

Aos familiares, em especial as queridas tias Gisele, Silvana e Elaine, que sempre me apoiaram e com quem compartilho do interesse pela educação, e os primos Pedro, Lucas, Rafael, Vinícius e Luísa, que alegram meus finais de semana.

Ao Leonardo, pelo amor e incentivo. Obrigada por estar sempre ao meu lado se alegrando com minhas conquistas e torcendo pelo meu sucesso. 

Qgradecimentos Especiais 

Agradeço primeiramente à Deus, Quem me concedeu a vida, e a Quem decidi entrega-la. Tenho aprendido a fazer todas as coisas, como para o Senhor, e tudo têm se bem sucedido. Obrigada por me acompanhar, abençoar meus caminhos, e por despertar em mim, continuamente, o amor pela profissão a qual me dedico. Graças ao Teu favor aqui estou e se há alguma honra e glória por isso, entrego-as ao Senhor.

À minha orientadora, Prof. Dra. Renata Cristina Silveira Rodrigues Ferracioli, por ter confiado em mim e se dedicado a este trabalho. Me sinto privilegiada pela oportunidade de conviver com a senhora e a tenho como grande exemplo de profissional e ser humano. Pesquisadora competente, com grande experiência clínica e de humildade admirável. Obrigada pela paciência, por toda ajuda e incentivo.

Ao Prof. Dr. Ricardo Faria Ribeiro, quem me acolheu desde a graduação e apresentou sua equipe de trabalho. Obrigada por ter aberto as portas do laboratório, do qual é responsável, para que eu pudesse fazer iniciação científica e me identificar com a carreira acadêmica. Foi uma oportunidade ímpar para que eu pudesse direcionar meus interesses na Odontologia. Agradeço também por toda colaboração no desenvolvimento deste trabalho.

À Dra. Adriana Cláudia Lapria Faria Queiróz, técnica responsável pelo Laboratório de Estudos Biomecânicos em Prótese e Implante, onde grande parte deste trabalho foi realizado. Obrigada pela amizade e colaboração. Estes anos de convivência fizeram com que eu passasse a admirar você, que é uma grande professora para todos os alunos que frequentam o laboratório. 

Qgradecimentos 

À Faculdade de Odontologia de Ribeirão Preto da Universidade de São Paulo, representada por sua diretora, Prof. Dra. Léa Assed Bezerra da Silva, pela oportunidade inestimável de ser aluna dos cursos de graduação e pós-graduação.

Ao Departamento de Química da Faculdade de Filosofia, Ciências e Letras de Ribeirão Preto, onde as análises de difração de raios- $X$ foram realizadas e ao técnico responsável, Lourivaldo dos Santos Pereira, pela prestatividade e paciência ao esclarecer minhas dúvidas sobre o método.

Ao Departamento de Odontologia Restauradora da Faculdade de Odontologia de Ribeirão Preto, em nome da Prof. Dra. Regina Guenka Palma-Dibb, por ter disponibilizado o Microscópio Confocal a Laser, e a técnica Dra. Juliana Jendiroba Faraoni, pela orientação das análises realizadas e solicitude.

Ao Programa de Pós-Graduação em Reabilitação Oral, representado por seu coordenador, Prof. Dr. Ricardo Faria Ribeiro, por todo conhecimento que foi adquirido nestes últimos dois anos. A organização do curso, disciplinas e palestras oferecidas tiveram papel fundamental em minha formação.

À Prof. Dra. Rossana Pereira de Almeida Antunes, relatora científica de pósgraduação. Obrigada por todas as valiosas considerações realizadas nos relatórios semestrais.

Aos demais professores do Programa de Pós-Graduação em Reabilitação Oral, pelo convívio e ensinamentos transmitidos.

À Dra. Izabela Cristina Maurício Moris, peça fundamental na elaboração do projeto de pesquisa. Obrigada pela participação.

À Dra. Ana Paula Macedo, pelo apoio, incentivo e por estar sempre disposta a ajudar. 
Aos colegas de turma, Alice Ramos, Cecília Vasconcelos, Geyson Galo, Millena Rocha, Micheli Menezes, Marília Lamenha e Bruna Neves, pela amizade e incentivo. Cursar disciplinas ao lado de pessoas tão comprometidas e de potencial, me impulsionou a buscar ser melhor em cada seminário ministrado.

Aos colegas de laboratório, Cristian Sbardelloto, Suleima Alves, Danilo Flamini, Renata Morais, Maria Paula Della Vechia e Bruna Tonin, pela convivência que tornou os dias de trabalho mais agradáveis.

À amiga Renata Cardoso, pela amizade verdadeira, carinho e convivência desde a graduação.

Aos funcionários da Faculdade de Odontologia de Ribeirão Preto, em especial àqueles ligados ao Programa de Pós-Graduação em Reabilitação Oral, Fernanda Talita de Freitas, Denise Martins Fontes Gonçalves, Regiane Tirado Damasceno, Mary Possani Carmessano e Carlos Feitosa dos Santos.

Aos Técnicos em Prótese Dentária, em especial ao Luis Sérgio Soares, pela amizade e prestatividade.

À Suleimy Mazin, estaticista responsável por desenvolver parte das análises deste trabalho. Obrigada pela paciência e disponibilidade para esclarecer minhas dúvidas.

À Coordenação de Aperfeiçoamento de Pessoal de Nível Superior (CAPES), pela bolsa concedida no primeiro ano do mestrado.

Ao Conselho Nacional de Desenvolvimento Científico e Tecnológico (CNPq), pela bolsa concedida no segundo ano do mestrado.

Meus sinceros agradecimentos a todos que contribuíram diretamente ou indiretamente na realização deste trabalho. 
Os que se encantam com a prática sem ciência são como limoneiros que entram em um navio sem Kimão e nem bússola, nunca tendo certeza do seu Destino.

(Leonardo da Oinci) 

Sesumo 

FIORIN, L. Efeito de diferentes protocolos de desgaste nas características superficiais e comportamento mecânico da zircônia (Y-TZP). 2017, 119p. Dissertação (Mestrado em Reabilitação Oral) - Faculdade de Odontologia de Ribeirão Preto, Universidade de São Paulo.

\section{RESUMO}

O objetivo deste estudo foi avaliar o efeito de diferentes protocolos de desgaste nas características superficiais e comportamento mecânico da zircônia utilizada para confeccionar infraestruturas e pilares protéticos. Amostras em forma de barra foram obtidas e divididas em três grupos $(n=21)$ : Grupo C (controle, não recebeu nenhum tipo de modificação superficial), Grupo A (desgaste realizado com fresas diamantadas de granulação média e acabamento com fresas diamantadas de granulação fina, com caneta de alta rotação sob refrigeração abundante de água) e Grupo B (desgaste realizado com pedras diamantadas de granulação grossa e acabamento realizado com pedras diamantadas de granulação média, com peça de mão acoplada em motor de baixa rotação e sem refrigeração). A topografia e rugosidade superficial (Sa) foram obtidos por microscopia confocal a laser $(n=21)$, o módulo de elasticidade dinâmico $(n=21)$ foi obtido por uma técnica de excitação por impulso, a transformação de fase foi avaliada por meio de difração de raios$X(n=1)$ e fadiga mecânica acelerada foi realizada pelo método step stress $(n=18)$. A análise estatística para rugosidade superficial e módulo de elasticidade foi ANOVA de um fator e teste complementar de Tukey e a resistência à fadiga foi comparada pela probabilidade de sobrevivência nos diferentes tipos de carregamento, quanto ao número de ciclos e a força. Houve diferença estatística entre os grupos para rugosidade superficial (Grupo A>Grupo $B>$ Grupo C) $(p \leq 0,05)$ e módulo de elasticidade dinâmico (Grupo B>Grupo $A=$ Grupo $C$ ) $(p=0,003)$. A difração de raios-X revelou mudança de fase cristalina para os grupos desgastados, sendo que o Grupo $C$ apresentou conteúdo cristalino somente na fase tetragonal, o Grupo A na fase tetragonal e monoclínica, e o Grupo B na fase tetragonal e cúbica. Não houve diferença estatística entre os grupos quando a taxa de sobrevivência foi comparada quanto ao número de ciclos e a força. Apesar do desgaste ter modificado as características superficiais, não houve prejuízo no comportamento mecânico da zircônia.

Palavras-chave: Zircônia, Desgaste, Propriedades Mecânicas, Fadiga 

Qbstract 

FIORIN, L. Effect of different grinding protocols on surface characteristics and mechanical behavior of zirconia ceramic. 2017, 119p. Dissertation (Masters in Oral Rehabilitation) Faculdade de Odontologia de Ribeirão Preto, Universidade de São Paulo.

\begin{abstract}
The purpose of this study was to evaluate the effect of different grinding protocols on surface characteristics and mechanical behavior of Y-TZP used to manufacture copings and abutments. Bar-shaped specimens were obtained and divided into three groups $(n=21)$ : Group C (control, untreated), Group A (grinding was performed using medium diamond burs, finishing was performed using fine diamond burs and high-speed hand piece under constant water cooling) and Group B (grinding was performed using coarse diamond stone, finishing was performed using medium diamond stone and slow-speed hand piece without water cooling). After the specimen grinding, topography and surface roughness $(n=21)$ were evaluated on laser confocal microscope, the Young's modulus $(n=21)$ was performed using the impulse excitation technique, crystallographic phase change was performed using an $x$ ray diffraction $(n=1)$ and step-stress accelerated life testing $(n=18)$ was performed. One-way ANOVA and Tukey's test were performed to analyze surface roughness and Young's modulus, and step-stress accelerated life testing was compared by the probability of survival, considering the number of cycles and strength. There was statistically significant difference between groups considering surface roughness (Group $A>$ Group B $>$ Group C) $(p \leq 0,05)$ and Young's modulus (Group B>Group $A=G$ roup $C)(p=0,003)$. X-ray diffraction data showed that grinding leads to phase change, once Group $C$ showed only tetragonal phase, Group A showed tetragonal and monoclinic phases and Group B showed tetragonal and cubic phases. There was no statistically significant difference among groups when the probability of survival was compared considering the number of cycles and strength. Although tested grinding protocols had modified the surface characteristics, did not damage the mechanical behavior of the zirconia.
\end{abstract}

Keywords: Zirconia, Grinding, Mechanical Properties, Fatigue 

Sumário 

1. INTRODUÇÃO

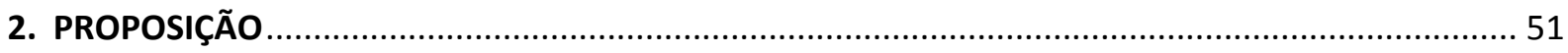

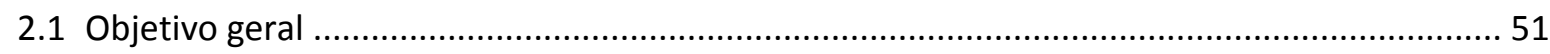

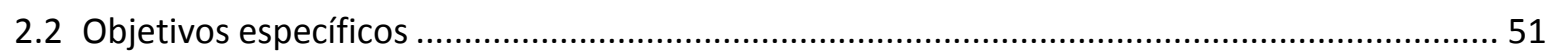

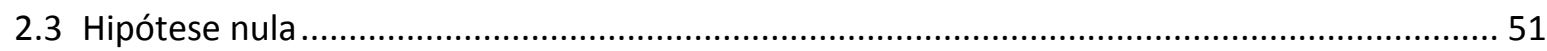

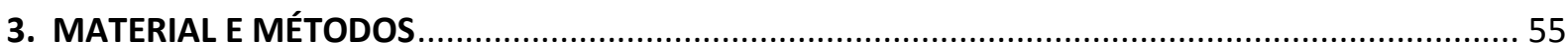

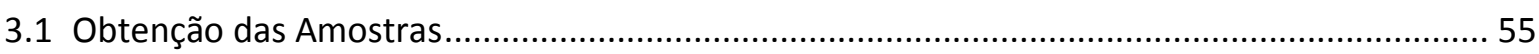

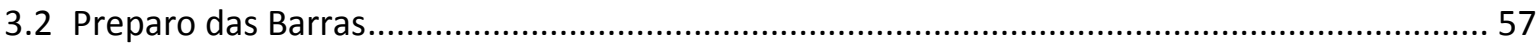

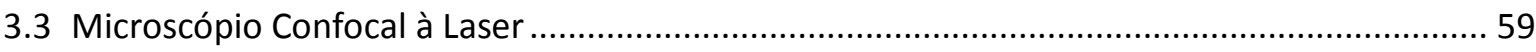

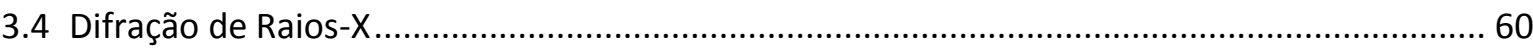

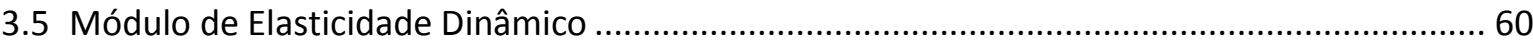

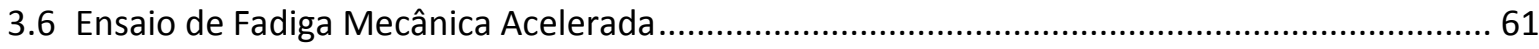

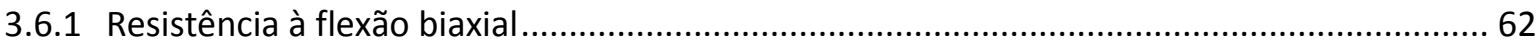

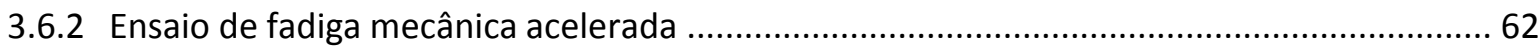

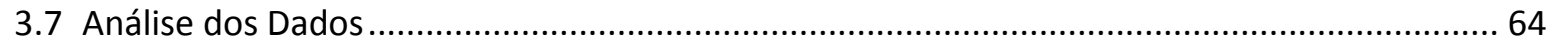

3.7.1 Análise estatística da rugosidade superficial e módulo de elasticidade dinâmico ................. 64

3.7.2 Análise estatística do teste de fadiga mecânica acelerada .................................................... 64

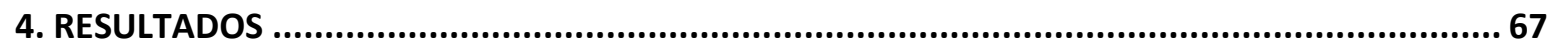

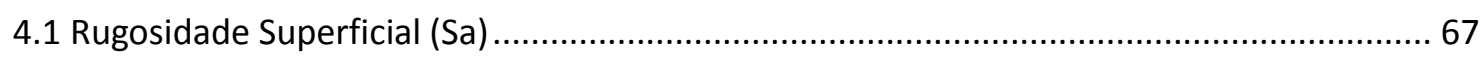

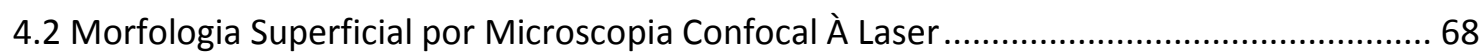

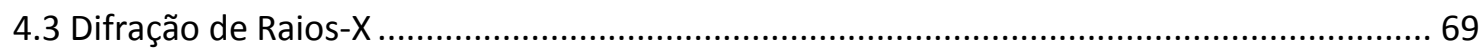

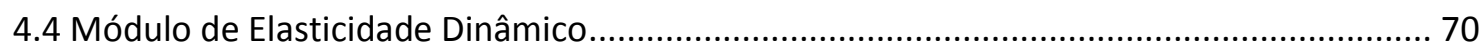

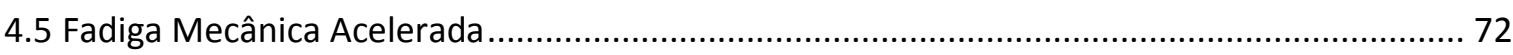

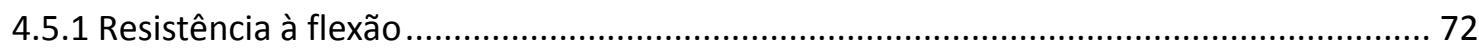

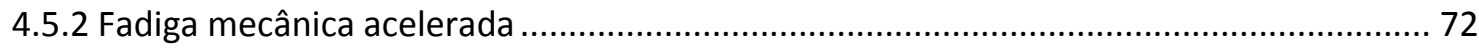

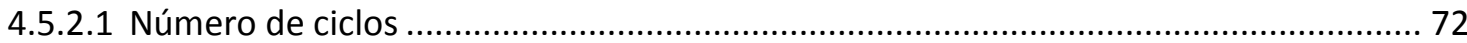

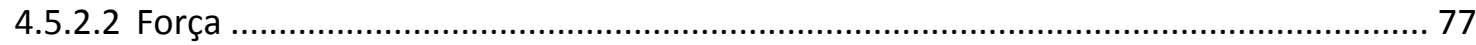

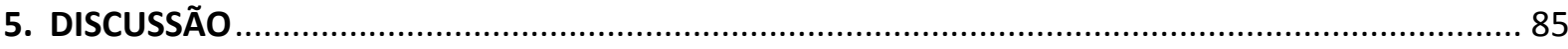

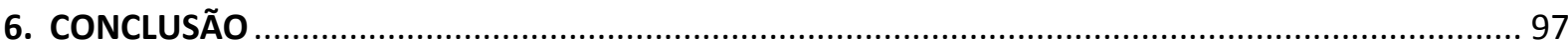

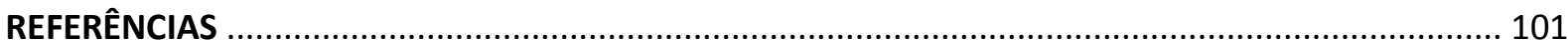

APÊNDICES 

1. Sntroduçãa 



\section{INTRODUÇÃO}

A Odontologia têm progredido continuamente graças ao desenvolvimento de novos materiais dentários e tecnologias de processamento. Os materiais cerâmicos evoluíram significativamente nos últimos anos para atender a demanda de pacientes que almejam restaurações livres de metal e os avanços na tecnologia CAD/CAM têm permitido alto controle sobre a qualidade de peças protéticas. Como consequência, a proporção de tratamentos utilizando sistemas totalmente cerâmicos têm crescido rapidamente (Griggs et al., 2007; Kelly \& Benetti, 2011; Miyazaki et al., 2013; Tanimoto, 2017; Silva et al., 2017).

Os materiais cerâmicos apresentam excelentes propriedades ópticas, sendo considerados os melhores em mimetizar a aparência do dente natural devido a capacidade de transmissão de luz. Além da estética, ainda se destacam pela estabilidade química, resistência à compressão e biocompatibilidade (Griggs, 2007; Kelly \& Benetti, 2011). Entretanto, são friáveis e apresentam susceptibilidade à fratura quando submetidos a carregamento mecânico (Sailer et al., 2007; Belli et al., 2014).

As restaurações metalocerâmicas consistem numa modalidade de tratamento executada há mais de quarenta anos na prática odontológica e de padrão ouro. No entanto, a presença de infraestrutura metálica dificulta a obtenção de estética semelhante à dos dentes naturais devido a coloração acinzentada do metal e a possibilidade destes oxidarem e ocasionarem a pigmentação da margem gengival (Anitha et al., 2013; Baldini et al., 2016; Jirajariyavej et al., 2017).

Ainda, quando pilares intermediários de titânio são utilizados na presença de tecido gengival delgado e/ou recessões gengivais, podem criar uma sombra acinzentada no terço cervical da restauração implantossuportada, resultando em uma aparência desagradável (Tripodakis et al., 1995; Yildirim et al., 2003; Schiroli, 2004; Park et al., 2007; Linkevicius \& Vaiteli, 2015; Varoni et al., 2017).

A crescente valorização da estética e a ciência das limitações das restaurações que possuem elementos metálicos motivaram a busca por melhorias nas propriedades mecânicas dos materiais cerâmicos. Neste ínterim, modificações microestruturais foram propostas para torna-los mais resistentes, minimizando a propagação de trincas e, consequentemente, a incidência de falhas catastróficas. As modificações mais importantes estão relacionadas ao mecanismo de endurecimento por dispersão de fase, que consiste na 
adição de uma fase dispersa de outro material, mais resistente, na matriz vítrea da cerâmica. Os materiais cerâmicos podem ser reforçados por meio da adição de cristais de alumina, leucita, hidroxiapatita, dissilicato de lítio e zircônia (Pallis et al., 2004; Miyazaki et al., 2013).

O estudo do comportamento mecânico dos materiais cerâmicos é clinicamente relevante, porque cria critérios para determinar a indicação de tratamentos (Belli et al., 2014). Na maioria das vezes, são utilizadas condições estáticas de carregamento para caracterizar as propriedades mecânicas destes materiais, tais como: módulo de elasticidade, resistência à flexão e tenacidade à fratura. Diferenças substanciais são observadas dentre os diferentes tipos de materiais cerâmicos disponíveis no mercado (Quinn et al., 2003; Griggs, 2007; Miyazaki et al., 2013; Belli et al., 2014).

As cerâmicas feldspáticas apresentam valores médios de módulo de elasticidade de $65 \mathrm{GPa}$, resistência à flexão de $100 \mathrm{MPa}$ e tenacidade à fratura de aproximadamente 1,0 $\mathrm{MPa} / \mathrm{m}^{1 / 2}$ e por isso, não estão indicadas para confecção infraestruturas (Gomes et al., 2008; Kelly \& Benetti, 2011). Já as cerâmicas reforçadas, apresentam resistência à flexão de aproximadamente $150 \mathrm{MPa}$ e tenacidade à fratura que pode variar de 2,0 a 5,0 $\mathrm{MPa} / \mathrm{m}^{1 / 2}$, estando indicadas para confecção de coroas unitárias anteriores e posteriores (Miyazaki et al., 2013). Dentre elas, as cerâmicas reforçadas por dissilicato de lítio podem ser utilizadas para confecção de infraestruturas de próteses parciais fixas de até três elementos (Gomes et al., 2008; Kelly \& Benetti, 2011).

Finalmente, cerâmicas policristalinas à base de alumina e à base de zircônia foram desenvolvidas e exibem propriedades mecânicas superiores às demais. Enquanto cerâmicas à base de alumina apresentam $400 \mathrm{MPa}$ de resistência flexural, valores entre 5 e $6 \mathrm{MPa} / \mathrm{m}^{1 / 2}$ de tenacidade à fratura e 350 GPa de módulo de elasticidade, a zircônia apresenta duas vezes o valor da resistência flexural destas cerâmicas (900-1400 MPa), tenacidade à fratura por volta de $10 \mathrm{MPa} / \mathrm{m}^{1 / 2}$ e $210 \mathrm{GPa}$ de módulo de elasticidade, de magnitude semelhante ao aço inoxidável (Piconi \& Maccauro, 1999; Kim et al., 2009; Harada et al., 2016).

O excelente desempenho mecânico da zircônia, que permitiu sua indicação para uma variedade de finalidades clínicas, tais como: confecção de infraestrutura para coroas unitárias e próteses parciais fixas, coroas monolíticas e pilares de prótese sobre implante (Beuer et al., 2012; Sabrah et al., 2013; Burke et al., 2013; Denry \& Kelly, 2014; Nakamura et al., 2015), pode ser justificado por suas características microestruturais (Lughi \& Sergo, 2010). 
A zircônia pura é um óxido cristalino, de cor branca e que apresenta o fenômeno da alotropia, ou seja, é possível que com a mesma composição química, apresente arranjos atômicos diferentes. Tipicamente exibe três fases cristalográficas: monoclínica, tetragonal e cúbica. Em pressão atmosférica e temperatura ambiente até $1170^{\circ} \mathrm{C}$, este material encontrase estável na fase monoclínica, apresentando grânulos fracamente unidos, microestrutura porosa e baixa resistência. Entre $1170^{\circ} \mathrm{C}$ e $2370^{\circ} \mathrm{C}$, encontra-se na fase tetragonal, apresentando microestrutura densa e alta resistência. Acima de $2370^{\circ} \mathrm{C}$, encontra-se na fase cúbica, permanecendo estável até que se atinja seu ponto de fusão (Garvie et al., 1975; Kobayashi et al., 1981; Kisi \& Howard, 1998). Ainda, pode apresentar fase cristalográfica ortorrômbica quando submetido à alta pressão (Garvie et al., 1975; Sakuma et al., 1985) e romboédrica quando sua superfície sofre abrasão, como por exemplo, após o desgaste (Sakuma et al., 1985; Denry \& Holloway, 2006). Após o resfriamento a partir de altas temperaturas, a transformação da fase cúbica para a tetragonal e a transformação da fase tetragonal para a monoclínica, são notavelmente atérmicas e não se difundem. Por isso, são denominadas "martensídicas", em analogia ao que ocorre com o aço (Evans \& Heauer, 1980; Lughi \& Sergo, 2010).

Quando a zircônia pura é examinada após o resfriamento, é possível observar que a transformação de grãos da fase tetragonal para monoclínica ocorre por volta de $950^{\circ} \mathrm{C}$ e é acompanhada por um aumento substancial do seu volume, de aproximadamente $5 \%$. Os estresses gerados por essa expansão, podem originar trincas durante o resfriamento que ocorre após o processo de sinterização e levar o material à falha catastrófica (Kobayashi et al., 1981; Kisi \& Howard, 1998; Piconi \& Maccauro, 1999). Portanto, $\quad$ óxidos estabilizantes, tais como: $\mathrm{CaO}, \mathrm{MgO}, \mathrm{CeO}_{2}$ e $\mathrm{Y}_{2} \mathrm{O}_{3}$ foram associados à zircônia pura para permitir a retenção metaestável da estrutura tetragonal em temperatura ambiente e consequentemente, oferecer controle sob o estresse induzido pela transformação da fase tetragonal para monoclínica (Ardlin, 2002; Deville et al., 2003; Sundh et al., 2008; Denry \& Kelly, 2008; Passos et al., 2014). Apenas a associação de zircônia pura com $\mathrm{Y}_{2} \mathrm{O}_{3}$ chegou a ter um padrão ISO (ISO 13356:2008) dedicado a aplicação como biomaterial (Lughi \& Sergo, 2010).

A zircônia policristalina parcialmente estabilizada na fase tetragonal com ítrio ( $Y$ TZP) geralmente contém 3 mol\% de óxido de ítrio $\left(\mathrm{Y}_{2} \mathrm{O}_{3}\right)$ como estabilizador e é sinterizada em temperaturas que variam entre $1350^{\circ} \mathrm{C}$ e $1600^{\circ} \mathrm{C}$, dependendo do fabricante. Chevalier 
et al. (2004), demonstraram que a presença de grãos de zircônia na fase cúbica não são desejáveis para Y-TZP, pois causam má distribuição dos íons de ítrio. Os íons de ítrio tendem a envolver os grãos dispostos na fase cúbica, enquanto os grãos dispostos na fase tetragonal tendem a ficar desprovidos do mesmo, e portanto, menos estáveis e mais susceptíveis a transformação para fase monoclínica (Chevalier et al., 2004; Denry \& Kelly, 2008).

O comportamento mecânico da Y-TZP é otimizado por um mecanismo conhecido como tenacificação por transformação de fase. Descrito por Garvie et al. (1975), a tenacificação por transformação de fase ocorre quando estresses superficiais ao redor de uma microtrinca desencadeiam transformação da fase tetragonal para fase monoclínica de grãos metaestáveis. A expansão volumétrica, resultante desta transformação, gera estresses compressivos sobre a microtrinca, prevenindo ou retardando sua propagação e melhorando a tenacidade à fratura do material (Chevalier et al., 1999; Hannink et al., 2000; Lughi \& Sergo, 2010). No entanto, a transformação da fase tetragonal para fase monoclínica na Y-TZP também pode ocorrer espontaneamente na presença de estresse local generalizado e/ou na presença de água, o que é conhecido como processo de degradação à baixas temperaturas ou envelhecimento térmico (Kobayashi et al., 1981).

O processo de degradação à baixas temperaturas têm sido observado quando a YTZP é submetida à ambiente úmido com temperatura variando entre $150-400^{\circ} \mathrm{C}$. Este processo inicia-se na superfície, com incorporação de água nos grãos superficiais, preenchendo as vacâncias de oxigênio, espalhando-se por toda superfície e chegando a afetar a estrutura interna do material. Resulta em um aumento da rugosidade superficial, no aparecimento de microtrincas, na diminuição da densidade da zircônia, comprometendo suas propriedades mecânicas e podendo levar este material à fratura (Kobayashi et al., 1981; Chevalier et al., 2007; Kim et al., 2010).

Ainda, a transformação da fase tetragonal para fase monoclínica pode ocorrer quando modificações superficiais, tais como o desgaste, são realizadas. Após o planejamento, a fresagem dos blocos pré-sinterizados de zircônia é realizada no sistema CAD/CAM e a precisão das peças obtidas depende do sistema utilizado, qualidade das fresas e qualidade do preparo dentário que irá receber a peça (Canneto et al., 2016). Usualmente peças de zircônia obtidas por CAD/CAM podem requerer ajustes manuais após a sinterização, seja para melhorar adaptação marginal, interna e relacionamento oclusal (Aboushelib et al., 2009; Preis et al., 2015; Jing, 2014; Pereira et al., 2015; Pereira et al., 
2016A; Canneto et al., 2016) ou para conferir perfil de emergência à pilares pré-fabricados customizáveis (Sundh et al., 2005; Nothdurft et al., 2011; Alqahtanie et al., 2014; Moris, 2015).

Quando necessário, o desgaste pode ser realizado pelo técnico de laboratório e/ou cirurgião-dentista. Entretanto, estudos têm sugerido que tratamentos superficiais podem afetar a estrutura da zircônia, introduzindo estresses residuais que podem acometer suas propriedades mecânicas (Sundh et al., 2005; Nothdurft et al., 2011; Moris, 2015; Canneto et al., 2016; Pereira et al., 2016C). Ainda, que a severidade do dano causado por este procedimento, tem relação com o instrumento de desgaste utilizado (Canneto et al., 2016; Pereira et al., 2016C).

Sendo assim, alguns pesquisadores têm investigado o efeito do desgaste, com diferentes instrumentos diamantados, nas propriedades mecânicas da zircônia. Denry \& Holloway (2006) avaliaram as mudanças microestruturais e na estrutura cristalina de uma zircônia utilizada em odontologia após procedimentos de desgaste. As amostras foram obtidas e divididas em grupos, de acordo com o tipo de desgaste realizado: ausência de desgaste, desgaste utilizando fresas diamantadas sob refrigeração abundante, desgaste seguido por polimento e desgaste seguido por tratamento térmico utilizando protocolo de $1.000^{\circ} \mathrm{C}$ por uma hora. A análise por difração de raios-X demonstrou que o grupo controle e o grupo que recebeu desgaste seguido por tratamento térmico continham $100 \%$ de estrutura cristalina na fase tetragonal. Entretanto, nos grupos em que houve somente desgaste e desgaste seguido por polimento, havia presença de estrutura cristalina na fase romboédrica e tetragonal. Concluíram que o tratamento térmico é capaz de remover tensões residuais na estrutura cristalina e eliminar a presença de fase romboédrica, e que o desgaste seguido por polimento causou a perda de grãos numa profundidade de $20 \mu \mathrm{m}$. Finalizam sugerindo que este tipo de dano pode ter impacto sobre o comportamento de fadiga da zircônia a longo prazo.

Kosmac et al. (2008) investigaram o efeito do desgaste, e do jateamento, no envelhecimento térmico, na resistência à flexão e comportamento de fadiga da zircônia. As amostras foram obtidas e divididas de acordo com o tratamento superficial realizado: controle - não recebeu nenhum tipo de tratamento, desgaste, jateamento, jateamento + ressinterização) e as variáveis (a seco, envelhecido em saliva $37^{\circ} \mathrm{C} / 24 \mathrm{~h}$, saliva $134{ }^{\circ} \mathrm{C} / 2 \mathrm{~h}$ e saliva $134 \stackrel{\circ}{\circ} / 24 h$ ). O desgaste foi realizado com fresa diamantada de $150 \mu \mathrm{m}$ em alta 
rotação, o jateamento com partículas de óxido de alumínio de $110 \mu \mathrm{m}$ e a ressinterização realizada a $920^{\circ} \mathrm{C}$ por 1 hora. Para análise do comportamento biomecânico da zircônia através do teste de resistência à fadiga, foram aplicados 106 ciclos a $15 \mathrm{~Hz}$. O grupo que sofreu desgaste apresentou menores valores de resistência à flexão e menor taxa de sobrevivência sob carga cíclica. Já o jateamento com partículas de óxido de alumínio, resultou no fortalecimento da superfície, e consequentemente, no aumento da resistência à flexão e taxa de sobrevivência sob carga cíclica. Quando ressinterizados, igualaram-se ao controle. Os valores dos experimentos a seco foram maiores do que quando realizados imersos em saliva. Os autores concluíram que o desgaste reduziu a resistência à flexão e a taxa de sobrevivência durante ciclagem, enquanto que o jateamento melhorou o comportamento das amostras.

Adatia et al. (2009) avaliaram a resistência à fratura de pilares em zircônia preparados com fresas diamantadas de granulação grossa, em peça de mão, com alta rotação, sob refrigeração, e pilares em zircônia não preparados. Concluíram que o desgaste de $1 \mathrm{~mm}$ da margem com irrigação não afetou a resistência à fratura e que a região mais fraca parece ser a interface pilar/análogo.

Ho et al. (2009), investigaram o efeito do desgaste, polimento e tratamento térmico, na resistência à flexão da zircônia. As amostras foram confeccionadas e divididas em quatro grupos: controle, desgaste, desgaste seguido por polimento e desgaste seguido por tratamento térmico. O desgaste foi realizado com pedra de granulação $40 \mu \mathrm{m}$ e o polimento com solução de sílica. O tratamento térmico foi realizado utilizando um protocolo de $1100^{\circ} \mathrm{C}$ por 2 horas. O desgaste aumentou a resistência à flexão das amostras. Entretanto, os procedimentos de polimento e o tratamento térmico, realizados de maneira independente, foram capazes de reduzir a resistência à flexão após o desgaste. Conteúdo de zircônia na fase monoclínica foi detectado em todos os grupos, exceto para o grupo que recebeu tratamento térmico. Concluíram que o desgaste é capaz de criar forças compressivas superficiais que aumentam sua resistência à flexão e que os procedimentos de polimento e tratamento térmico são capazes de reduzir estas forças.

Iseri et al. (2010) avaliaram o efeito do desgaste realizado com fresas diamantadas em alta rotação, e pedras de carbeto de silício em baixa rotação, ambos sem refrigeração, na resistência à flexão da zircônia, e compararam o desgaste realizado com duas estratégias de tempo: desgaste contínuo e intervalado com duração de 5 segundos. Os valores de 
resistência à flexão dos grupos desgastados com alta rotação foram maiores do que os com baixa rotação. A temperatura desenvolvida pelo desgaste realizado sob alta rotação foi maior do que quando realizado sob baixa rotação. Não houve diferença estatisticamente significante para as estratégias de tempo e concluíram que o desgaste reduziu a resistência à flexão, sendo que o grupo que apresentou os menores valores de resistência à flexão foi aquele que realizou o desgaste continuamente, e com alta rotação.

Att et al. (2011) avaliaram o efeito do preparo e a relação da espessura das paredes na resistência à fratura dos pilares de zircônia. O preparo foi realizado com fresas diamantadas sob refrigeração. Concluíram que o preparo e a diminuição na espessura das paredes dos pilares não foram suficientes para diminuir a capacidade destes pilares em resistirem as forças mastigatórias na região anterior.

Nothdurft et al. (2011) avaliaram a resistência à fratura de próteses parciais fixas na região posterior, sobre implantes, utilizando pilares em zircônia preparados com auxílio de peça de mão, em alta rotação, sob refrigeração e utilizando pilares em zircônia não preparados. Os autores observaram que a individualização da porção cervical não afetou a resistência, mas a redução das paredes do pilar levou à diminuição da resistência à fratura.

Park et al. (2012) compararam a resistência à fratura, adaptação marginal e interna de pilares de zircônia pré-fabricados e pilares de zircônia personalizáveis, ambos de conexão hexágono interno. A personalização por desgaste foi realizada com fresas diamantadas em peça de mão sob alta rotação e refrigeração. Os autores observaram que os pilares de zircônia personalizáveis se tornaram significativamente mais resistentes após o desgaste, mas a presença de ajuste tornou a adaptação marginal menos precisa. Ainda assim, a adaptação estava dentro dos limites clinicamente aceitáveis.

Subasi et al. (2014), avaliaram o efeito do desgaste realizado com fresas diamantadas, em baixa rotação, sem refrigeração, e do tratamento térmico da zircônia sobre o conteúdo na fase monoclínica e sua resistência a flexão. Concluíram que o conteúdo de zircônia na fase monoclínica aumentou após o desgaste, mas que a resistência à flexão não sofreu alteração significante. Notou-se também que, após o tratamento térmico preconizado pelo fabricante, uma pequena quantidade de zircônia na fase monoclínica permaneceu na superfície.

Moris (2015) avaliou o efeito da personalização por desgaste em pilares de zircônia cone morse na resistência à fratura do conjunto coroa/pilar/implante. O preparo foi 
realizado com pedras de desgaste de granulação grossa, em baixa rotação e sem refrigeração. Foi possível concluir que os pilares de zircônia preparados apresentaram maior resistência à fratura do que os pilares de zircônia não-preparados.

Pereira et al. (2015) investigaram o efeito do desgaste realizado com fresas diamantadas em baixa rotação, com refrigeração, e da utilização de discos diamantados utilizados para simular o desgaste realizado com as fresas, na rugosidade superficial, estrutura cristalina e resistência à flexão de uma zircônia para infraestrutura. As amostras foram obtidas e divididas em cinco grupos: controle, desgaste realizado com fresas diamantadas de granulação extra fina, desgaste realizado com fresas diamantadas de granulação grossa, desgaste realizado com discos diamantados de granulação extra fina e discos diamantados de granulação grossa. Todos os protocolos de desgaste utilizados promoveram aumento da rugosidade superficial e transformação da fase tetragonal para fase monoclínica. Não houve diferença estatística nos valores de resistência à flexão e no módulo de Weibull para os diferentes grupos. Concluíram que o desgaste realizado com fresa diamantada de granulação extra fina parece ser mais adequado para zircônia e que, do ponto de vista metodológico, discos diamantados não devem ser utilizados para simular o desgaste clínico realizado com fresas diamantadas.

Lee et al. (2016) avaliaram a rugosidade superficial, o conteudo de zircônia na fase monoclínica e a resistência à flexão da zircônia após o preparo com fresas específicas para zircônia, com diferentes granulações, em baixa rotação e sem refrigeração. Concluiram que aquelas que continham partículas de diamante em sua superfície fizeram com que a zircônia preparada se apresentasse na fase monoclínica, com maior rugosidade superficial e sem alteração na sua resistência à flexão.

Ramos et al. (2016) avaliaram o efeito do desgaste da zircônia, antes e após tratamento térmico, na rugosidade superficial e resistência a flexão deste material. Para isso, utilizaram lixas d'água de granulação $80(200 \mu \mathrm{m}), 120(160 \mu \mathrm{m})$ e $600(25 \mu \mathrm{m})$, simulando o desgaste com fresas diamantadas de granulação grossa, média e extra fina, respectivamente. Concluíram que o desgaste realizado com fresa diamantada de granulação fina não afeta a estrutura cristalina do material e apresenta menor rugosidade superficial quando comparado à fresas de granulações maiores. O grupo controle foi o que apresentou menores valores de resistência à flexão. O protocolo de tratamento térmico utilizado neste 
trabalho $\left(1200^{\circ} \mathrm{C} / 2\right.$ horas) provou ser eficaz e pode ser realizado quando é desejável a ausência da fase monoclínica.

Polli et al. (2016) avaliaram o efeito do desgaste e do tratamento térmico, no comportamento à fadiga e nas características superficiais da zircônia. O desgaste foi realizado com fresas diamantadas, sob alta rotação, com e sem refrigeração. $O$ tratamento térmico foi realizado utilizando protocolo de $1000^{\circ} \mathrm{C}$ por trinta minutos. O comportamento à fadiga ( 500.000 ciclos, $10 \mathrm{~Hz}$ ) foi avaliado pelo método staircase em dispositivo de flexão em 4 pontos. O limite de fadiga foi calculado considerando o menor valor de resistência à flexão, o número de amostras que falharam e sobreviveram nos diferentes patamares de força e número total de amostras que falharam e sobreviveram. Os grupos que sofreram desgaste e não receberam tratamento térmico apresentaram maior limite de fadiga, ou seja, maior resistência do que os grupos que sofreram desgaste e receberam tratamento térmico, e que o grupo controle.

Hatanaka et al. (2016) avaliaram o efeito do desgaste e do tratamento térmico na microestrutura, alteração da fase cristalográfica e resistência à flexão da zircônia. O desgaste foi realizado utilizando fresas diamantadas em alta rotação, com e sem refrigeração e o tratamento térmico foi realizado utilizando protocolo de $1000^{\circ} \mathrm{C}$ por trinta minutos. $\mathrm{O}$ desgaste aumentou a resistência à flexão das amostras que não foram submetidas ao tratamento térmico. Os autores concluíram que o desgaste deve ser realizado sob refrigeração e o tratamento térmico deve ser realizado para eliminar o conteúdo de zircônia na fase monoclínica que aparece nos grupos que sofreram desgaste.

Pereira et al. (2016A) avaliaram o efeito do desgaste com fresas diamantadas, e do envelhecimento térmico, nas propriedades mecânicas (resistência à flexão e confiabilidade estrutural), topografia superficial e transformação de fase de uma zircônia monolítica. 0 desgaste foi realizado utilizando fresas diamantadas de diferentes granulações, grossa e extra fina, ambas em peça de mão, baixa rotação e com refrigeração abundante. 0 envelhecimento térmico foi simulado em autoclave, utilizando um protocolo de $134^{\circ} \mathrm{C}, 2$ bar de pressão, por 20 horas. Observaram que o desgaste promoveu o aumento da rugosidade superficial, de acordo com a granulação da fresa utilizada, e transformação da fase tetragonal para fase monoclínica, que por sua vez, resultou no aumento da resistência à flexão. Já o envelhecimento térmico não causou o aumento da rugosidade superficial, porém também promoveu transformação para fase monoclínica. O módulo de Weibull foi 
semelhante para todos os grupos. Concluíram que tanto o envelhecimento térmico, como o desgaste, não foram prejudiciais às propriedades mecânicas da zircônia, mas ambos causaram o aumento de conteúdo de zircônia na fase monoclínica.

Pereira et al. (2016B) avaliaram o efeito do desgaste e do envelhecimento térmico na resistência à fadiga de uma zircônia para infraestrutura e uma zircônia monolítica. As amostras foram obtidas e divididas em diferentes grupos de acordo com o tipo de tratamento realizado: controle (não recebeu nenhum tipo de tratamento), desgaste, envelhecimento térmico, desgaste seguido por envelhecimento térmico. 0 desgaste foi realizado utilizando contra-ângulo em baixa rotação, fresas diamantadas de granulação grossa sob refrigeração com água. O envelhecimento térmico foi simulado em autoclave, à $134^{\circ} \mathrm{C}, 2$ bar de pressão, por 20 horas. 0 método selecionado para avaliar a resistência à fadiga foi o step stress. Concluíram que a realização do desgaste sob estas condições e o envelhecimento térmico não alteram significamente a resistência à fadiga, ainda que tenham provocado o aumento do conteúdo de zircônia na fase monoclínica nos dois tipos de zircônia.

Canneto et al. (2016) avaliaram o dano causado pelo desgaste na superfície de cerâmicas altamente resistentes, processadas por CAD/CAM, dentre elas a zircônia. 0 desgaste foi realizado com discos diamantados de granulação $75 \mu \mathrm{m}, 54 \mu \mathrm{m}$ e $18 \mu \mathrm{m}$ e os autores estimaram a perda da resistência do material baseada no tamanho das trincas encontradas na superfície após o desgaste. Notaram que após o desgaste com disco diamantado de granulação $75 \mu \mathrm{m}$, a zircônia apresentou perda estimada em 12\% da resistência, quando comparada com as informações fornecidas pelo fabricante, e que todas as cerâmicas que participaram do estudo não apresentaram trincas críticas quando desgastadas com disco diamantado de granulação $18 \mu \mathrm{m}$. Os autores concluíram que quando o desgaste é realizado com discos diamantados de granulação média (75 $\mu \mathrm{m}$ ou 54 $\mu \mathrm{m})$, pode haver consequências negativas sobre suas propriedades mecânicas. Entretanto, se o ajuste é necessário, é recomendado que seja realizado o polimento com instrumentos diamantados de granulação fina.

Ryan et al. (2017) avaliaram o efeito do desgaste e do tratamento térmico na microestrutura e a alteração na fase cristalográfica da zircônia. O desgaste foi realizado utilizando fresas diamantadas em alta rotação, com e sem refrigeração. O protocolo de tratamento térmico utilizado foi de $1000^{\circ} \mathrm{C}$ por trinta minutos. Os autores concluíram que o 
tratamento térmico após o desgaste permite a obtenção de uma estrutura com $100 \%$ dos grãos na fase tetragonal.

Chougule et al. (2017) avaliaram o efeito de diferentes modificações superficiais na resistência à flexão da zircônia monolítica. As modificações superficiais foram realizadas utilizando duas técnicas diferentes: desgaste associado a polimento e desgaste associado a aplicação de glaze. O desgaste foi realizado com pedra diamantada, em baixa rotação, sem refrigeração, o polimento com um kit específico para esta finalidade e o glaze foi aplicado, seguido pela queima à $790^{\circ} \mathrm{C}$ por oito minutos. $\mathrm{O}$ grupo que recebeu desgaste e aplicação e queima do glaze apresentou maiores valores de resistência à flexão quando comparado ao grupo controle e ao grupo que recebeu desgaste, seguido por polimento.

Dutra et al. (2017) avaliaram o efeito do desgaste com fresas diamantadas e do envelhecimento térmico nas características superficiais e adesão bacteriana da zircônia. As amostras foram obtidas a partir da secção de blocos pré-sinterizados, sinterizadas e divididas em seis grupos de acordo com dois fatores: desgaste (controle, desgaste com fresas diamantadas de granulação extra-fina e desgaste com fresas diamantadas de granulação grossa, ambos utilizando contra ângulo, baixa rotação e refrigeração abundante) e envelhecimento térmico (controle e envelhecido). Tanto o desgaste, como o envelhecimento térmico, aumentaram o conteúdo de zircônia na fase monoclínica. A rugosidade superficial aumentou com o aumento da granulação da fresa diamantada utilizada e que a adesão bacteriana foi menor para os grupos que não foram submetidos ao envelhecimento térmico. Concluíram que o desgaste e o envelhecimento térmico modificaram características superficiais da zircônia e o desgaste com fresas diamantadas de diferentes granulações não afeta a adesão bacteriana.

Ozer et al. (2017) avaliaram o efeito da espessura e de modificações superficiais na resistência à flexão de uma zircônia monolítica. As amostras foram obtidas com duas espessuras diferentes: $0,8 \mathrm{~mm}$ e 1,3 $\mathrm{mm}$ e divididas em três grupos de acordo com o tipo de tratamento superficial realizado: controle, jateamento com óxido de alumínio e desgaste com instrumentos diamantados. O desgaste foi realizado com fresas diamantadas de granulação média, em baixa rotação, sob refrigeração abundante, seguido por polimento. Concluíram que a resistência à flexão aumenta com o aumento da espessura da amostra e quando as amostras são submetidas ao jateamento com óxido de alumínio. Entretanto, o desgaste com fresas diamantadas seguido por polimento não afetou esta propriedade. 
Khayat et al. (2017) avaliaram o efeito do desgaste e do polimento, na rugosidade superficial e resistência à flexão de uma zircônia monolítica. Todas as amostras foram submetidas à simulação de envelhecimento térmico. Concluíram que o desgaste aumenta a rugosidade superficial e como consequência, torna a zircônia mais susceptível ao envelhecimento térmico. Não há evidências que o desgaste seguido por polimento possa afetar a resistência à flexão da zircônia após o envelhecimento térmico. Não foi encontrada correlação entre rugosidade superficial e resistência à flexão.

Chun et al. (2017) investigaram propriedades microestruturais e a resistência à fadiga de uma zircônia monolítica após simulação de diferentes protocolos de ajustes clínicos. As amostras foram obtidas e divididas em seis grupos de acordo com o tipo e sequência de tratamentos superficiais realizados: controle (não recebeu nenhum tipo de tratamento), glaze, desgaste seguido por glaze, glaze seguido por desgaste, desgaste seguido por polimento e glaze, glaze seguido por desgaste e polimento. $\mathrm{O}$ desgaste foi realizado com lixa d'água, simulando o desgaste realizado com fresa diamantada de granulação média. 0 comportamento à fadiga foi avaliado por meio do método step stress em três perfis de carregamento (leve, moderado e agressivo), variando os incrementos de carga e número de ciclos. Não houve alteração na cristalografia da zircônia após os diferentes tipos de tratamento superficiais e quando o desgaste foi seguido por polimento, a superfície se apresentou mais uniforme. As amostras do grupo controle apresentaram menor probabilidade de sobrevivência após 600.000 ciclos a $200 \mathrm{~N}$, quando comparada aos demais grupos. Concluíram que a zircônia tem maior probabilidade de sobrevivência quando o desgaste é realizado e seguido pelo glaze ou polimento.

Zucuni et al. (2017A) avaliaram e compararam o efeito de diferentes tratamentos superficiais na zircônia após a sinterização e desgaste com fresas diamantadas (polimento, tratamento térmico, glaze, polimento seguido por tratamento térmico e polimento seguido por glaze), em suas características superficiais (morfologia e rugosidade), transformação de fase e resistência à fadiga. Todos os tratamentos influenciaram as características superficiais, sendo que o polimento diminuiu a rugosidade, o conteúdo de zircônia na fase monoclínica e aumentou a resistência à fadiga. Já o glaze, diminuiu os valores de rugosidade, porém apresentou os menores valores de resistência à fadiga. O tratamento térmico mostrou ter efeito sob a rugosidade superficial e foi eficaz em transformar conteúdo de fase monoclínica em fase tetragonal, porém não melhorou o comportamento à fadiga. Portanto, concluíram 
que um protocolo de polimento após o ajuste clínico (desgaste) de restaurações monolíticas é obrigatório para preservar características superficiais e o comportamento mecânico da zircônia.

Candido et al. (2017) avaliaram o efeito do desgaste na rugosidade superficial, molhabilidade e estrutura cristalina da zircônia, e a efetividade da realização de tratamento térmico para reverter a transformação da fase tetragonal para monoclínica. $O$ desgaste foi realizado com pedras diamantadas, em baixa rotação, com e sem refrigeração. 0 tratamento térmico foi realizado utilizando diferentes protocolos $\left(700^{\circ} \mathrm{C}, 800^{\circ} \mathrm{C}, 900^{\circ} \mathrm{C}\right.$ e $1.000^{\circ} \mathrm{C}$, por 30 e 60 minutos). Concluíram que o desgaste com pedras diamantadas causa transformação da fase tetragonal para fase monoclínica, aumento na rugosidade superficial e na molhabilidade da zircônia. $\mathrm{O}$ desgaste com pedras diamantadas sem refrigeração foi menos prejudicial às propriedades avaliadas. E a transformação da fase tetragonal para fase monoclínica pode ser revertida por meio da utilização dos seguintes protocolos de tratamento térmico: $800^{\circ} \mathrm{C}$ por 60 minutos, $900^{\circ} \mathrm{C}$ por 60 minutos ou $1000^{\circ} \mathrm{C}$ por 30 minutos.

Neste contexto, é notável que a literatura apresenta resultados conflitantes. Alguns estudos exibem um efeito positivo do desgaste nas propriedades mecânicas do material (Ho et al., 2009; Pereira et al., 2016A; Ramos et al., 2016; Polli et al., 2016, Hatanaka et al., 2016) e outros observam que o desgaste pode introduzir defeitos superficiais e tornar o material mais susceptível à falha catastrófica (Kosmac et al., 2008; Iseri et al., 2010; Canneto et al., 2016).

Além disso, a maioria dos estudos realizados para caracterizar as propriedades mecânicas da zircônia após o desgaste utilizam condições estáticas de carregamento mecânico (Ho et al., 2009; Iseri et al., 2010; Subasi et al., 2014; Pereira et al., 2016A; Lee et al., 2016; Ramos et al., 2016; Hatanaka et al., 2016; Chougule et al., 2017; Ozer et al., 2017; Khayat et al., 2017), enquanto uma minoria avalia o impacto do desgaste no comportamento sob condições dinâmicas (Kosmac et al., 2008; Polli et al., 2016; Pereira et al., 2016B; Zucuni et al., 2017A).

A maioria das fraturas de restaurações e próteses se desenvolvem progressivamente sob condições dinâmicas de carregamento mecânico. A avaliação da resistência à fadiga é realizada por meio de um ensaio mecânico submetendo a amostra à uma tensão cíclica (Anusavice et al., 2013). Quando o ensaio mecânico é associado a variação de temperatura e submetido à ambiente aquoso, têm potencial para representar as 
condições de fadiga presentes na cavidade bucal (Elshiyab et al., 2017). Sendo assim, o comportamento da fadiga deve ser estudado para garantir que esse material possa ser indicado clinicamente com segurança (Polli et al., 2016).

Tendo em vista que não existe um protocolo bem estabelecido para o desgaste da zircônia, que não há um consenso na literatura sobre a influência do desgaste em suas propriedades mecânicas e que poucos estudos têm relacionado o desgaste com comportamento sob condições dinâmicas de carregamento mecânico, este estudo foi proposto. 
2. Proposiçãa 



\section{PROPOSIÇÃO}

\subsection{Objetivo geral}

Avaliar as possíveis alterações ocorridas na zircônia após a utilização de diferentes protocolos de desgaste, por meio da caracterização superficial, análise da estrutura cristalina, módulo de elasticidade dinâmico e análise da sobrevida pela fadiga mecânica acelerada.

\subsection{Objetivos específicos}

Avaliar o efeito de diferentes protocolos de desgaste nas seguintes propriedades da zircônia:

2.2.1 Morfologia da superfície e rugosidade superficial, através de microscopia confocal à laser.

2.2.2. Módulo de elasticidade dinâmico, utilizando técnica de excitação por impulso.

2.2.3 Estrutura cristalina da zircônia, por meio de difração de raios-X.

2.2.4 Comportamento mecânico, por meio do teste de fadiga mecânica acelerada.

\subsection{Hipótese nula}

A hipótese nula testada é que a utilização de diferentes protocolos de desgaste não têm influência sobre a morfologia e rugosidade superficial, estrutura cristalina, módulo de elasticidade dinâmico e comportamento mecânico da zircônia. 

3. Makerial e Métodos 



\section{MATERIAL E MÉTODOS}

\subsection{Obtenção das Amostras}

Para a realização deste estudo, as amostras foram obtidas utilizando blocos de zircônia Zirkom ST Super Translucent (Qinhuangdao Aidite High-technical Ceramics, Qinhuangdao City, China) (Figuras 1A e 1B), prensados de maneira isostática e desenhados para CAD/CAM odontológico. Consistem em óxido de zircônia estabilizado por ítrio, présinterizado e com temperatura máxima de sinterização de $1.530^{\circ} \mathrm{C}$, utilizado para confeccionar infraestruturas de coroas unitárias e próteses parciais fixas e pilares protéticos.

Figura 1. A) Embalagem comercial dos blocos de zircônia Zirkom ST Super Translucent e B) Bloco de óxido de zircônia estabilizado por ítrio pré-sinterizado.
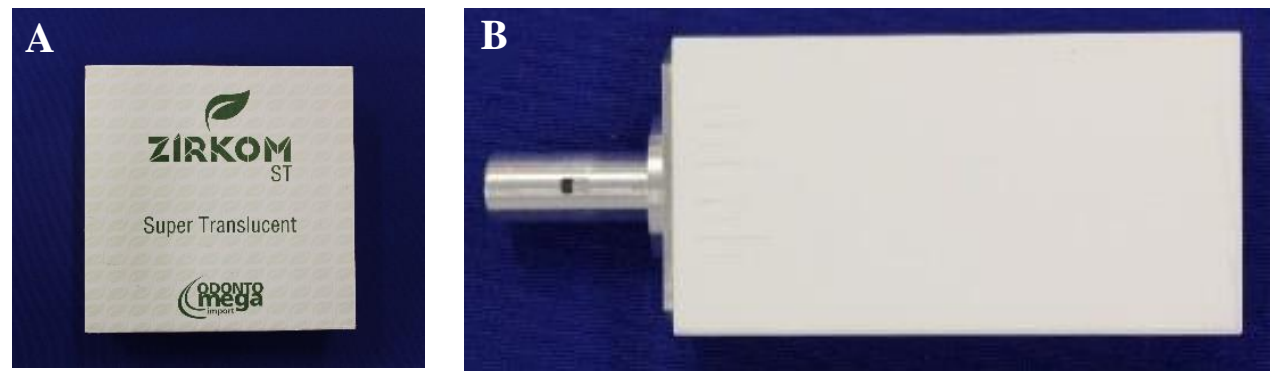

Sessenta e três barras de zircônia pré-sinterizadas $(n=21)$ foram confeccionadas através da secção dos blocos com disco diamantado (Allied High Tech Products Inc., Racho Dominguez, Canadá), em cortadeira de precisão (Isomet 1000 Precision Saw, Buehler, Illinois, EUA) (Figuras 2A e 2B) com refrigeração e receberam acabamento manual com lixas d'água (3M Espe, São Paulo, Brasil) de granulação 600 (25 ㅆm).

Figura 2. A) Cortadeira de precisão Isomet 1000 Precision Saw e B) Bloco de óxido de zircônia estabilizado por ítrio pré-sinterizado posicionado para secção.
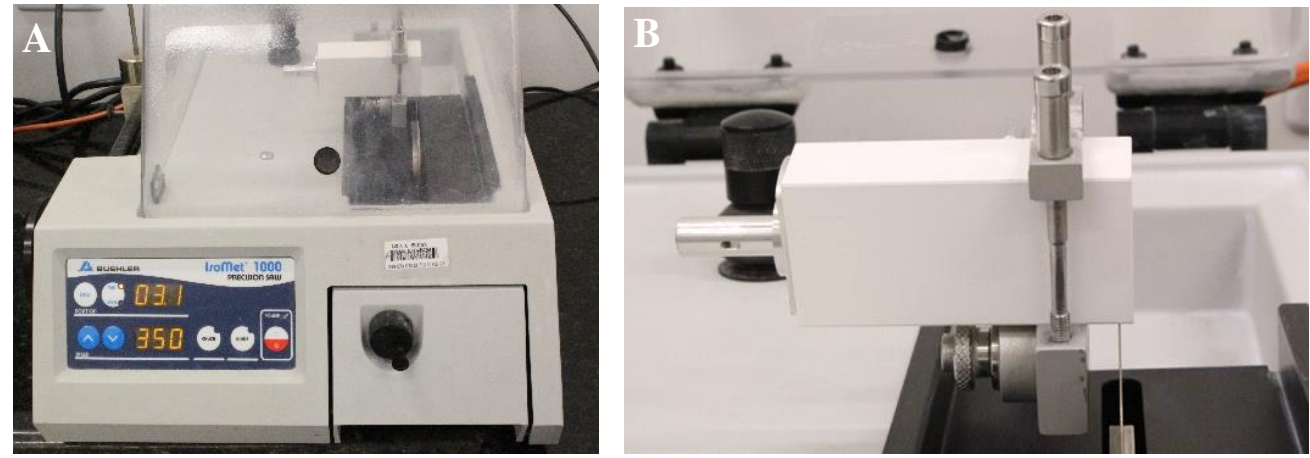
O paquímetro digital (Mitutoyo, Kanagawa, Japão) foi utilizado para mensurar as dimensões das barras, que foram estabelecidas considerando a contração volumétrica que ocorre após o processo de sinterização.

A sinterização foi realizada no forno inFire HTC Speed (Sirona, Bensheim, Alemanha) (Figuras 3A e 3B) seguindo as recomendações preconizadas pelo fabricante e as amostras foram divididas em três grupos de acordo com o protocolo de desgaste utilizado:

Grupo C: Barras em zircônia ( $\mathrm{n}=21$ ) com $37 \mathrm{~mm}$ de comprimento, $5 \mathrm{~mm}$ de largura e 1,5 mm de espessura previamente a sinterização. Após a sinterização ficaram com tamanho final de $30 \mathrm{~mm} \times 4 \mathrm{~mm} \times 1,2 \mathrm{~mm}$ e não receberam nenhum tipo de tratamento superficial e/ou preparo.

Grupo A: Barras em zircônia $(n=21)$ com $37 \mathrm{~mm}$ de comprimento x 5,3 mm de largura $\times 2 \mathrm{~mm}$ de espessura previamente a sinterização. Após a sinterização ficaram com 30 $\mathrm{mm}$ de comprimento $\times 4,4 \mathrm{~mm}$ de largura e 1,6 $\mathrm{mm}$ de espessura. Essas barras foram preparadas com fresas diamantadas, em alta rotação, sob refrigeração, sendo que ao final do preparo, foram reduzidas às mesmas dimensões que as barras não preparadas (grupo C).

Grupo B: Barras em zircônia $(n=21)$ com as mesmas dimensões das barras do grupo A. Essas barras foram preparadas com pedras de desgaste, em baixa rotação, sem refrigeração, sendo que ao final do preparo, foram reduzidas às mesmas dimensões que as barras não preparadas (grupo C).

Figura 3. A) Forno inFire HTC Speed, B) Barras de zircônia pré-sinterizadas posicionadas para sinterização e C) Barras sinterizadas.

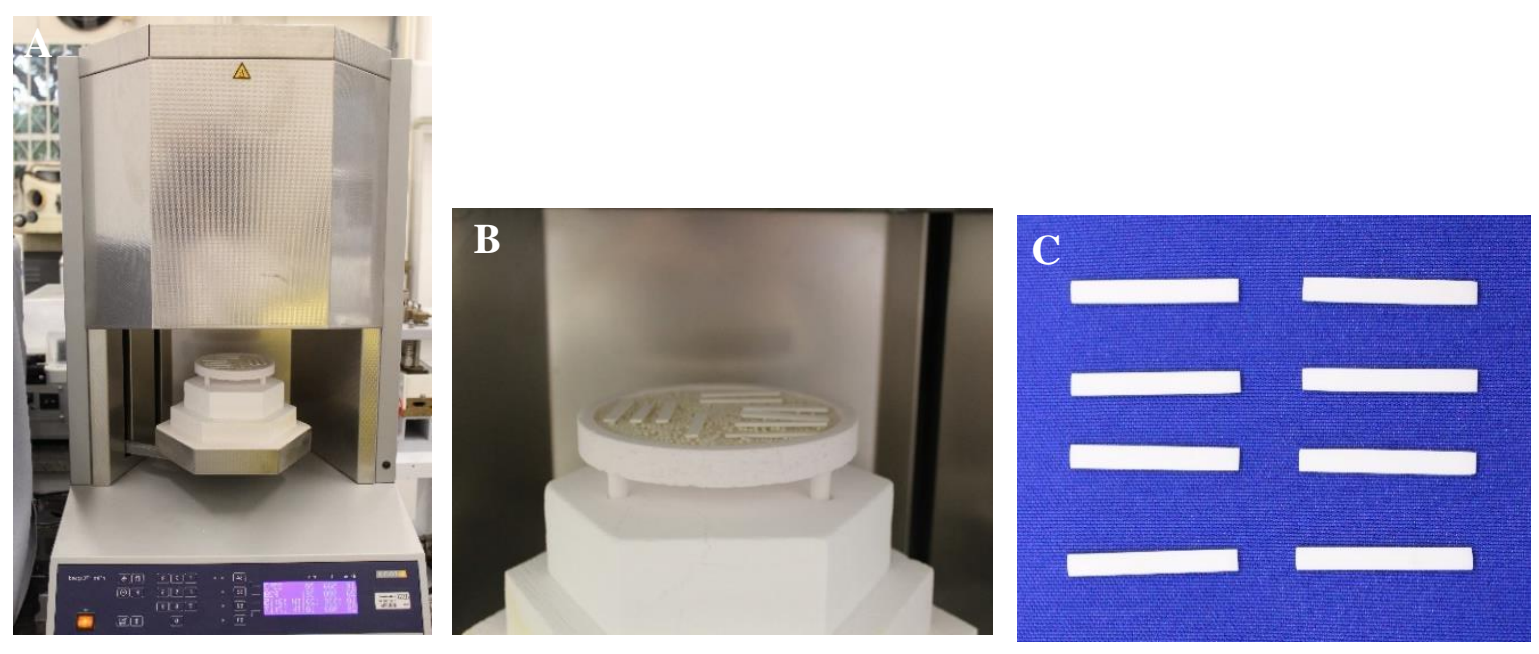




\subsection{Preparo das Barras}

O preparo das barras foi realizado com auxílio de um dispositivo que permite o desgaste padronizado. Este dispositivo consiste em um paralelômetro (Figura 4A) que possui duas hastes, uma horizontal e outra vertical, ambas com uma escala em milímetros (Figuras 4B e 4C), que são utilizadas para controlar a quantidade de desgaste realizado.

Figura 4. A) Dispositivo que permite o desgaste padronizado; B) Escala em milímetros na horizontal, que controla o quão próximo a barra está da ponta/pedra; C) Manivela que permite a movimentação da peça de mão acoplada; D) Dispositivo para fixação da amostra e E) Amostra posicionada no dispositivo.
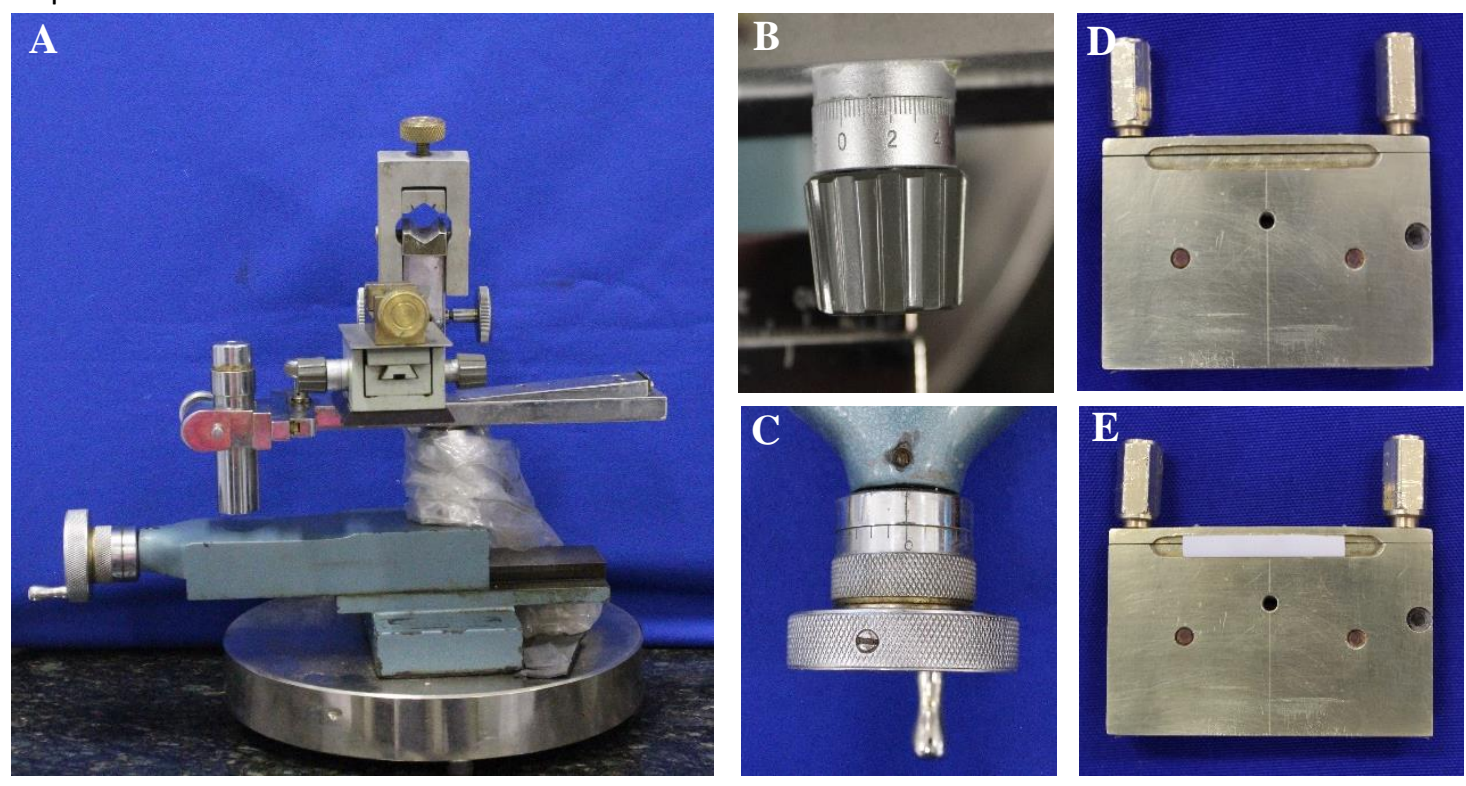

No grupo A, o preparo foi realizado com fresa diamantada cilíndrica (3101, KG Sorensen, São Paulo, Brasil) (Figuras 5A e 5C) de granulação média (90 $\mu \mathrm{m}-120 \mu \mathrm{m}$ ) e o acabamento foi realizado com fresa diamantada cilíndrica (3101F, KG Sorensen, São Paulo, Brasil) de granulação fina (46 $\mu \mathrm{m}$ ) (Figura 5B). Ambos utilizando peça de mão em alta rotação (Dabi Atlante, São Paulo, Brasil), à 400.000 rpm e com refrigeração. 
Figura 5. A) Caneta em alta rotação posicionada no dispositivo; B) Pontas diamantadas 3101 e $3101 \mathrm{~F}$ e C) Ponta diamantada posicionada próximo à barra para dar início ao desgaste.
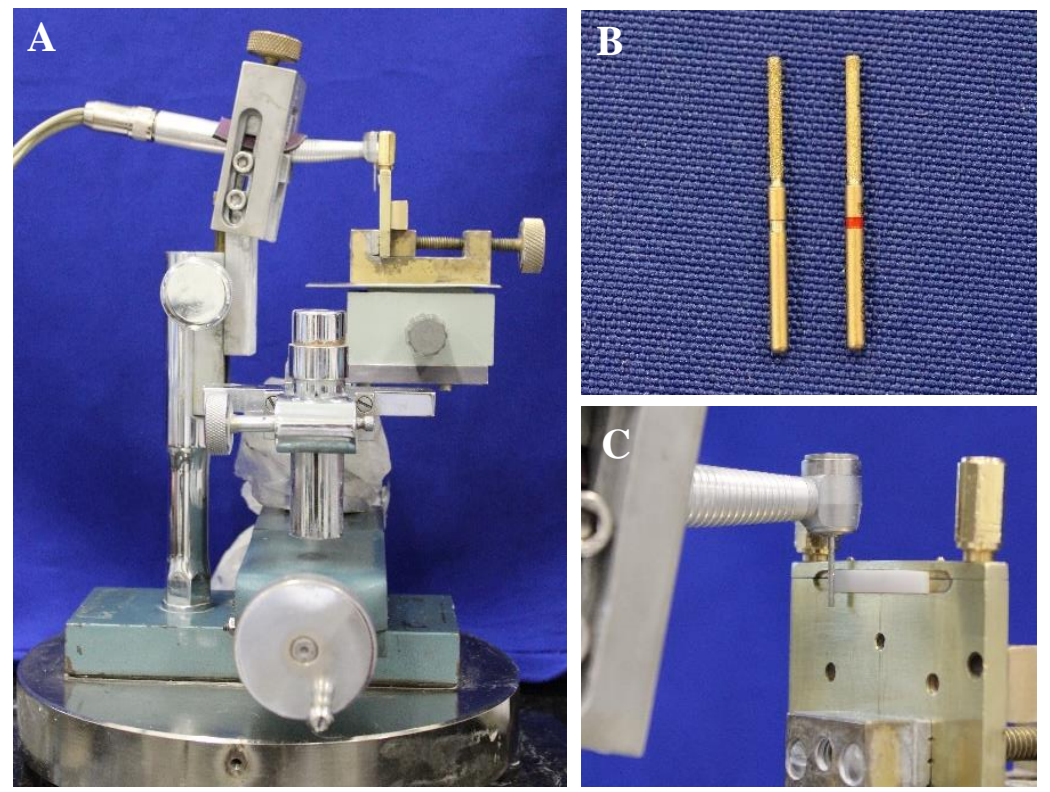

No grupo B, o preparo foi realizado com pedra de desgaste cilíndrica (DYP 14g, Eve Ernst Vetter $\mathrm{GmbH}$, Baden-Württemberg, Alemanha) (Figuras 6A e 6C) de granulação grossa e o acabamento com pedra de desgaste cilíndrica (DYP 14m, Eve Ernst Vetter GmbH, BadenWürttemberg, Alemanha) de granulação média (Figura 6B). Ambos utilizando peça de mão associado à micromotor, em baixa rotação (Dabi Atlante, São Paulo, Brasil), de 3.000 a 18.000 rpm e sem refrigeração.

Figura 6. A) Peça de mão em baixa rotação posicionada no dispositivo; B) Pedras de desgaste DYP-14g e DYP-14m e C) Pedra de desgaste posicionada próximo à barra para dar início ao acabamento.

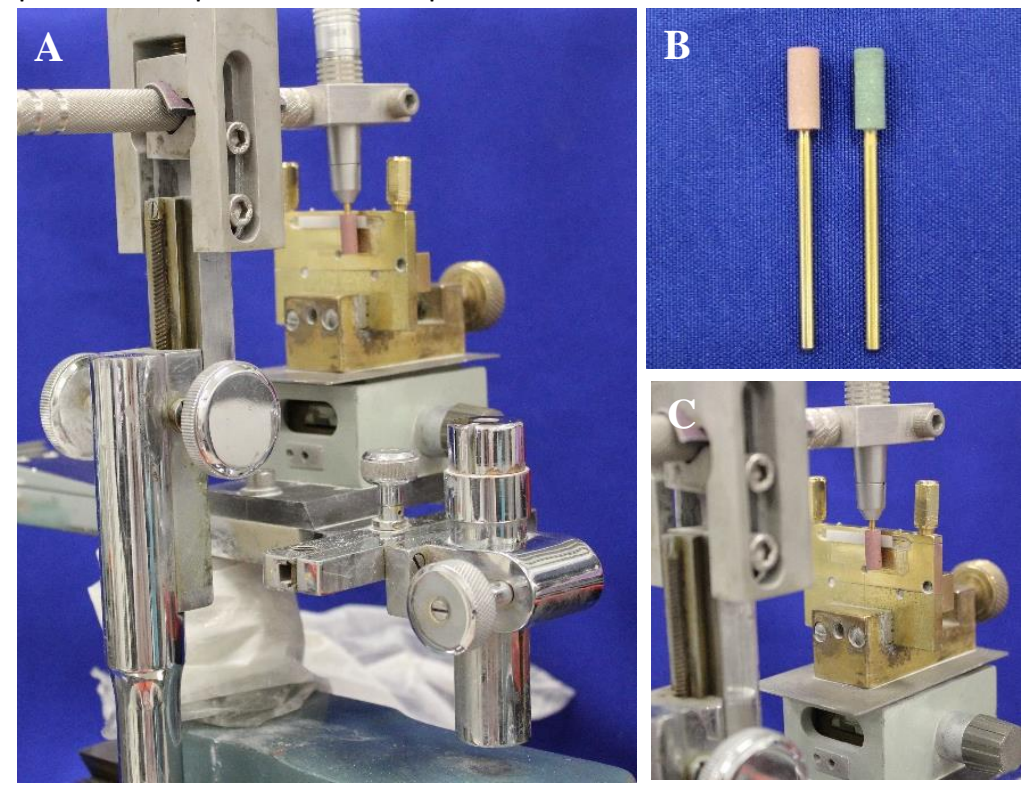


Para ambos os grupos, o preparo consistiu na redução de $0,4 \mathrm{~mm}$ de largura $(0,2$ $\mathrm{mm}$ de cada lado) e 0,4 $\mathrm{mm}$ de espessura $(0,2 \mathrm{~mm}$ de cada lado), seguido pelo acabamento. Foi utilizada uma fresa/pedra por amostra, tanto para o preparo, como para o acabamento. Ao final desta etapa, todas as barras ficaram com a mesma dimensão de $30 \mathrm{~mm}$ de comprimento $\times 4 \mathrm{~mm}$ de largura $\times 1,2 \mathrm{~mm}$ de espessura.

\subsection{Microscópio Confocal à Laser}

O Microscópio Confocal à Laser CLSM (LEXT OLS4000, Olympus, Massachusetts, EUA) foi utilizado para avaliar a topografia das amostras, focando nas modificações superficiais, e para obtenção da rugosidade superficial (Sa).

Foram obtidas cinco imagens da superfície de cada amostra $(n=21)$, totalizando 63 amostras, utilizando lente de aumento de 5 vezes e campo de visão de $2574 \times 2577 \mu \mathrm{m}$ para digitalização. A topografia das amostras foi comparada através de uma imagem selecionada de cada grupo, baseado no padrão repetitivo encontrado.

A rugosidade superficial (Sa) foi calculada pelo software (LEXT 3D Measuring Laser Microscope OLS4000, OLYMPUS, Tokyo, Japão) (Figura 7), que analisa toda a superfície digitalizada e calcula sua rugosidade média (Sa), expressa em valor numérico ( $\mu \mathrm{m})$. Os valores foram automaticamente transferidos para planilhas no formato do Excel.

Figura 7. Software LEXT 3D Measuring Laser Microscope OLS4000.

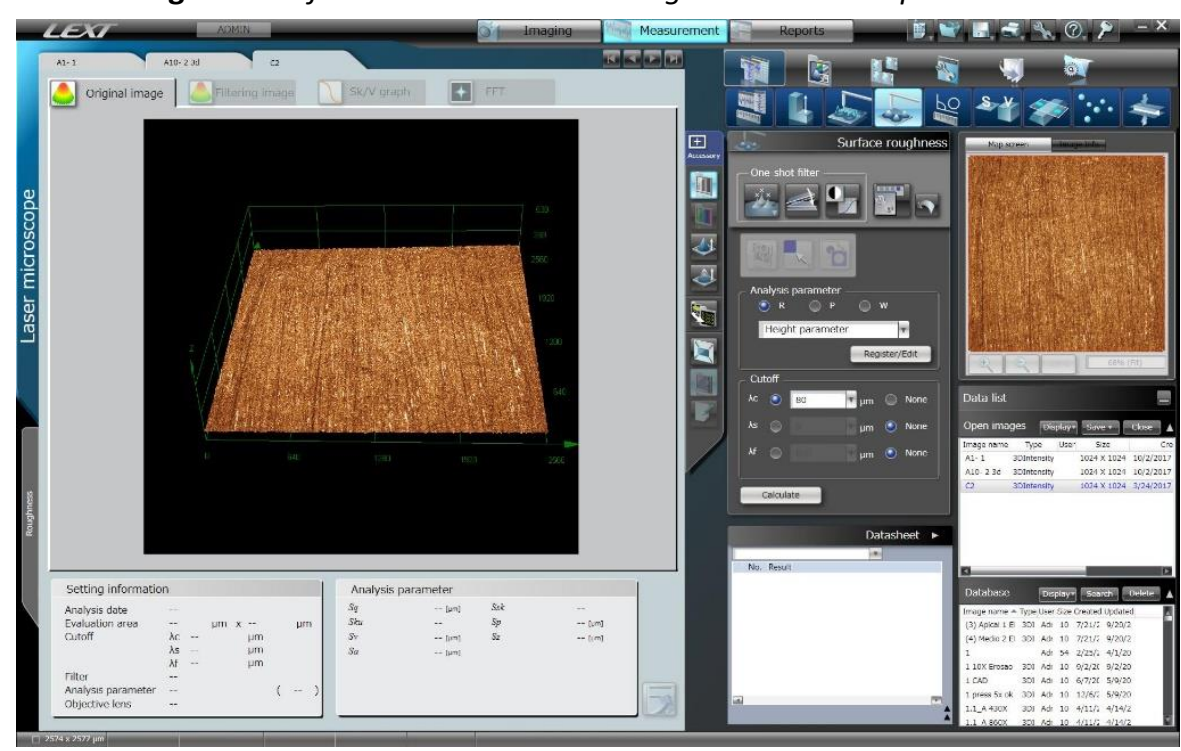




\subsection{Difração de Raios-X}

A técnica de difração de raios-X foi utilizada para determinar a estrutura cristalina das amostras, identificando a porcentagem das fases cristalográficas da zircônia. Para isso, uma amostra de cada grupo $(n=1)$ foi posicionada em difratômetro D2 Phaser (Bruker AXS Corporation, Massachucetts, EUA) e o escaneamento da superfície foi realizado baseado nos seguintes parâmetros: radiação de $\mathrm{Cu}-\mathrm{K} \alpha$, tensão de $30 \mathrm{kV}$, corrente de $10 \mathrm{~mA}$, varredura de $20^{\circ}$ a $90^{\circ}$, passo angular de $0,02^{\circ}$ e velocidade de medição de $1 \mathrm{~s} /$ ponto de contagem.

A análise semi-quantitativa dos dados foi realizada utilizando software COD Crystallography Open Database (CrystalEye, Cambridge, Reino Unido).

\subsection{Módulo de Elasticidade Dinâmico}

O equipamento Sonelastic e o software Sonelastic v. 2.2 (ATCP Engenharia Física, São Carlos, Brasil) (Figura 8) foram utilizados para caracterização de forma não-destrutiva do módulo de elasticidade pela técnica de excitação por impulso, de acordo com a norma ASTM E-1876.

Figura 8. Conjunto utilizado para mensurar o módulo de elasticidade dinâmico (Equipamento e software Sonelastic)

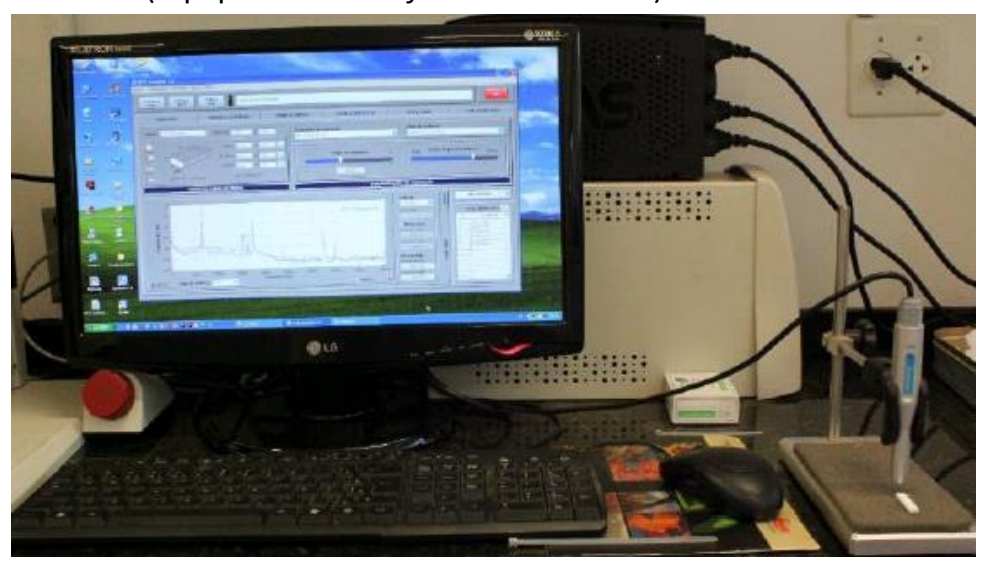

O software Sonelastic ${ }^{\circledR}$ consiste em um analisador de vibrações transitórias, das quais são extraídas as frequências e a respectiva taxa de atenuação para a realização do cálculo do amortecimento. Para isso, o software identifica quais são as frequências de vibração e os respectivos amortecimentos mediante o processamento da resposta acústica do corpo de prova, que é induzida por uma excitação mecânica por impulso. 
Para a realização da caracterização do módulo de elasticidade dinâmico, as amostras $(n=21)$ foram apoiadas em um suporte adequado à sua geometria e às condições de contorno e precisão desejadas (Figuras 9A e 9B). Quando devidamente posicionadas, foram excitadas por um pulsador eletromagnético.

A resposta acústica foi captada por um captador acústico e processada pelo software, que calculou os módulos elásticos e o amortecimento a partir das frequências naturais de vibração.

As amostras tiveram os módulos de elasticidade determinados para avaliar se a realização do desgaste têm influência sobre esta propriedade mecânica.

Figura 9. A e B) Captador acústico e pulsador eletromagnético.
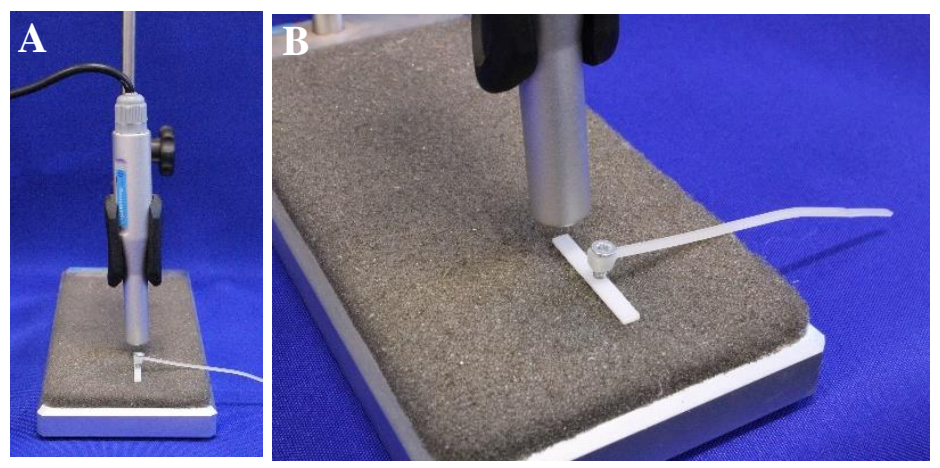

\subsection{Ensaio de Fadiga Mecânica Acelerada}

Para análise da resistência à fadiga mecânica acelerada foi utilizada uma metodologia conhecida como step-stress (Bonfante et al., 2010; Guess et al., 2013; Belli et al. 2014; Bonfante et al., 2015; Amaral et al., 2016; Fraga et al., 2016; Pereira et al., 2016B; Shembish et al., 2016; Polli et al., 2016; Aboushelib et al., 2016; Chun et al., 2017; Zucuni et al., 2017A; Zucuni et al., 2017B), que consiste na aplicação de um teste mecânico estático, como o ensaio de resistência à flexão biaxial, para que, baseado em seus resultados, sejam atribuídos perfis de carregamento mecânico (leve, moderado e severo) para o teste dinâmico.

Sendo assim, previamente ao ensaio de fadiga mecânica acelerada foi realizado o teste de resistência à flexão (MPa). 


\subsubsection{Resistência à flexão biaxial}

O ensaio de resistência a flexão biaxial foi realizado em máquina universal de ensaios (Biopdi, São Carlos, Brasil) (Figura 10A), utilizando célula de carga de 100kgf e com deslocamento de 0,5mm/min, de acordo com a ISO 6872 .

Figura 10. A) Máquina universal de ensaios e B) Barra de zircônia posicionada na máquina universal de ensaios para teste de resistência à flexão biaxial
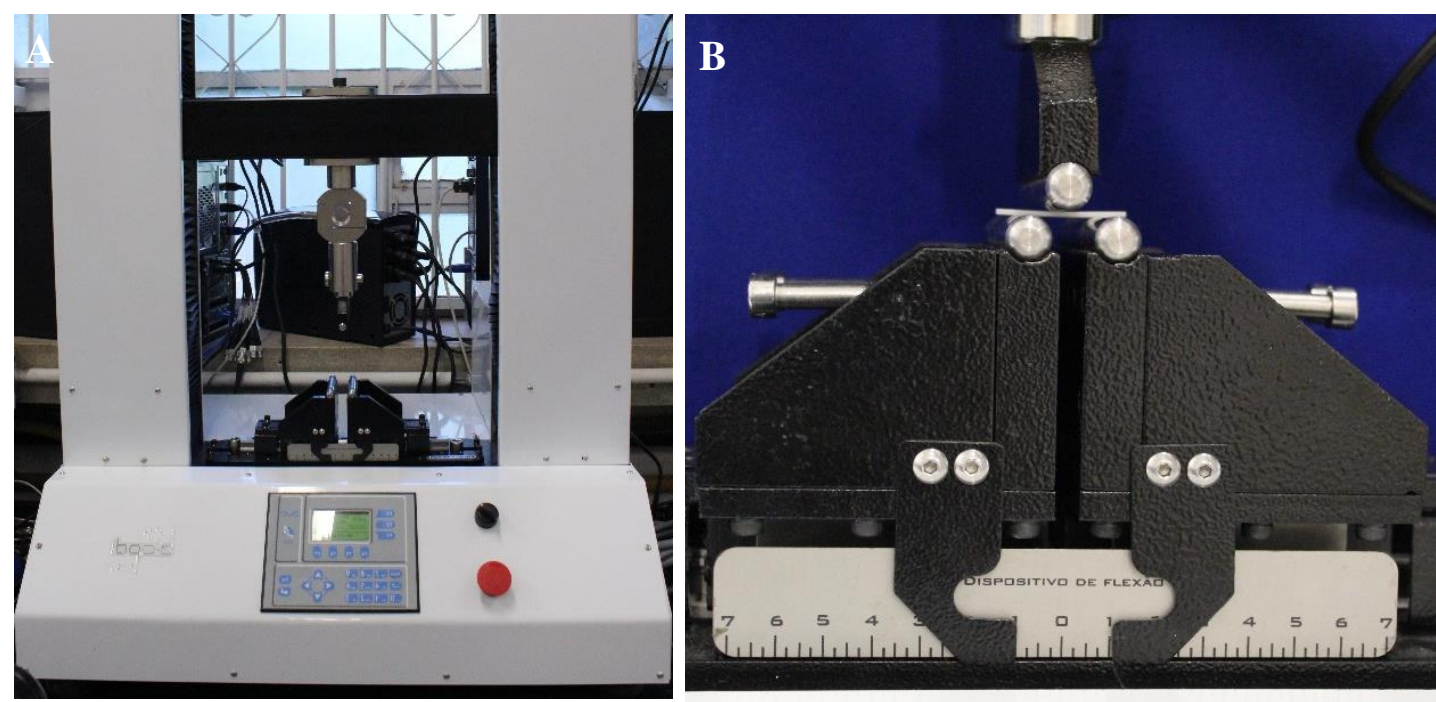

As amostras de cada grupo $(n=3)$ (Bonfante et al., 2010; Guess et al., 2013; Fraga et al., 2016; Shembish et al., 2016; Chun et al., 2017; Zucuni et al., 2017B) foram posicionadas em um suporte metálico, apoiado em dois pontos, um em cada extremidade, com uma distância entre os apoios de $20 \mathrm{~mm}$, sendo a carga aplicada no centro da barra até a deformação permanente ou ruptura (Figura 10B). Posteriormente, os valores de resistência à flexão foram calculados em MPa.

\subsubsection{Ensaio de fadiga mecânica acelerada}

O ensaio de fadiga mecânica acelerada foi realizado em cicladora mecânica pneumática (Biopdi, São Carlos, Brasil) (Figura 11) utilizando protocolo de carregamento isométrico com frequência de $4 \mathrm{~Hz}$. 
Figura 11. Barras posicionadas na cicladora mecânica pneumática para ensaio de fadiga mecânica acelerada

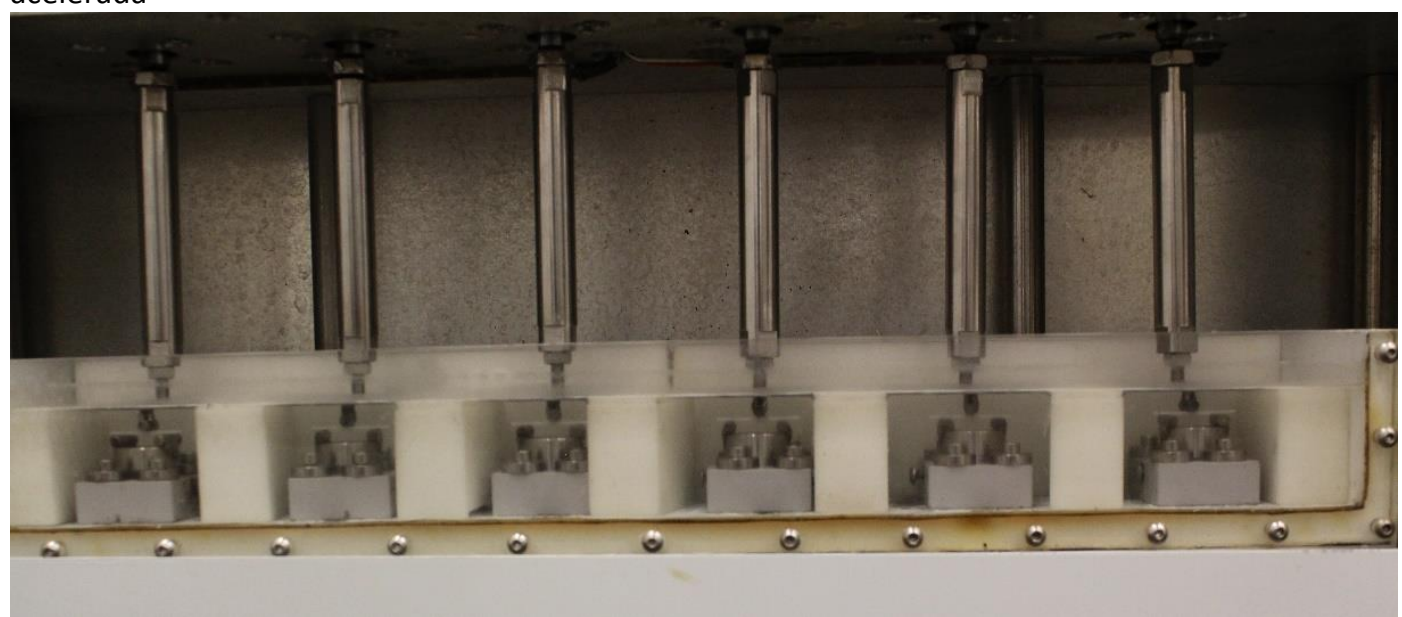

As amostras foram posicionadas em dispositivo semelhante ao utilizado no teste de resistência à flexão, apoiadas em dois pontos, com distância de $20 \mathrm{~mm}$ entre eles (Figura 12A). A carga foi aplicada no centro das barras por uma ponta aplicadora de carga (Figura 12B) e durante o ensaio, elas ficaram totalmente submersas em água (Figura 11C) com temperatura de $37^{\circ} \mathrm{C}$.

Figura 12. A) Dispositivo utilizado para posicionar as barras para o ensaio de fadiga mecânica acelerada, B) Ponta aplicadora de carga e C) Barra posicionada durante o ensaio totalmente submersa em água.
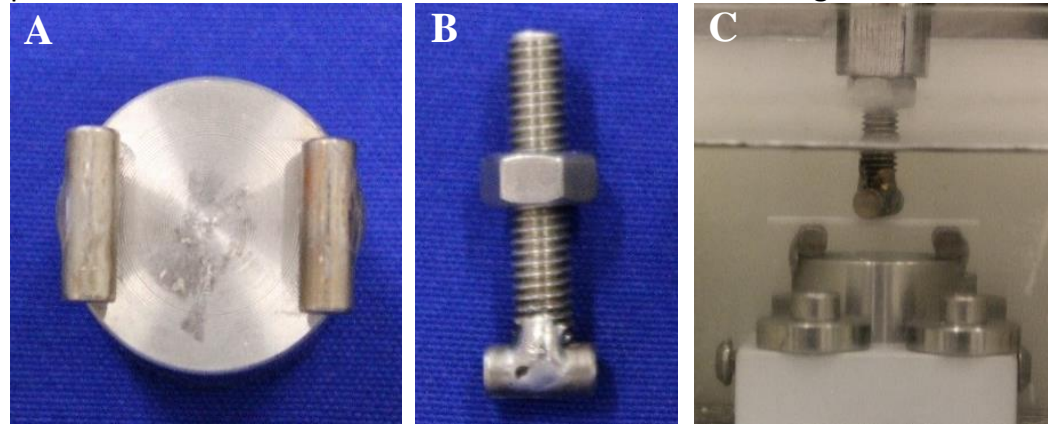

Baseado na média aritmética dos valores obtidos no ensaio de resistência à flexão biaxial, de cada grupo, patamares de cargas foram estabelecidos para cada perfil de carregamento e as amostras foram carregadas até à falha ou até 14.400 ciclos por patamar.

No carregamento leve, as amostras $(n=6)$ foram submetidas à 11 patamares utilizando cargas progressivas de $40 \%, 45 \%, 50 \%, 55 \%, 60 \%, 65 \%, 70 \%, 75 \%, 80 \%, 85 \%$ e 90\% do valor correspondente a resistência à flexão média de cada grupo (Chun et al., 2017). Já no moderado $(n=6)$, foram submetidas à 6 patamares com uma progressão de carga maior do que no carregamento leve, de $40 \%, 50 \%, 60 \%, 70 \%, 80 \%$ e $90 \%$ do valor correspondente 
à resistência à flexão média de cada grupo (Chun et al., 2017). Por fim, o carregamento severo $(n=6)$ se deu em 5 patamares, com uma progressão de carga maior do que nos carregamentos leve e moderado, de $40 \%, 55 \%, 60 \%, 75 \%$ e $90 \%$ do valor correspondente à resistência à flexão média de cada grupo (Chun et al., 2017).

Tabela 1. Tipos de carregamento aos quais as amostras foram submetidas.

\begin{tabular}{llllllllllll} 
& $\mathbf{1}$ & $\mathbf{2}$ & $\mathbf{4}$ & $\mathbf{4}$ & $\mathbf{5}$ & $\mathbf{6}$ & $\mathbf{7}$ & $\mathbf{8}$ & $\mathbf{9}$ & $\mathbf{1 0}$ & $\mathbf{1 1}$ \\
\hline Carregamento leve & $40 \%$ & $45 \%$ & $50 \%$ & $55 \%$ & $60 \%$ & $65 \%$ & $70 \%$ & $75 \%$ & $80 \%$ & $85 \%$ & $90 \%$ \\
Carregamento moderado & $40 \%$ & $50 \%$ & $60 \%$ & $70 \%$ & $80 \%$ & $90 \%$ & & & & & \\
Carregamento severo & $40 \%$ & $55 \%$ & $60 \%$ & $75 \%$ & $90 \%$ & & & & & & \\
\hline
\end{tabular}

Ao final de cada patamar, foi tabulado o número de amostras que fraturaram e que sobreviveram, permitindo o cálculo da probabilidade de sobrevivência em cada patamar.

\subsection{Análise dos Dados}

\subsubsection{Análise estatística da rugosidade superficial e módulo de elasticidade dinâmico}

Inicialmente foi realizada uma análise descritiva através de medidas de posição central e dispersão de dados, seguida por análise de variância (ANOVA) de um fator e teste complementar de Tukey ( $\alpha=5 \%$ ) no software SPSS (SPSS 15.0, SPSS Inc., EUA).

\subsubsection{Análise estatística do teste de fadiga mecânica acelerada}

Foi realizada uma análise de sobrevida para estimar o número de ciclos até a fratura e a força até a fratura em cada grupo de estudo. O gráfico de Kaplan Meier foi construído para visualizar a probabilidade de fratura em relação ao número de ciclos, e a variável força. Um modelo de regressão Weibull foi ajustado para verificar se existe diferença estatísticas em relação ao número de ciclos até a fratura em cada grupo de estudo, foi ajustado um outro modelo para verificar a força até a fratura em cada grupo de estudo. As análises foram implementadas no programa R Project for Statistical Computing versão 3.1 .1 (R Statistical Programming Language 3.1.1, Viena, Áustria). 
4. Resultados 



\section{RESULTADOS}

\subsection{Rugosidade Superficial (Sa)}

Foi realizada análise descritiva, das medidas de posição central e de dispersão dos dados, bem como obtidos os valores médios de rugosidade superficial e desvio padrão, apresentados na Tabela 2 e Figura 13.

Tabela 2. Medidas de posição central e de dispersão dos grupos analisados quanto à rugosidade superficial (Sa) em $\mu \mathrm{m}$

\begin{tabular}{ccccccccc}
\hline Grupo & N & Média & Desvio Padrão & Mediana & Q1 & Q3 & Min & Max \\
\hline Grupo C & 21 & 1,7184 & 0,24750 & 0,05401 & 1,6058 & 1,8311 & 1,40 & 2,51 \\
Grupo A & 21 & 6,7935 & 0,89834 & 0,19603 & 6,3846 & 7,2025 & 4,98 & 7,99 \\
Grupo B & 21 & 5,3352 & 1,18012 & 0,25752 & 4,7980 & 5,8724 & 3,45 & 8,35 \\
\hline
\end{tabular}

Figura 13 - Gráfico: Valores de rugosidade superficial (Sa) ilustrados como média (Desvio Padrão).

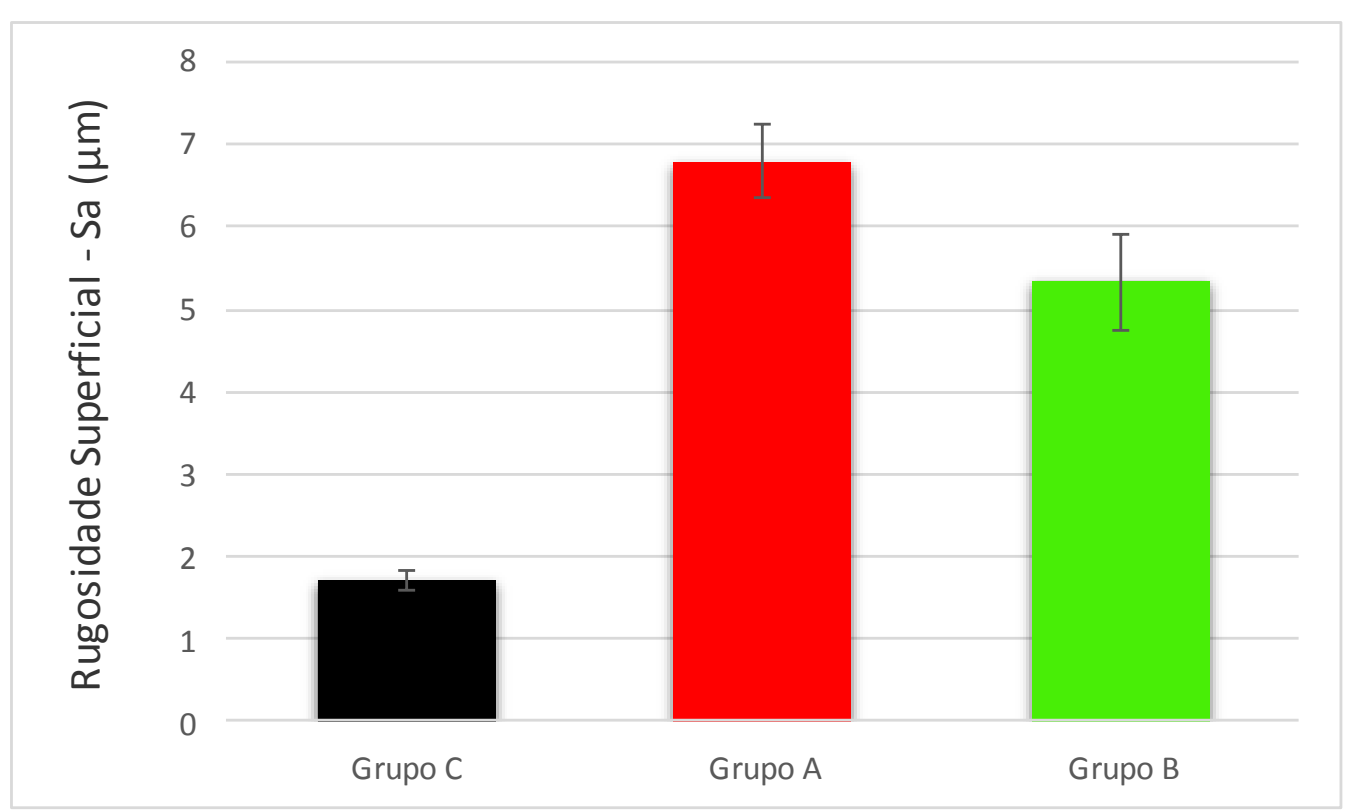

A comparação da rugosidade superficial das amostras (Tabelas 3 e 4) mostrou haver diferença estatística entre os grupos $(p \leq 0,05)$, sendo que o grupo que sofreu desgaste com alta rotação, sob refrigeração, foi o que apresentou maiores valores de rugosidade superficial (Grupo $A=6,7935$ ), seguido pelo grupo que sofreu desgaste com baixa rotação, sem refrigeração (Grupo $B=5,3352$ ) e o grupo que apresentou menores valores foi o grupo que não teve sua superfície modificada (Grupo $C=1,7184$ ). 
Tabela 3. Análise de variância (ANOVA) - Comparação da rugosidade superficial.

\begin{tabular}{cccccc} 
& $\begin{array}{c}\text { Soma dos } \\
\text { quadrados }\end{array}$ & DF & $\begin{array}{c}\text { Quadrados } \\
\text { médios }\end{array}$ & F & Sig \\
\hline $\begin{array}{c}\text { Entre os } \\
\text { grupos }\end{array}$ & 286,750 & 2 & 143,375 & 190,241 & 0,000 \\
$\begin{array}{c}\text { Dentro dos } \\
\text { grupos }\end{array}$ & 45,219 & 60 & 0,754 & & \\
Total & 331,969 & 62 & & & \\
\hline
\end{tabular}

Tabela 4. Teste complementar de Tukey para rugosidade superficial.

\begin{tabular}{ccccc}
\hline Grupo & $\mathbf{N}$ & $\mathbf{1}$ & $\mathbf{2}$ & $\mathbf{3}$ \\
\hline Grupo C & 21 & 1,7184 & & \\
Grupo A & 21 & & 6,7935 & 5,3352 \\
Grupo B & 21 & & & \\
\hline
\end{tabular}

\subsection{Morfologia Superficial por Microscopia Confocal À Laser}

Foram obtidas imagens da morfologia superficial das amostras com lente de aumento de 5 vezes através de microscopia confocal à laser e observado variações entre os grupos. As imagens representativas de cada grupo estão apresentadas a seguir: 
Figura 14 - Imagens da morfologia superficial dos diferentes grupos.
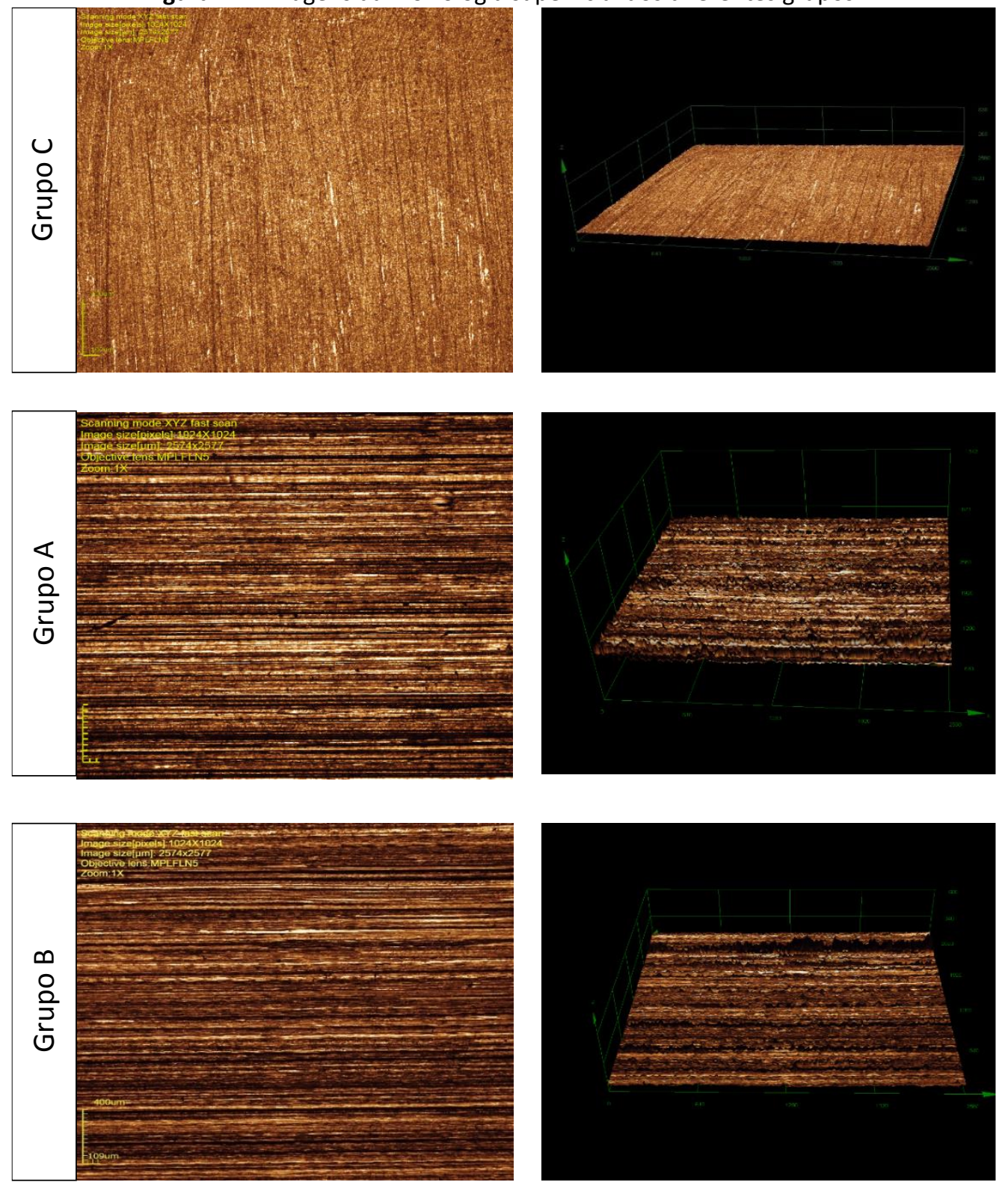

Na Figura 14, notam-se modificações acentuadas de morfologia superficial para os grupos A e B, que foram submetidos ao desgaste. Enquanto nestes grupos são encontradas lacunas e riscos, o grupo C apresenta uma superfície uniforme.

\subsection{Difração de Raios-X}

A Figura 15 apresenta os gráficos de identificação da fase cristalina da zircônia, obtidos por difração de raios-X. Todos os grupos apresentaram perfil difratográfico semelhante ao grupo C, que apresentou $100 \%$ de conteúdo cristalino na fase tetragonal. Entretanto, o software COD (Crystallography Open Database), por meio de análise semi- 
quantitativa, constatou que o grupo A apresenta, aproximadamente, 16,3\% de conteúdo cristalino na fase monoclínica, e que o grupo B apresenta, aproximadamente, $17,4 \%$ de conteúdo cristalino na fase cúbica.

Figura 15 - Gráfico: Difratogramas obtidos das barras de zircônia submetidas a diferentes protocolos de desgaste.
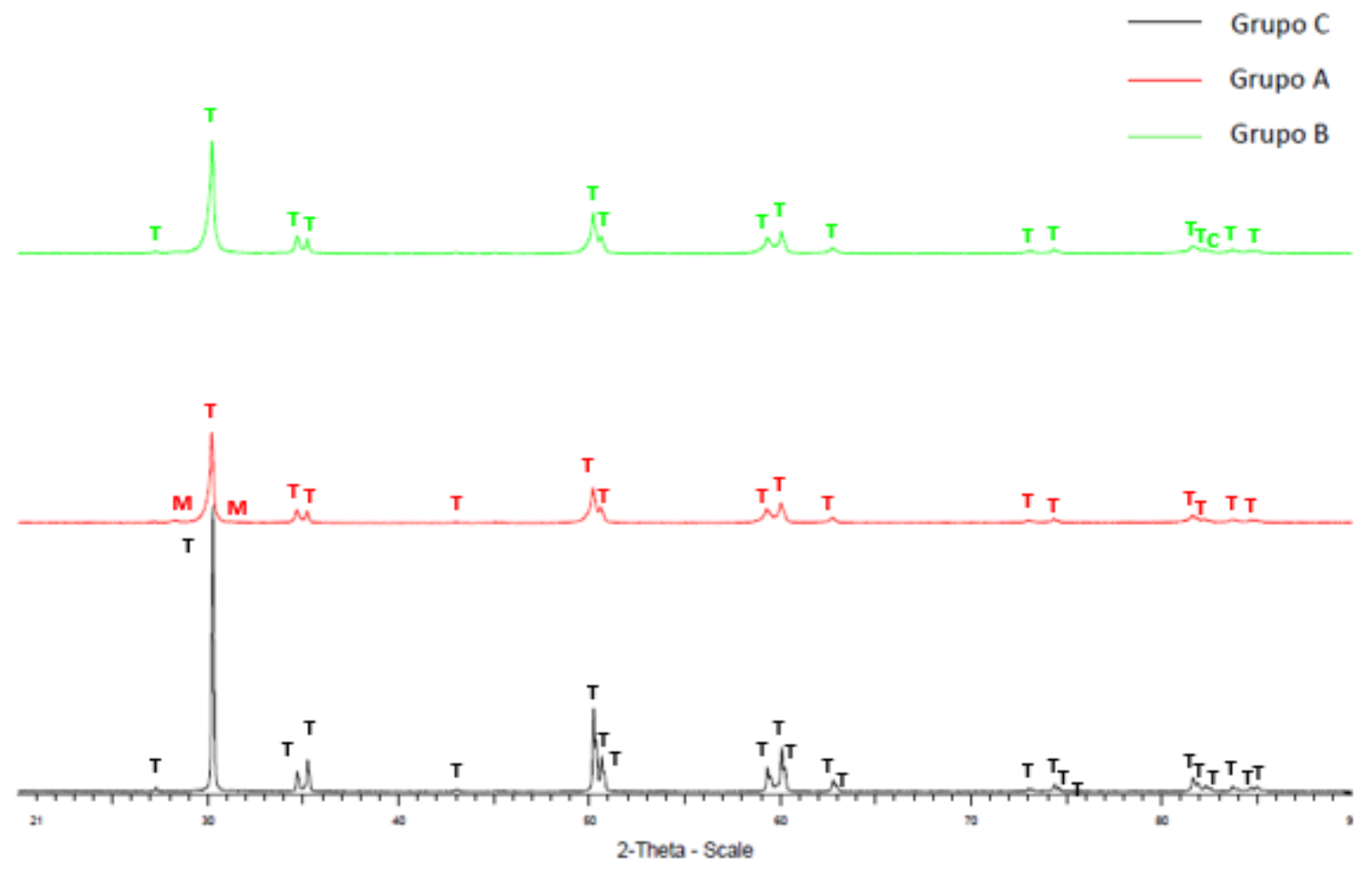

\subsection{Módulo de Elasticidade Dinâmico}

As medidas de posição central e de dispersão, bem como os valores médios de módulo de elasticidade e desvio padrão, são apresentados a seguir, na Tabela 5 e Figura 16.

Tabela 5. Medidas de posição central e de dispersão dos grupos analisados quanto ao módulo de elasticidade dinâmico (GPa).

\begin{tabular}{ccccccccc}
\hline Grupo & N & Média & $\begin{array}{c}\text { Desvio } \\
\text { Padrão }\end{array}$ & Mediana & Q1 & Q3 & Min & Max \\
\hline Grupo C & 21 & 202,2110 & 20,45364 & 4,46335 & 192,9006 & 211,5213 & 160,13 & 232,92 \\
Grupo A & 21 & 199,1067 & 18,52739 & 4,04301 & 190,6731 & 207,5402 & 134,19 & 220,29 \\
Grupo B & 21 & 217,1700 & 12,48766 & 2,72503 & 211,4857 & 222,8543 & 195,00 & 238,83 \\
\hline
\end{tabular}


Figura 16 - Gráfico: Valores de módulo de elasticidade dinâmico (GPa) apresentados como média (desvio padrão).

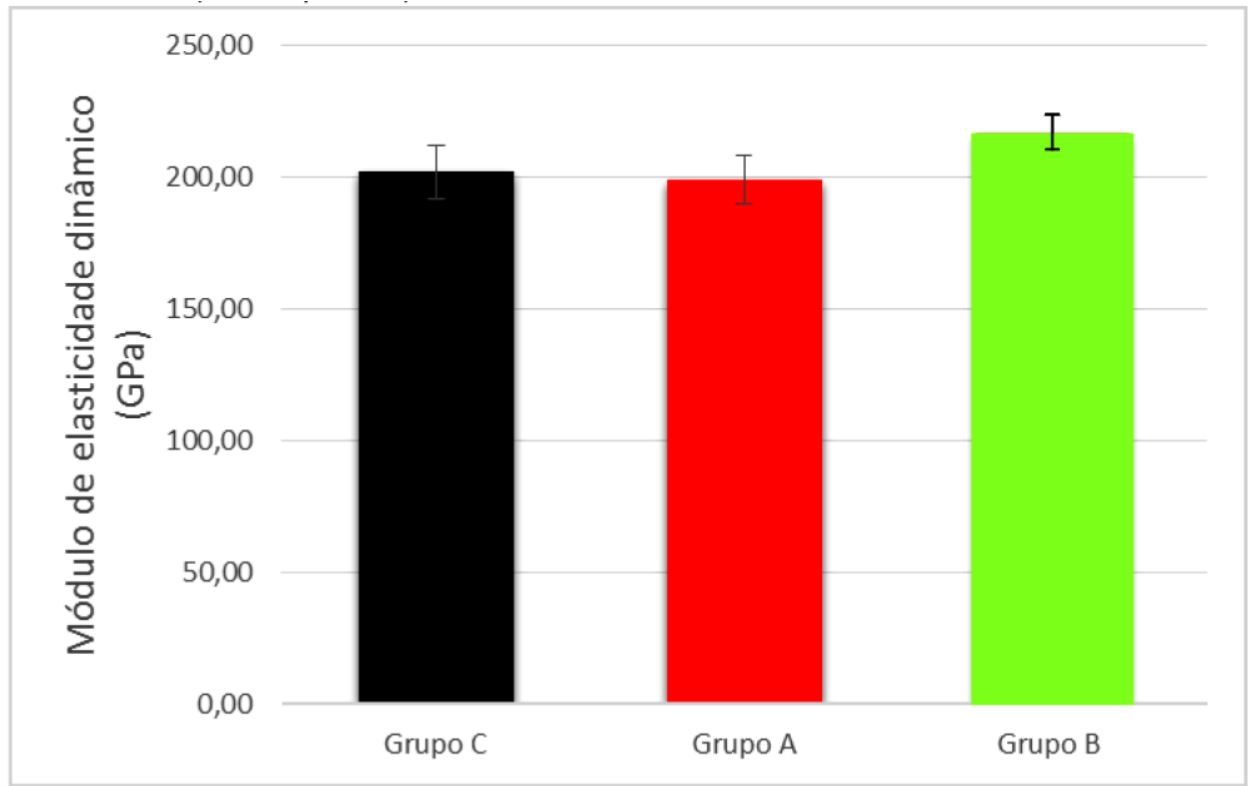

A análise estatística (Tabelas 5 e 6) revelou que quando o protocolo de desgaste do grupo B foi utilizado, houve aumento do módulo de elasticidade dinâmico da zircônia quando comparado aos demais $(p=0,003)$. Não houve diferença estatística entre os grupos $C$ e A.

Tabela 6. Análise de variância (ANOVA) - Comparação do módulo de elasticidade dinâmico.

\begin{tabular}{cccccc}
\cline { 2 - 5 } & $\begin{array}{c}\text { Soma dos } \\
\text { quadrados }\end{array}$ & DF & $\begin{array}{c}\text { Quadrados } \\
\text { médios }\end{array}$ & F & Sig \\
\hline $\begin{array}{c}\text { Entre os grupos } \\
\begin{array}{c}\text { Dentro dos } \\
\text { grupos }\end{array}\end{array}$ & 3917,856 & 2 & 1958,928 & 6,405 & 0,003 \\
$\quad 18351,147$ & 60 & 305,852 & & \\
Total & 22269,003 & 62 & & & \\
\hline
\end{tabular}

Tabela 7. Teste complementar de Tukey para o módulo de elasticidade dinâmico.

\begin{tabular}{cccc}
\hline Grupo & N & $\mathbf{1}$ & $\mathbf{2}$ \\
\hline Grupo C & 21 & 202,2110 & \\
Grupo A & 21 & 199,1067 & 217,1700 \\
Grupo B & 21 & & \\
\hline
\end{tabular}




\subsection{Fadiga Mecânica Acelerada}

\subsubsection{Resistência à flexão}

As cargas utilizadas nos carregamentos foram estabelecidas baseado nos resultados obtidos no ensaio de resistência à flexão biaxial (Tabela 8).

Tabela 8. Média da resistência à flexão dos diferentes grupos (MPa).

\begin{tabular}{ccc}
\hline Grupo & N & Média \\
\hline Grupo C & 3 & 1106,528 \\
Grupo A & 3 & 1175,83 \\
Grupo B & 3 & 1525,446 \\
\hline
\end{tabular}

\subsubsection{Fadiga mecânica acelerada}

A taxa de sobrevivência das amostras dos diferentes grupos foi analisada quanto ao número de ciclos e a força. Os estimadores de produto-limite de Kaplan-Meier foram calculados baseados em uma tábua de sobrevida.

\subsubsection{Número de ciclos}

Para variável número de ciclos, os estimadores foram calculados baseados na tábua de sobrevida (Tabela 9) e apresentados na Figura 17. 
Tabela 9. Tábua de sobrevida para variável número de ciclos.

\begin{tabular}{|c|c|c|c|c|c|c|}
\hline \multirow{2}{*}{ Grupo } & \multirow{2}{*}{ № ciclos } & \multirow{2}{*}{ № risco } & \multirow{2}{*}{ Sobrevida } & \multirow{2}{*}{ Erro Padrão } & \multicolumn{2}{|c|}{ IC 95\% } \\
\hline & & & & & LI & LS \\
\hline \multirow{6}{*}{$\begin{array}{c}\text { Grupo C } \\
\text { Carregamento } \\
\text { leve }\end{array}$} & 31960 & 6 & 0,833 & 0,152 & 0,583 & 1,000 \\
\hline & 34104 & 5 & 0,667 & 0,192 & 0,379 & 1,000 \\
\hline & 59069 & 4 & 0,500 & 0,204 & 0,225 & 1,000 \\
\hline & 63044 & 3 & 0,333 & 0,192 & 0,108 & 1,000 \\
\hline & 74044 & 2 & 0,167 & 0,152 & 0,028 & 0,997 \\
\hline & 120157 & 1 & 0,000 & & & \\
\hline \multirow{5}{*}{$\begin{array}{c}\text { Grupo C } \\
\text { Carregamento } \\
\text { moderado }\end{array}$} & 14596 & 6 & 0,833 & 0,152 & 0,583 & 1,000 \\
\hline & 15724 & 5 & 0,667 & 0,192 & 0,379 & 1,000 \\
\hline & 29169 & 4 & 0,500 & 0,204 & 0,225 & 1,000 \\
\hline & 57679 & 3 & 0,333 & 0,192 & 0,108 & 1,000 \\
\hline & 57834 & 2 & 0,167 & 0,152 & 0,028 & 0,997 \\
\hline \multirow{6}{*}{$\begin{array}{c}\text { Grupo C } \\
\text { Carregamento } \\
\text { severo }\end{array}$} & 30042 & 6 & 0,833 & 0,152 & 0,583 & 1,000 \\
\hline & 37192 & 5 & 0,667 & 0,192 & 0,379 & 1,000 \\
\hline & 39612 & 4 & 0,500 & 0,204 & 0,225 & 1,000 \\
\hline & 43987 & 3 & 0,333 & 0,192 & 0,108 & 1,000 \\
\hline & 45603 & 2 & 0,167 & 0,152 & 0,028 & 0,997 \\
\hline & 50547 & 1 & 0,000 & & & \\
\hline \multirow{6}{*}{$\begin{array}{c}\text { Grupo A } \\
\text { Carregamento } \\
\text { leve }\end{array}$} & 1500 & 6 & 0,833 & 0,152 & 0,583 & 1,000 \\
\hline & 3171 & 5 & 0,667 & 0,192 & 0,379 & 1,000 \\
\hline & 3562 & 4 & 0,500 & 0,204 & 0,225 & 1,000 \\
\hline & 45639 & 3 & 0,333 & 0,192 & 0,108 & 1,000 \\
\hline & 86661 & 2 & 0,167 & 0,152 & 0,028 & 0,997 \\
\hline & 89389 & 1 & 0,000 & & & \\
\hline \multirow{6}{*}{$\begin{array}{c}\text { Grupo A } \\
\text { Carregamento } \\
\text { moderado }\end{array}$} & 27947 & 6 & 0,833 & 0,152 & 0,583 & 1,000 \\
\hline & 43284 & 5 & 0,667 & 0,192 & 0,379 & 1,000 \\
\hline & 43341 & 4 & 0,500 & 0,204 & 0,225 & 1,000 \\
\hline & 43485 & 3 & 0,333 & 0,192 & 0,108 & 1,000 \\
\hline & 55182 & 2 & 0,167 & 0,152 & 0,028 & 0,997 \\
\hline & 72706 & 1 & 0,000 & & & \\
\hline \multirow{6}{*}{$\begin{array}{c}\text { Grupo A } \\
\text { Carregamento } \\
\text { severo }\end{array}$} & 12820 & 6 & 0,833 & 0,152 & 0,583 & 1,000 \\
\hline & 14520 & 5 & 0,667 & 0,192 & 0,379 & 1,000 \\
\hline & 17062 & 4 & 0,500 & 0,204 & 0,225 & 1,000 \\
\hline & 30994 & 3 & 0,333 & 0,192 & 0,108 & 1,000 \\
\hline & 43909 & 2 & 0,167 & 0,152 & 0,028 & 0,997 \\
\hline & 43998 & 1 & 0,000 & & & \\
\hline \multirow{6}{*}{$\begin{array}{c}\text { Grupo B } \\
\text { Carregamento } \\
\text { leve }\end{array}$} & 49271 & 6 & 0,833 & 0,152 & 0,583 & 1,000 \\
\hline & 72778 & 5 & 0,667 & 0,192 & 0,379 & 1,000 \\
\hline & 87800 & 4 & 0,500 & 0,204 & 0,225 & 1,000 \\
\hline & 87830 & 3 & 0,333 & 0,192 & 0,108 & 1,000 \\
\hline & 89204 & 2 & 0,167 & 0,152 & 0,028 & 0,997 \\
\hline & 117351 & 1 & 0,000 & & & \\
\hline \multirow{6}{*}{$\begin{array}{c}\text { Grupo B } \\
\text { Carregamento } \\
\text { moderado }\end{array}$} & 1020 & 6 & 0,833 & 0,152 & 0,583 & 1,000 \\
\hline & 15630 & 5 & 0,667 & 0,192 & 0,379 & 1,000 \\
\hline & 19254 & 4 & 0,500 & 0,204 & 0,225 & 1,000 \\
\hline & 29292 & 3 & 0,333 & 0,192 & 0,108 & 1,000 \\
\hline & 43586 & 2 & 0,167 & 0,152 & 0,028 & 0,997 \\
\hline & 60936 & 1 & 0,000 & & & \\
\hline \multirow{6}{*}{$\begin{array}{l}\text { Grupo B } \\
\text { Carregamento } \\
\text { severo }\end{array}$} & 18435 & 6 & 0,833 & 0,152 & 0,583 & 1,000 \\
\hline & 29120 & 5 & 0,667 & 0,192 & 0,379 & 1,000 \\
\hline & 43240 & 4 & 0,500 & 0,204 & 0,225 & 1,000 \\
\hline & 43249 & 3 & 0,333 & 0,192 & 0,108 & 1,000 \\
\hline & 43374 & 2 & 0,167 & 0,152 & 0,028 & 0,997 \\
\hline & 57942 & 1 & 0,000 & & & \\
\hline
\end{tabular}


Figura 17 - Gráfico: Estimativa da probabilidade de sobrevida para variável número de ciclos.

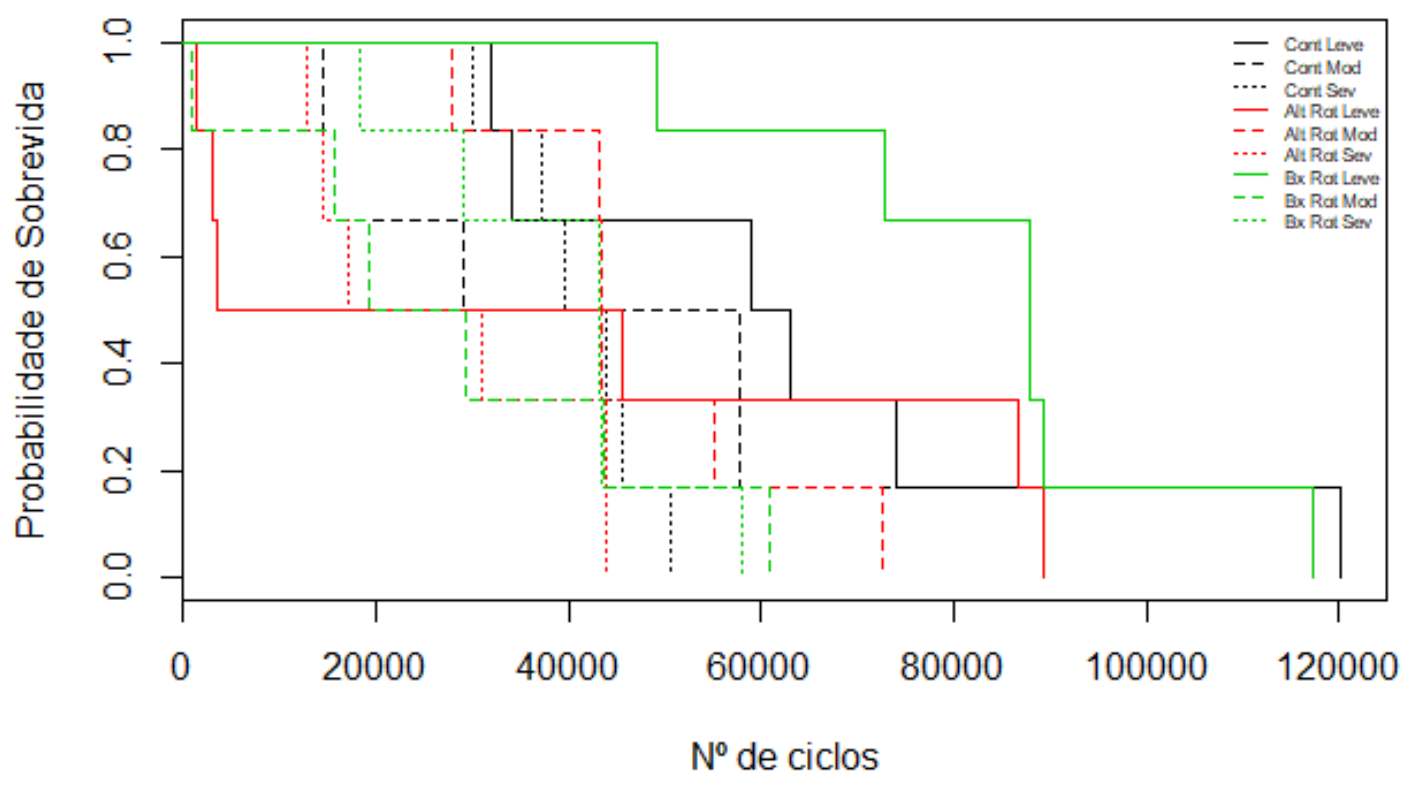

As amostras do grupo C, quando submetidas à carregamento leve, apresentam probabilidade de $50 \%$ de sobreviverem a 59069 ciclos, sendo que a taxa de sobrevida sob carregamento leve é maior do que sob carregamento moderado (29169 ciclos) e severo (39612 ciclos).

Já as amostras do grupo A, quando submetidas a carregamento leve, apresentam probabilidade de $50 \%$ de sobreviverem a 3562 ciclos, sendo que a taxa de sobrevida neste carregamento é menor do que para os outros tipos de carregamento, moderado (43341 ciclos) e severo (17062 ciclos). Quando as amostras do grupo A são comparadas com as amostras do Grupo C, submetidas ao mesmo tipo de carregamento, apresentam probabilidade menor de sobreviverem sob carregamento leve (55507 ciclos a menos) e severo ( 22550 ciclos a menos) e maior sob carregamento moderado ( 14172 ciclos a mais).

Por fim, as amostras do grupo B, quando submetidas a carregamento leve, apresentam probabilidade de $50 \%$ de sobreviverem a 87800 ciclos, sendo que a taxa de sobrevida para este tipo de carregamento é maior do que para os outros tipos de carregamento, moderado (19254 ciclos) e severo (43240 ciclos). Quando a taxa de sobrevida das amostras deste grupo é comparada a taxa de sobrevida do grupo C, submetidas ao mesmo tipo de carregamento, apresentam probabilidade maior de sobreviverem sob carregamento leve (28731 ciclos a mais) e severo (3628 ciclos a mais) e menor sob carregamento moderado (9915 ciclos a menos). 
Para estabelecer comparações entre as curvas de sobrevida, tendo como parâmetro a variável número de ciclos, foi considerado um modelo de regressão paramétrico com distribuição de Weibull. As comparações foram realizadas entre os grupos (Tabelas 10, 11 e 12) e entre os tipos de carregamento no mesmo grupo (Tabelas 13, 14 e 15).

Tabela 10. Modelo de distribuição de Weibull para comparação da variável número de ciclos entre os diferentes grupos para o tipo de carregamento leve.

\begin{tabular}{ccccc}
\hline Grupo & Estimativa & Erro Padrão & Estatística z & p- valor \\
\hline $\begin{array}{c}\text { Grupo A } \\
\text { Carregamento Leve } \\
\begin{array}{c}\text { Grupo B } \\
\text { Carregamento leve }\end{array}\end{array}$ & $-0,272$ & 0,307 & $-0,888$ & 0,375 \\
\hline
\end{tabular}

* Grupo C-Carregamento leve foi utilizado como referência

Tabela 11. Modelo de distribuição de Weibull para comparação da variável número de ciclos entre os diferentes grupos para o tipo de carregamento moderado.

\begin{tabular}{ccccc}
\hline Grupo & Estimativa & Erro Padrão & Estatística z & p- valor \\
\hline $\begin{array}{c}\text { Grupo A } \\
\text { Carregamento moderado } \\
\text { Grupo B }\end{array}$ & $-0,1099$ & 0,32 & $-0,343$ & 0,731 \\
Carregamento moderado & $-0,4882$ & 0,32 & $-1,524$ & 0,128 \\
\hline
\end{tabular}

* Grupo C - Carregamento moderado foi utilizado como referência

Tabela 12. Modelo de distribuição de Weibull para comparação da variável número de ciclos entre os diferentes grupos para o tipo de carregamento severo

\begin{tabular}{ccccc}
\hline Grupo & Estimativa & Erro Padrão & Estatística z & p- valor \\
\hline $\begin{array}{c}\text { Grupo A } \\
\text { Carregamento severo } \\
\text { Grupo B }\end{array}$ & $-0,3293$ & 0,306 & $-1,077$ & 0,281 \\
Carregamento severo & $-0,0159$ & 0,305 & $-0,052$ & 0,959
\end{tabular}

* Grupo C - Carregamento severo foi utilizado como referência

A análise estatística (Tabelas 10, 11 e 12) realizada para estabelecer comparações entre a taxa de sobrevivência dos diferentes grupos, revelou que não há diferença estatística entre eles para os diferentes tipos de carregamento.

Tabela 13. Modelo de distribuição de Weibull para comparação da variável número de ciclos entre os diferentes tipos de carregamento para o grupo $C$.

\begin{tabular}{ccccc}
\hline Grupo & Estimativa & Erro Padrão & Estatística z & p- valor \\
\hline $\begin{array}{c}\text { Grupo C } \\
\text { Carregamento moderado }\end{array}$ & $-0,232$ & 0,320 & $-0,725$ & 0,469 \\
$\begin{array}{c}\text { Grupo C } \\
\text { Carregamento severo }\end{array}$ & $-0,513$ & 0,306 & $-1,677$ & 0,094 \\
\hline
\end{tabular}

* Grupo C-Carregamento leve foi utilizado como referência 
Tabela 14. Modelo de distribuição de Weibull para comparação da variável número de ciclos entre os diferentes tipos de carregamento para o grupo A.

\begin{tabular}{ccccc}
\hline Grupo & Estimativa & Erro Padrão & Estatística z & p- valor \\
\hline $\begin{array}{c}\text { Grupo A } \\
\text { Carregamento moderado } \\
\text { Grupo A }\end{array}$ & $-0,0698$ & 0,308 & $-0,227$ & 0,8210 \\
Carregamento severo & $-0,5699$ & 0,306 & $-1,86$ & 0,0629 \\
\hline
\end{tabular}

* Grupo A - Carregamento leve foi utilizado como referência

Tabela 15. Modelo de distribuição de Weibull para comparação da variável número de ciclos entre os diferentes tipos de carregamento para o grupo B.

\begin{tabular}{ccccc}
\hline Grupo & Estimativa & Erro Padrão & Estatística z & p- valor \\
\hline $\begin{array}{c}\text { Grupo B } \\
\text { Carregamento moderado } \\
\text { Grupo B }\end{array}$ & $-0,936$ & 0,306 & $-3,054$ & 0,0023 \\
Carregamento severo & $-0,744$ & 0,305 & $-2,438$ & 0,0147 \\
\hline
\end{tabular}

* Grupo B - Carregamento leve foi utilizado como referência

A análise estatística (Tabelas 13, 14 e 15) realizada para estabelecer comparações entre a taxa de sobrevivência nos diferentes tipos de carregamento dentro do mesmo grupo revelou que não houve diferença para os grupos C e A. Entretanto, houve diferença estatística para os carregamentos moderado e severo quando comparados ao carregamento leve no grupo $B$.

Tabela 16. Estimativa das razões de risco para variável número de ciclos

\begin{tabular}{cccc}
\hline Grupo & HR $^{* *}$ & LI & LS \\
\hline $\begin{array}{c}\text { Grupo C } \\
\text { Carregamento moderado } \\
\text { Grupo C } \\
\text { Carregamento severo } \\
\quad \text { Grupo A } \\
\text { Carregamento leve } \\
\quad \text { Grupo A }\end{array}$ & 1,5510632 & 0,4708133 & 5,109875 \\
$\begin{array}{c}\text { Carregamento moderado } \\
\text { Grupo A } \\
\text { Carregamento severo } \\
\text { Grupo B } \\
\text { Carregamento leve } \\
\text { Grupo B }\end{array}$ & 1,6380821 & 0,8200083 & 8,487082 \\
$\begin{array}{c}\text { Carregamento moderado } \\
\text { Grupo B }\end{array}$ & 1,9094752 & 0,539643 & 5,188549 \\
Carregamento severo & 4,9188192 & 0,605746 & 16,1639 \\
\hline
\end{tabular}

\footnotetext{
* Grupo C-Carregamento leve foi utilizado como referência
}

** HR: Hazard Ratio 
Na Tabela 16 é apresentada uma estimativa das razões de risco utilizando as amostras do grupo C, submetidas ao carregamento leve, como referência.

No grupo C, os carregamentos moderado e severo apresentam fator de risco e é notável que quando progressão de carga aumenta, aumenta o risco a fratura. As amostras submetidas a carregamento severo são as que apresentam maior risco e 2,6380821 vezes mais chance de fraturar do que as amostras submetidas a carregamento leve.

No grupo A, esta condição se repete, ou seja, o risco a fratura aumenta quando há uma progressão de carga maior dentro do carregamento. Os diferentes tipos de carregamento apresentam fator de risco e as amostras sob carregamento severo são as que apresentam maior risco e 4,9188192 vezes mais chance de fraturar do que as amostras utilizadas como referência.

No grupo B, quando as amostras são submetidas a carregamento leve, apresentam fator de proteção e 0,6650564 menos chance de fraturar do que as amostras utilizadas como referência. Entretanto, para os carregamentos moderado e severo existe fator de risco. Para este grupo, as amostras submetidas a carregamento moderado são as que apresentam maior risco e 3,9066205 vezes mais chance de fraturar do que as amostras utilizadas como referência.

As amostras do grupo A são as que apresentam maior risco à fratura para os tipos de carregamentos leve e severo. Já para o carregamento moderado, o maior risco à fratura é das amostras do grupo B.

\subsubsection{Força}

Para variável força, os estimadores foram calculados baseados na tábua de sobrevida (Tabela 17). 
Tabela 17. Tábua de sobrevida para variável força.

\begin{tabular}{|c|c|c|c|c|c|c|}
\hline \multirow{2}{*}{ Grupo } & \multirow{2}{*}{ Força (N) } & \multirow{2}{*}{ № risco } & \multirow{2}{*}{ Sobrevida } & \multirow{2}{*}{ Erro Padrão } & \multicolumn{2}{|c|}{ IC 95\% } \\
\hline & & & & & LI & LS \\
\hline \multirow{4}{*}{$\begin{array}{c}\text { Grupo C } \\
\text { Carregamento } \\
\text { leve }\end{array}$} & 105 & 6 & 0,667 & 0,192 & 0,379 & 1,000 \\
\hline & 126 & 4 & 0,333 & 0,192 & 0,108 & 1,000 \\
\hline & 136 & 2 & 0,167 & 0,152 & 0,028 & 0,997 \\
\hline & 168 & 1 & 0,000 & & & \\
\hline \multirow{3}{*}{$\begin{array}{c}\text { Grupo C } \\
\text { Carregamento } \\
\text { moderado }\end{array}$} & 105 & 6 & 0,667 & 0,192 & 0,379 & 1,000 \\
\hline & 126 & 4 & 0,500 & 0,204 & 0,225 & 1,000 \\
\hline & 168 & 3 & 0,167 & 0,152 & 0,028 & 0,997 \\
\hline \multirow{2}{*}{$\begin{array}{c}\text { Grupo C } \\
\text { Carregamento } \\
\text { severo }\end{array}$} & 126 & 6 & 0,500 & 0,204 & 0,225 & 1,000 \\
\hline & 157 & 3 & 0,000 & & & \\
\hline \multirow{3}{*}{$\begin{array}{c}\text { Grupo A } \\
\text { Carregamento } \\
\text { leve }\end{array}$} & 91,5 & 6 & 0,500 & 0,204 & 0,225 & 1,000 \\
\hline & 137,2 & 3 & 0,333 & 0,192 & 0,108 & 1,000 \\
\hline & 160,1 & 2 & 0,000 & & & \\
\hline \multirow{3}{*}{$\begin{array}{c}\text { Grupo A } \\
\text { Carregamento } \\
\text { moderado }\end{array}$} & 114 & 6 & 0,833 & 0,152 & 0,583 & 1,000 \\
\hline & 126 & 5 & 0,667 & 0,192 & 0,379 & 1,000 \\
\hline & 160 & 4 & 0,000 & & & \\
\hline \multirow{4}{*}{$\begin{array}{c}\text { Grupo A } \\
\text { Carregamento } \\
\text { severo }\end{array}$} & 91,5 & 6 & 0,833 & 0,152 & 0,583 & 1,000 \\
\hline & 125,8 & 5 & 0,500 & 0,204 & 0,225 & 1,000 \\
\hline & 171,6 & 3 & 0,167 & 0,152 & 0,028 & 0,997 \\
\hline & 205,9 & 1 & 0,000 & & & \\
\hline \multirow{4}{*}{$\begin{array}{c}\text { Grupo B } \\
\text { Carregamento } \\
\text { leve }\end{array}$} & 162 & 6 & 0,833 & 0,152 & 0,583 & 1,000 \\
\hline & 192 & 5 & 0,667 & 0,192 & 0,379 & 1,000 \\
\hline & 207 & 4 & 0,167 & 0,152 & 0,028 & 0,997 \\
\hline & 236 & 1 & 0,000 & & & \\
\hline \multirow{5}{*}{$\begin{array}{c}\text { Grupo B } \\
\text { Carregamento } \\
\text { moderado }\end{array}$} & 118 & 6 & 0,833 & 0,152 & 0,583 & 1,000 \\
\hline & 148 & 5 & 0,500 & 0,204 & 0,225 & 1,000 \\
\hline & 177 & 3 & 0,333 & 0,192 & 0,108 & 1,000 \\
\hline & 207 & 2 & 0,167 & 0,152 & 0,028 & 0,997 \\
\hline & 236 & 1 & 0,000 & & & \\
\hline \multirow{4}{*}{$\begin{array}{l}\text { Grupo B } \\
\text { Carregamento } \\
\text { severo }\end{array}$} & 162 & 6 & 0,833 & 0,152 & 0,583 & 1,000 \\
\hline & 177 & 5 & 0,667 & 0,192 & 0,379 & 1,000 \\
\hline & 221 & 4 & 0,167 & 0,152 & 0,028 & 0,997 \\
\hline & 266 & 1 & 0,000 & & & \\
\hline
\end{tabular}

As amostras do grupo $\mathrm{C}$ apresentam probabilidade de $66 \%$ de sobreviverem a uma força de $105 \mathrm{~N}$ quando submetidas à carregamento leve e moderado. Já para carregamento severo, a probabilidade é de $50 \%$ de sobrevida a uma força de $126 \mathrm{~N}$. 
Já as amostras do grupo A, apresentam probabilidade de $50 \%$ de sobreviverem a uma força de $91,5 \mathrm{~N}$ sob carregamento leve e de $83,3 \%$ de sobreviverem a uma força de 114 $\mathrm{N}$ sob carregamento moderado e $91,5 \mathrm{~N}$ sob carregamento severo.

Por fim, as amostras do grupo B apresentam probabilidade de $83,3 \%$ de sobreviverem a uma força de $162 \mathrm{~N}$ sob carregamento leve e severo, e $118 \mathrm{~N}$ sob carregamento moderado.

Para estabelecer comparações entre as curvas de sobrevida, tendo como parâmetro a variável força, foi considerado um modelo de regressão paramétrico com distribuição de Weibull. As comparações foram realizadas entre os tipos de carregamento no mesmo grupo.

Tabela 18. Modelo de distribuição de Weibull para comparação da variável força entre os diferentes tipos de carregamento para o grupo $\mathrm{C}$.

\begin{tabular}{ccccc}
\hline Grupo & Estimativa & Erro Padrão & Estatística z & p- valor \\
\hline $\begin{array}{c}\text { Grupo C } \\
\text { Carregamento moderado }\end{array}$ & 0,180 & 0,101 & 1,778 & 0,075 \\
\hline $\begin{array}{c}\text { Grupo C } \\
\text { Carregamento severo }\end{array}$ & 0,063 & 0,097 & 0,652 & 0,515 \\
\hline
\end{tabular}

* Grupo C - Carregamento leve foi utilizado como referência

Figura 18 - Gráfico: Estimativa da probabilidade de sobrevida para variável força entre os diferentes tipos de carregamento do grupo $\mathrm{C}$.

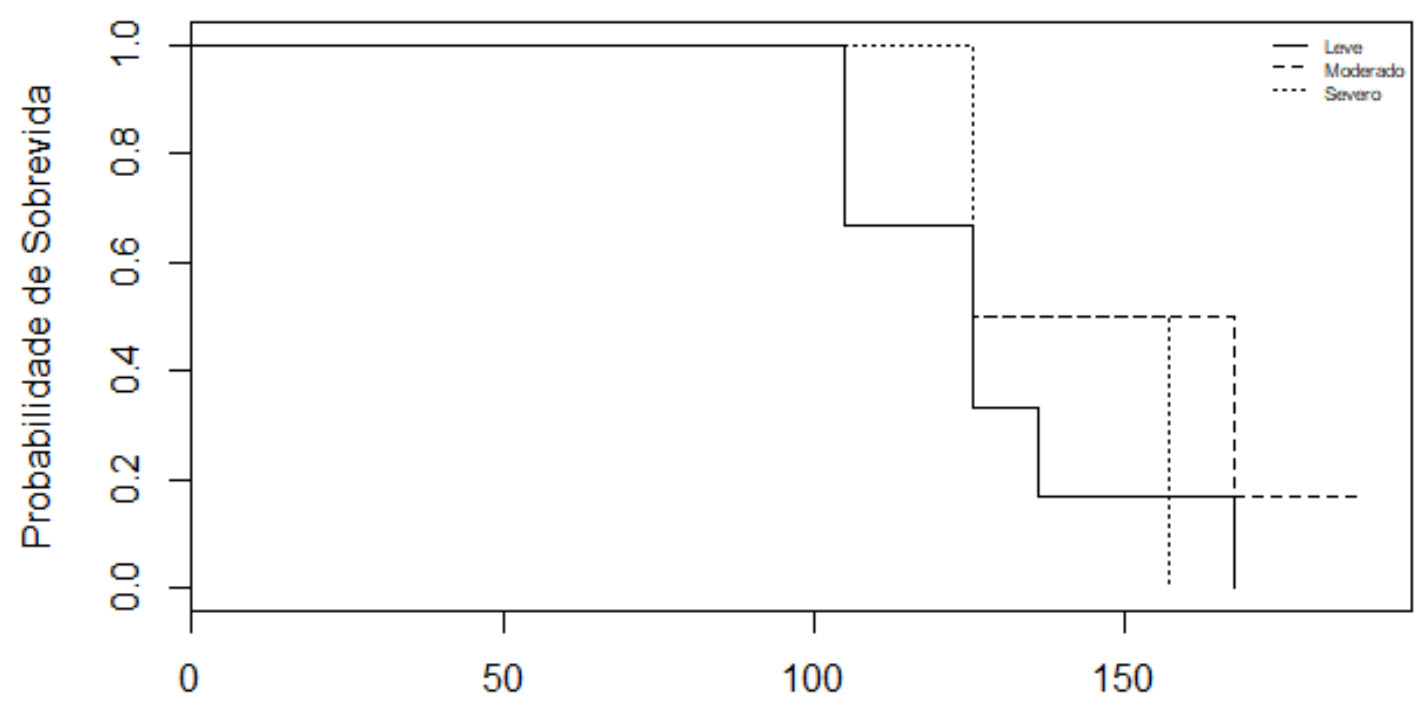


Tabela 19. Modelo de distribuição de Weibull para comparação da variável força entre os diferentes tipos de carregamento do grupo A.

\begin{tabular}{|c|c|c|c|c|}
\hline Grupo & Estimativa & Erro Padrão & Estatística z & p-valor \\
\hline Grupo A & & & & \\
\hline $\begin{array}{c}\text { Carregamento moderado } \\
\text { Grupo A }\end{array}$ & 0,101 & 0,1088 & 0,927 & 0,3540 \\
\hline Carregamento severo & 0,195 & 0,108 & 1,802 & 0,0716 \\
\hline
\end{tabular}

* Grupo A - Carregamento leve foi utilizado como referência

Figura 19 - Gráfico: Estimativa da probabilidade de sobrevida para variável força entre os diferentes tipos de carregamento do grupo A.

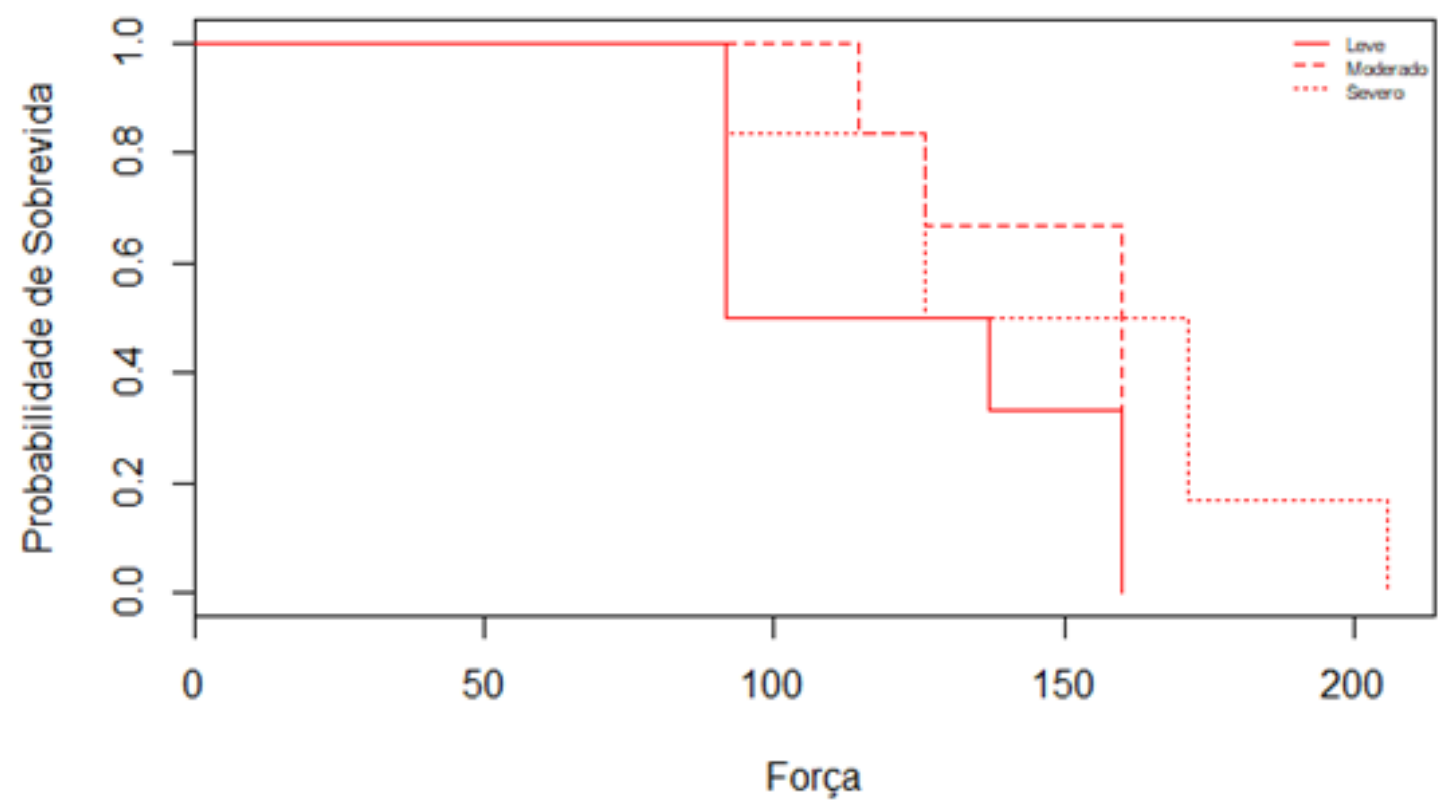

Tabela 20. Modelo de distribuição de Weibull para comparação da variável força entre os diferentes tipos de carregamento do grupo B.

\begin{tabular}{ccccc}
\hline Grupo & Estimativa & Erro Padrão & Estatística z & p- valor \\
\hline $\begin{array}{c}\text { Grupo B } \\
\text { Carregamento moderado } \\
\text { Grupo B }\end{array}$ & $-0,0666$ & 0,0888 & $-0,751$ & 0,4530 \\
Carregamento severo & 0,0797 & 0,0878 & 0,907 & 0,3640 \\
\hline
\end{tabular}

* Grupo B - Carregamento leve foi utilizado como referência 
Figura 20 - Gráfico: Estimativa da probabilidade de sobrevida para variável força entre os diferentes tipos de carregamento do grupo $B$

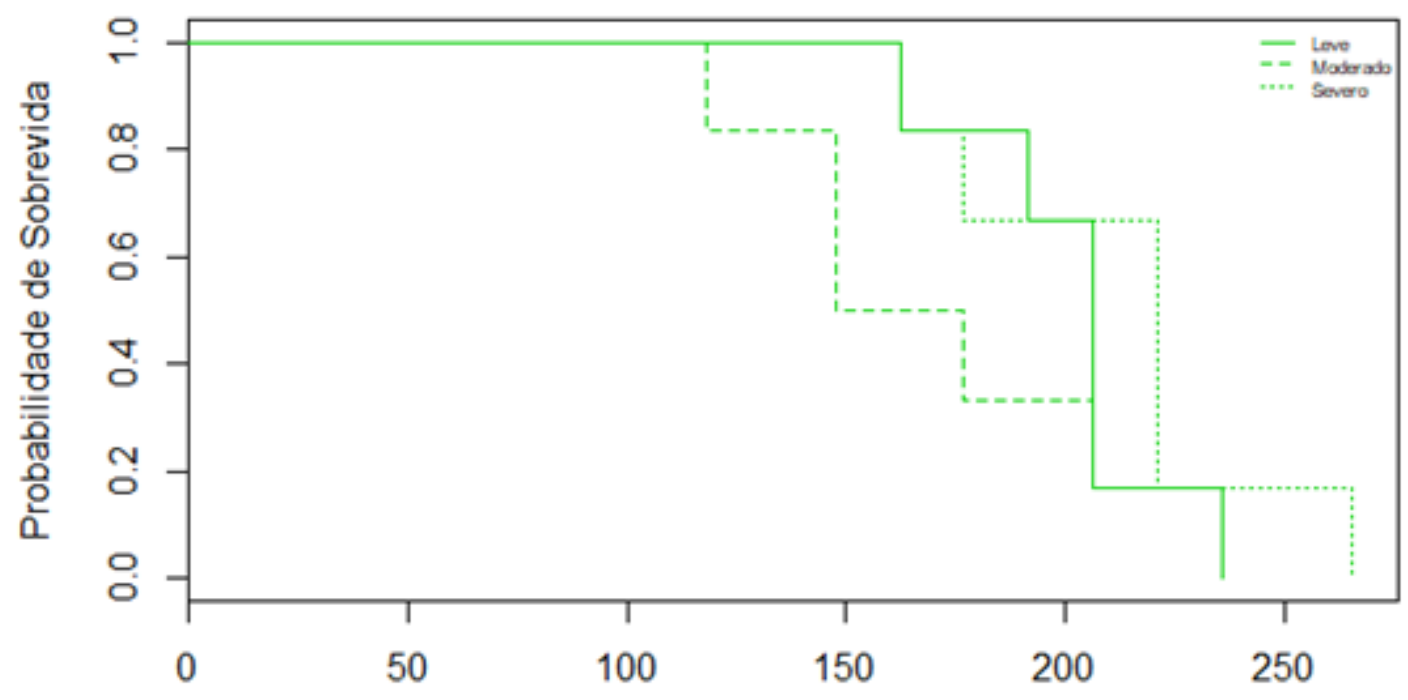

Força

A análise estatística (Tabelas 18, 19 e 20) comparou a taxa de sobrevivência, tendo como parâmetro a variável força, nos diferentes tipos de carregamento para os grupos C, A e B e revelou que não há diferença estatística. Os estimadores foram calculados e apresentados nas Figuras 18, 19 e 20, respectivamente. 

5. Discussão 



\section{DISCUSSÃO}

A hipótese nula testada para este trabalho foi rejeitada, uma vez que os diferentes protocolos de desgaste utilizados têm influência sobre a morfologia e rugosidade superficial, estrutura cristalina e módulo de elasticidade dinâmico da zircônia. Entretanto, não houve diferença no comportamento à fadiga deste material.

A utilização da tecnologia CAD/CAM têm se tornado cada vez mais comum na prática odontológica e a introdução da zircônia ampliou as possibilidades e a aplicação de restaurações totalmente cerâmicas. Ainda que a utilização desta tecnologia permita a obtenção de peças protéticas de zircônia precisas, ajustes são rotineiramente requeridos, seja no ambiente laboratorial e/ou clínico, para que infraestruturas, coroas, próteses parciais fixas e pilares protéticos apresentem forma e contorno adequados (Aboushelib et al., 2009; Preis, 2015; Jing, 2014; Pereira et al., 2015; Pereira et al., 2016A; Pereira et al., 2016B; Pereira et al., 2016C; Canneto et al., 2016; Hatanaka et al., 2016).

A necessidade de ajuste e de um protocolo que permita que o desgaste possa ser realizado mantendo as propriedades mecânicas ou causando o mínimo possível de danos ao material, motivou as pesquisas que vem sendo realizadas nesta área. Pereira et al. (2016C) afirmaram que diferentes protocolos de desgaste podem causar efeitos distintos nas propriedades da zircônia, dependendo da granulação da fresa utilizada, do tipo de rotação do motor acoplado ao instrumento de desgaste, da presença ou ausência de refrigeração com água e da pressão realizada durante o desgaste. Sobretudo, a literatura mostra que o desgaste pode introduzir defeitos superficiais, provocar transformação de fase e consequentemente, modificar o comportamento mecânico da zircônia (Karakoca \& Yilmaz, 2009; Mochales et al.,2011; Maerten et al.,2013).

Vários autores têm relatado que o desgaste provoca o aumento da rugosidade superficial e que este aumento está diretamente relacionado a granulação da fresa utilizada para realizar o desgaste (Chang et al., 2011; Yin, 2012; Canneto et al., 2016; Pereira et al., 2016A; Pereira et al., 2016B; Pereira et al., 2016C).

As fresas diamantadas, comumente utilizadas nos laboratórios de prótese, são divididas conforme sua granulação: extra grossa $(150-180 \mu \mathrm{m})$, grossa $(125-150 \mu \mathrm{m})$, média $(100-110 \mu \mathrm{m})$, fina $(45-50 \mu \mathrm{m})$ e extra fina $(15-30 \mu \mathrm{m})$ (Canneto et al., 2016). Neste 
trabalho, o Grupo A teve sua superfície desgastada com fresas diamantadas de granulação média e recebeu acabamento com fresas diamantadas de granulação fina. O fabricante recomenda que a utilização destas fresas seja associada à refrigeração abundante de água, para evitar o superaquecimento e auxiliar na remoção de detritos da superfície desgastada. Apesar deste protocolo de desgaste não ser específico para zircônia, tem como vantagens: o custo reduzido, tendo em vista o custo de fresas específicas para zircônia, e a alta acessibilidade, uma vez que são facilmente encontradas em lojas de produtos odontológicos.

Pereira et al. (2016A) avaliaram o efeito do desgaste realizado com fresas diamantadas de granulação grossa $(181 \mu \mathrm{m})$ e extra fina $(25 \mu \mathrm{m})$, utilizando contra ângulo acoplado em motor de baixa rotação sob refrigeração abundante com água e observaram que a rugosidade superficial das amostras desgastadas aumentou de acordo com a granulação da fresa utilizada, uma vez que as amostras desgastadas com fresas diamantadas de granulação grossa apresentaram os maiores valores de rugosidade superficial. Além disso, o desgaste acarretou no aumento do conteúdo cristalino na fase monoclínica e consequentemente, no aumento da resistência à flexão, o que pode ser justificado pelo desencadeamento do mecanismo de tenacificação por transformação de fase. A confiabilidade estrutural (Módulo de Weibull) não foi afetada pelo desgaste. Guilardi et al. (2017) propuseram um estudo semelhante a este, utilizando os mesmos protocolos de desgaste, porém para uma zircônia monolítica e apresentaram resultados semelhantes.

Além das fresas, encontram-se disponíveis no mercado, pedras diamantadas projetadas especialmente para zircônia, que apresentam alta eficiência de desgaste e dispensam o uso de refrigeração, porque possuem pouco ou nenhum potencial para gerar de calor sobre a superfície do material (Lee et al., 2016; Canneto et al., 2016). No grupo B, o protocolo empregado utilizou pedras de granulação grossa e média, para desgaste e acabamento, respectivamente.

Poucos estudos têm sido realizados para avaliar o efeito do desgaste com pedras diamantadas específicas para zircônia. Candido et al. (2017) avaliaram o efeito do desgaste realizado com pedras diamantadas, em baixa rotação, com e sem refrigeração, na estrutura cristalina, rugosidade e molhabilidade da zircônia. Concluíram que o desgaste aumentou o conteúdo cristalino na fase monoclínica, a rugosidade superficial e a molhabilidade, e que quando realizado sem refrigeração foi menos prejudicial à zircônia. Os autores afirmaram 
que quando o desgaste é realizado sob refrigeração, há o aumento da capacidade de corte da pedra, promovendo um desgaste mais severo do que quando realizado sem refrigeração, e resultando em maiores valores de rugosidade superficial. Dados discordantes foram encontrados por Pereira et al. (2016C) que afirmaram que a presença de refrigeração durante o desgaste não tem influência sobre a rugosidade superficial da zircônia.

Chang et al. (2011) explicaram que, o desgaste realizado em alta rotação e irrigação com água pode causar um choque térmico e induzir trincas superficiais na zircônia. Isto porque, o contato da fresa com a superfície do material gera o aumento da temperatura, que logo em seguida, diminui em virtude da presença da água. Pereira et al. (2016C) acrescentam que, a utilização de alta rotação leva a uma maior introdução de defeitos na superfície da zircônia e sugerem que sua utilização pode comprometer as propriedades mecânicas deste material.

Neste estudo, após a execução dos protocolos de desgaste, as amostras foram levadas ao Microscópio Confocal à Laser para obtenção da rugosidade superficial. A utilização deste método possibilita a análise tridimensional de toda superfície e a mensuração da rugosidade superficial sem o contato direto com a amostra, evitando a introdução de defeitos superficiais que poderiam influenciar os resultados obtidos nas análises subsequentes. Foi observado que os valores de rugosidade superficial dos grupos $\mathrm{A}$ e $B$, que tiveram sua superfície desgastada, foram maiores do que os encontrados no grupo C, que não sofreu nenhum tipo de modificação superficial, corroborando com os relatos de outros autores na literatura (Curtis et al., 2006; Kou et al., 2006; Karakoca \& Yilmaz, 2009; Subasi et al., 2014; Gungor et al., 2015; Pereira et al., 2014; Preis et al., 2015; Pereira et al., 2015, Pereira et al., 2016A; Pereira et al., 2016B; Pereira et al., 2016C; Khayat et al., 2017; Guilardi et al., 2017).

Os maiores valores de rugosidade superficial foram obtidos nas amostras do Grupo A e essa ocorrência deve estar relacionada à alta rotação do motor, ao tamanho e disposição dos diamantes presentes na parte ativa da fresa e a presença de irrigação durante o desgaste.

Clinicamente, o aumento da rugosidade superficial em mais de 0,2 $\mu \mathrm{m}$ têm sido associado ao acúmulo de biofilme e consequentemente, ao aumento do risco à carie e à inflamação periodontal, se a peça protética estiver exposta no ambiente bucal (Bollen et al., 
1997). Entretanto, Dutra et al. (2017) constatou que ainda que haja o aumento da rugosidade superficial após o desgaste com fresas diamantadas de diferentes granulações, a adesão bacteriana na zircônia não é afetada.

Quinn (2007) afirma que pode existir uma correlação entre a rugosidade superficial e a resistência à flexão, mas somente é observada em casos específicos, dependendo do balanço existente entre a introdução de defeitos superficiais através da realização do desgaste e dos defeitos superficiais pré-existentes. Explica que quando a profundidade dos defeitos introduzidos é maior do que a profundidade dos defeitos dos pré-existentes, a correlação é esperada.

Alguns estudos constataram que o aumento da rugosidade superficial pode provocar a diminuição da resistência à flexão da zircônia (Kosmac et al., 2008; Iseri et al., 2010; Canneto et al., 2016), enquanto alguns estudos não encontraram esta correlação (Curtis et al., 2006; Subasi et al., 2014; Preis et al., 2015; Lee et al., 2016; Hatanaka et al., 2016; Pereira et al., 2015; Khayat et al., 2017; Ozer et al., 2017) e outros afirmaram que pode haver o aumento da resistência à flexão (Ho et al., 2009; Pereira et al., 2016A; Ramos et al., 2016). Outra propriedade que possui relação com a resistência e comportamento mecânico dos materiais dentários é o módulo de elasticidade.

O módulo de elasticidade descreve a rigidez relativa do material, é uma constante de proporcionalidade entre a tensão que o material recebe e a deformação resultante da aplicação desta tensão (Anusavice et al., 2013), e é determinado, principalmente, pela composição e microestrutura do material (Belli et al., 2017).

Coldea et al. (2015) afirmaram que a profundidade de corte, durante o desgaste, está relacionada com o módulo de elasticidade do material, uma vez que materiais com módulo de elasticidade menor permitem uma maior profundidade de corte.

Não foram encontrados na literatura, estudos comparando o módulo de elasticidade da zircônia antes e após o desgaste, porém os valores encontrados neste estudo para o grupo controle estão em concordância com o relato de outros autores (Piconi \& Maccauro, 1999; Coldea et al., 2015).

Não houve diferença estatística entre os Grupos C e A, porém o Grupo B apresentou os maiores valores de módulo de elasticidade dinâmico e foi estatisticamente diferente dos demais. Clinicamente, o aumento no módulo de elasticidade implica no aumento da rigidez 
relativa da restauração e confere a ela maior resistência à deformação (Flury et al., 2012). Os maiores valores de módulo de elasticidade do Grupo B podem ser justificados pelo arranjo de sua estrutura cristalina, uma vez que foi o único grupo que apresentou conteúdo cristalino na fase cúbica.

Basicamente, a zircônia é um material polimórfico e metaestável, que quando submetido a estímulos mecânicos, físicos e/ou químicos pode apresentar transformação de fase (Garvie and Nicholson, 1972; Hannink, 2000; Amaral et al., 2013; Pereira et al., 2015). Alguns autores têm relatado que o desgaste pode causar transformação da fase tetragonal para fase monoclínica (Ho et al., 2009; Karakoca \& Yilmaz, 2009; Guess et al., 2010; Maerten et al., 2013; Subasi et al., 2014; Gungor et al., 2015; Coldea et al., 2015; Lee et al., 2016; Ramos et al., 2016; Pereira et al., 2016A; Pereira et al., 2016B; Hatanaka et al., 2016; Ryan et al., 2017; Guilardi et al., 2017), enquanto outros não observam a presença desta fase após o desgaste (Kosmac, 2004; Denry \& Holloway, 2006; Curtis et al., 2006; Amaral et al., 2013; Strasberg et al., 2014; Chun et al., 2017).

A literatura relata que a susceptibilidade da zircônia à transformação de fase depende de fatores, tais como: alterações na composição química, quantidade do óxido estabilizador e as condições de processamento (Chevalier et al., 2007; Denry \& Kelly, 2008; Pereira et al., 2015). Entretanto, autores têm afirmado que, considerando a possibilidade de transformação de fase, a escolha do protocolo de desgaste é mais relevante do que pequenas diferenças na composição e processamento deste material (Pereira et al., 2016C; Guilardi et al., 2017).

Neste estudo, as amostras do grupo controle apresentaram somente de fase tetragonal, o que era esperado, uma vez que o processo de sinterização foi realizado seguindo as recomendações do fabricante e nenhuma modificação superficial foi realizada. Já no grupo A, foi encontrado conteúdo cristalino na fase tetragonal e monoclínica, em concordância com os estudos supracitados. E por fim, o grupo B apresentou conteúdo cristalino na fase tetragonal e cúbica.

A presença de conteúdo cristalino na fase cúbica foi identificado por alguns autores quando a temperatura de sinterização foi de $1400^{\circ} \mathrm{C}$ a $1600^{\circ} \mathrm{C}$ (Scott, 1975 ; Ruiz \& Readey, 1996; Matsui et al., 2003; Chevalier et al., 2004; Polli et al., 2016; Ryan et al., 2017) e após o desgaste (Curtis et al., 2006) devido ao estresse gerado durante este procedimento 
(Hasegawa et al., 1985). Entretanto, a presença desta fase não é muito relatada na literatura, porque pode haver sobreposição entre os planos da fase cúbica em relação a tetragonal, dificultando sua identificação (Denry \& Holloway, 2006).

As propriedades da zircônia podem ser modificadas na presença desta fase, pois são altamente influenciadas pelo volume das fases cristalinas e a fase cúbica possui duas vezes o volume da fase tetragonal (Ryan et al., 2017). Como consequência da presença desta fase, pode haver má distribuição dos íons de ítrio (Matsui et al., 2003; Chevalier et al., 2004) e a zircônia pode ficar mais susceptível ao processo de degradação à baixas temperaturas (Chevalier et al., 2004).

Clinicamente, as restaurações cerâmicas estão susceptíveis à falha por fadiga, principalmente pela presença das forças cíclicas, durante a mastigação, e condição de umidade (Gonzaga et al., 2011; Zhang et al., 2013). Apesar de ser um fato extensivamente conhecido, poucos estudos foram realizados para avaliar a influência do desgaste no comportamento à fadiga da Y-TZP (Polli et al., 2016; Pereira et al., 2016B; Zucuni et al., 2017A; Chun et al., 2017).

Para avaliar o comportamento à fadiga após diferentes protocolos de desgaste, foi realizado ensaio de fadiga mecânica acelerada, que têm como objetivo avaliar a capacidade do material em resistir a um determinado número de ciclos. O método utilizado para realização deste ensaio é conhecido como step-stress e foi selecionado porque têm sido amplamente utilizado para esta finalidade, uma vez que é rápido, preciso e produz baixa variabilidade de dados (Villefort et al., 2017).

A utilização dos perfis de carregamento leve, moderado e severo, baseou-se na necessidade de distribuir as falhas em diferentes cargas, o que permite melhores estatísticas de previsão, e estreita os limites de confiança, com base em cálculos de Weibull (Chun et al., 2017).

Não houve diferença estatística no comportamento à fadiga, independente do protocolo de desgaste utilizado, considerando o número de ciclos que eles sobreviveram nos perfis de carregamento leve, moderado e severo.

Resultados semelhantes foram obtidos por Pereira et al. (2016B) que avaliaram o efeito do desgaste e do processo de degradação à baixas temperaturas no comportamento à fadiga de uma zircônia para infraestrutura e uma zircônia monolítica. O desgaste foi 
realizado com fresas diamantadas de granulação grossa, sob baixa rotação e refrigeração com água, e o processo de degradação à baixas temperaturas foi simulado em autoclave, à $134^{\circ} \mathrm{C}, 2$ bar de pressão, por 20 horas. A metodologia para avaliar o comportamento à fadiga utilizada foi a do step-stress. Os autores concluíram que tanto o desgaste, como o processo de degradação à baixas temperaturas, não afetam a resistência à fadiga da zircônia significantemente para os dois materiais testados, apesar das duas condições testadas promoverem o aumento da fase monoclínica.

Ao contrário de Polli et al. (2016), que relataram que o desgaste, realizado com pontas diamantadas, sob alta rotação, com e sem refrigeração, é capaz de aumentar a resistência à fadiga da zircônia.

Apesar de não haver diferença estatística no comportamento à fadiga dos grupos deste estudo, é possível observar que o grupo A sobreviveu a um número maior de ciclos do que o grupo $C$, sob carregamento moderado e severo, devido à presença de conteúdo cristalino na fase monoclínica, uma vez que foi desencadeado o mecanismo de tenacificação por transformação de fase. A expansão volumétrica decorrente da transformação da fase tetragonal para fase monoclínica, cria tensões de compressão sobre as trincas presentes, fazendo com que uma energia maior seja necessária para que elas se propaguem, melhorando a tenacidade à fratura do material (Hannink et al., 2000; Vagkopoulou et al., 2009). Já o grupo B, sobreviveu a um maior número de ciclos para todos os tipos de carregamentos, porque o conteúdo cristalino na fase cúbica foi capaz de aumentar os valores de módulo de elasticidade, e consequentemente, uma tensão maior foi requerida para causar a deformação do material.

A zircônia é um material friável e suporta pouca ou nenhuma deformação plástica (Denry \& Kelly, 2008). Sendo assim, quando submetida à carregamento cíclico, a concentração de tensões sobre os defeitos promove propagação de trincas (Mitov et al., 2011) e consequentemente, leva o material à falha catastrófica, o que justifica o fato da maioria das amostras fraturarem durante o ensaio.

Este estudo não teve como objetivo avaliar a resistência à flexão dos diferentes grupos, mas o ensaio foi realizado para estabelecer a força de cada patamar dentro dos diferentes perfis de carregamento mecânico. Os grupos submetidos aos diferentes protocolos de desgaste apresentaram os maiores valores de resistência à flexão, em 
concordância com estudos anteriores (Ho et al., 2009; Pereira et al., 2016A; Ramos et al., 2016; Hatanaka et al., 2016) e portanto, foram submetidos à cargas maiores do que as utilizadas para o grupo C durante o carregamento mecânico.

As amostras deste estudo foram submetidas forças variando entre, aproximadamente, 90 e $270 \mathrm{~N}$, e não houve diferença estatística entre os diferentes tipos de carregamento, ou seja, entre as diferentes progressões de carga, para os grupos C, A e B. Varga et al. (2011) relataram que a força mastigatória de um indivíduo adulto saudável têm sido reportada entre 100 e $900 \mathrm{~N}$, com uma média de $500 \mathrm{~N}$ para região dos molares. No entanto, não é possível estabelecer uma relação entre as forças da mastigação e as forças as quais as amostras foram submetidas, porque as amostras não possuem características anatômicas semelhantes a do dente e a carga aplicada durante o ensaio difere da carga oclusal. Além disso, a zircônia utilizada neste estudo é indicada para confecção de infraestruturas, e não receberia carga diretamente, uma vez que seria recoberta por uma camada de cerâmica.

Diversos autores têm estudado diferentes protocolos de tratamento térmico, realizados após o desgaste, com o objetivo reverter transformação de fase e obter peças protéticas com 100\% de conteúdo cristalino na fase tetragonal (Guazzato et al., 2005; Ho et al., 2009; Subasi et al., 2014; Hatanaka et al., 2016; Polli et al., 2016; Ryan et al., 2017; Candido et al., 2017). Esse fenômeno é geralmente acompanhado pelo relaxamento das tensões de compressão na superfície do material (Guazzato et al., 2005) e maior estabilidade estrutural (Subasi et al., 2014; Hatanaka et al., 2016; Polli et al., 2016; Candido et al., 2017). Contudo, implica em um passo clínico adicional, que nem sempre é possível de ser realizado como, por exemplo, após o preparo de pilares pré-fabricados customizáveis torqueados, e pode acarretar na diminuição da resistência à fadiga da zircônia (Zucuni et al., 2017A).

Este trabalho propôs avaliar o efeito do desgaste propriamente dito e teve como limitações: a ausência de um grupo experimental utilizando protocolo em que o desgaste é realizado com pedras diamantadas associadas à refrigeração abundante com água, o fato de não avaliar fatores complexos presentes na cavidade oral, tais como a dinâmica da carga oclusal, forças neuromusculares e hábitos parafuncionais, e as amostras não apresentarem anatomia semelhante às peças protéticas confeccionadas com zircônia. A realização de estudos clínicos utilizando estes protocolos em peças protéticas ainda se fazem necessários. 
Com base na discussão dos resultados, é possível afirmar que ainda que a utilização de diferentes protocolos de desgaste tenha introduzido alterações na superfície das amostras, provocando o aumento da rugosidade superficial e alterado a estrutura cristalina da zircônia, as modificações que ocorreram não foram capazes de prejudicar as propriedades mecânicas avaliadas. Sendo assim, é possível sugerir que qualquer um destes protocolos podem ser utilizados na clínica odontológica. 

6. Conchusão 



\section{CONCLUSÃO}

Baseado na metodologia empregada e considerando as limitações deste estudo, é possível concluir que:

1) O desgaste promoveu modificações na morfologia superficial. O grupo $A$ apresentou maior rugosidade superficial, seguido pelo grupo B e grupo $C$.

2) O grupo $B$ apresentou o maior módulo de elasticidade dinâmico, enquanto não houve alterações para esta propriedade quando o protocolo de desgaste do grupo A foi comparado com o grupo C.

3) Os dois protocolos de desgaste utilizados promoveram transformação de fase cristalográfica, sendo que o grupo A apresentou conteúdo cristalino na fase tetragonal e monoclínica, e o grupo B apresentou conteúdo cristalino na fase tetragonal e cúbica.

4) A resistência à fadiga da zircônia não foi alterada pelos protocolos de desgaste utilizados. Não houve diferença estatística entre os grupos quando a taxa de sobrevivência foi comparada quanto ao número de ciclos e a força. 

Referencias 



\section{REFERÊNCIAS ${ }^{1}$}

Aboushelib, M. N.; Feilzer A. J.; Kleverlaan, C. J. Bridging the gap between clinical failure and laboratory fracture strength tests using a fractographic approach. Dent Mater 2009; 25(3): 383-391.

Aboushelib, M. N.; Wang, H.; Kleverlaan, C. J.; Feilzer, A. J. Fatigue behavior of zirconia under different loading conditions. Dent Mater 2016; 32(7): 915- 920.

Adatia, N. D.; Bayne, S. C.; Cooper, L. F.; Thompson, J. Y. Fracture resistance of yttriastabilized zirconia dental implant abutments. J Prosthodont 2009 Jan;18(1):17-22.

Alqahtani, F.; Flinton, R. Post fatigue fracture resistance of modified prefabricated zirconia implant abutments. J Prosthet Dent 2014; 112(2):299-305.

Amaral, M.; Cesar, P. F.; Bottino, M. A.; Lohbauer, U.; Valandro, L. F. Fatigue behavior of YTZP ceramic after surface treatments. J Mech Behav Biomed Mater 2016; 57: 149-156.

Anitha, K. V.; Dhanraj, M.; Haribabu, R. Comparison of the effect of different ceramic alloys and porcelain systems upon the color of metal-ceramic restorations: An in vitro study. J Indian Prosthodont Soc 2013; 13(3): 296-02.

Anusavice, K. J.; Shen, C.; Rawls, H. R.; Magne, P.; Urs, B. Phillips: Materiais Dentários. São Paulo: Elsevier 2013. p. 48-68.

Ardlin, B. I. Transformation toughened zirconia for dental inlays, crowns and ridges: chemical stability and effect of low temperature aging on flexural strength and surface structure. Dent Mater 2002; 18(8): 590-595.

Att, W.; Yajima, D. N.; Wolkewitz, M.; Witkowski, S.; Strub, J. R. Influence of preparation and wall thickness on the resistance to fracture of zirconia implant abutments. Clin Implant Dent Relat Res 2011; 14(1): 196-203

Baldini, N.; D'Elia, C.; Clementini, M.; Carrillo de Albornoz, A.; Sanz, M.; De Sanctis, M. Esthetic outcomes of single-tooth implant-supported restorations using metal-ceramic restorations with zirconia or titanium abutments: A randomized controlled clinical study. Int J Periodontics Restorative Dent 2016; 36(4): 59-66.

Belli, R.; Geinzer, E.; Muschweck, A.; Petschelt, A.; Lohbauer, U. Mechanical fatigue degradation of ceramics versus resin composites for dental restorations. Dent Mater 2014; 30(4): 424-32.

Belli, R.; Wendler, M.; de Ligny, D.; Cicconi, MR.; Petschelt, A.; Peterlik, H.; Lohbauer, U. Chairside CAD/CAM materials. Part 1: Measurement of elastic constants and microstructural characterization. Dent Mater 2017; 33(1): 84-98.

1 As referências seguiram as normas do Committee of International Medical Journals Editors - Grupo Vancouver. As abreviaturas dos periódicos estão de acordo com o Medline. 
Beuer, F.; Stimmelmayr, M.; Gueth, J. F.; Edelhoff, D.; Naumann, M. In vitro performance of full-contour zirconia single crowns. Dent Mater 2012; 28(4): 449-456.

Bollen, C. M.; Lambrechts, P.; Quirynen, M. Comparison of surface roughness of oral hard materials to the threshold surface roughness for bacterial plaque retention: a review of the literature. Dent Mater 1997; 13(4): 258-69.

Bonfante, E. A.; Coelho, P. G.; Guess, P. C.; Thompson, V. P.; Silva, N. R. Fatigue and damage accumulation of veneer porcelain pressed on Y-TZP. J Dent 2010; 38(4): 318-24.

Bonfante, E. A.; Suzuki, M.; Lorenzoni, F. C.; Sena, L. A.; Hirata, R.; Bonfante, G., et al. Probability of survival of implant supported metal ceramic and CAD/CAM resin nano ceramic crowns. Dent Mater 2015; 31(8): 168-77

Boudrias, P.; Shoghikian, E.; Morin, E.; Hutnik, P. Esthetic option for the implant- supported single-tooth restoration - treatment sequence with a ceramic abutment. J Can Dent Assoc 2001; 67(9): 508-14.

Burke, F. J.; Crisp, R. J.; Cowan, A. J.; Lamb, J.; Thompson, O.; Tulloch, N. Five-year clinical evaluation of zirconia-based bridges in patients in UK general dental practices. J Dent 2013; 41(11): 992-9.

Candido, L. M.; Fais, L. M. G.; Ferreira, E. B.; Antonio, S. G.; Pinelli, L. A. P. Characterization of a diamond ground Y-TZP and reversion of the tetragonal to monoclinic transformation. Oper Dent 2017; 42(4): 407-417.

Canneto, J. J.; Cattani-Lorente, M.; Durual, S.; Wiskott, A. H. W.; Scherrer, S. S. Grinding damage assessment on four high-strength ceramics. Dent Mater 2016; 32(2): 171-182.

Chang, C. W.; Waddell, J. N.; Lyons, K. M.; Swain, M. V. Cracking of porcelain surfaces arising from abrasive grinding with a dental air turbine. J Prosthodont 2011; 20(8): 613-20.

Chevalier, J.; Deville, S.; Munch, E.; Jullian, R.; Lair, F. Critical effect of cubic phase on aging in 3 mol\% yttria-stabilized zirconia ceramics for hip replacement prosthesis. Biomaterials 2004; 25(24): 5539-45.

Chevalier, J.; Gremillard, L.; Deville, S. Low-temperature degradation of zirconia and implications for biomedical implants. Annu Rev Mater Res 2007; 37(1): 1-32.

Chevalier, J.; Olagnon, C.; Fantozzi, G. Subcritical crack propagation in 3Y-TZP ceramics: static and cyclic fadigue. J Am Ceram 1999; 82(11): 3129 - 3138.

Chougule, K. J.; Wadkar, A. P. An in vitro comparative evaluation of flexural strength of monolithic zirconia after surface alteration utilising two different techniques. J Clin Diagn Res 2017; 11(8): 20-23.

Chun, E. P.; Anami, L. C.; Bonfante, E. A.; Bottino, M. A. Microstructural analysis and reliability of monolithic zirconia after simulated adjustment protocols. Dent Mater 2017; 33(8): 934-943. 
Coldea, A.; Fischer, J.; Swain, M. V.; Thiel, N. Damage tolerance of indirect restorative materials (including PICN) after simulated bur adjustments. Dent Mater 2015; 31(6): 684-94.

Curtis, A. R.; Wright, A. J.; Fleming, G. J. P. The influence of surface modification techniques on the performance of a Y-TZP dental ceramic. J Dent 2006; 34(3): 195-206.

Denry, I.; Kelly, J. R. Emerging ceramic-based materials for dentistry. J Dent Res 2014; 93(12): 1235-1242.

Denry, I.; Kelly, J. R. State of the art of zirconia for dental applications. Dent Mater 2008; 24(3): 299-307.

Denry, I. L.; Holloway, J. A. Microstructural and crystallographic surface changes after grinding zirconia-based dental ceramics. J Biomed Mater Res B Appl Biomater 2006; 76(2): 440-448.

Deville, S.; Chevalier, J.; Fantozzi, G.; Bartolome, J. F.; Requena, J.; Moya, J. S.; Torrecillas, R.; Díaz, L. A. Low-temperature ageing of zirconia-toughened alumina ceramics and its implication in biomedical implants. J Eur Ceram Soc 2003; 23(15): 2975-2982.

Dutra, D. A. M.; Pereira, G. K. R.; Kantorski, K. Z.; Exterkate, R. A. M.; Kleverlaan, C. J.; Valandro, L. F.; Zanatta, F. B. Grinding with diamond burs and hydrothermal aging of a Y-TZP material: Effect on the material surface characteristics and bacterial adhesion. Oper Dent 2017; 42(6):669-678.

Elshiyab, S. H.; Nawafleh, N.; George, R. Survival and testing parameters of zirconia-based crowns under cyclic loading in an aqueous environment: A systematic review. J Investig Clin Dent 2017; 8(4): 2041-1626.

Evans, A. G.; Heuer, A. H. Review-transformation toughening in ceramics: martensitic transformations in crack-tip stress fields. J Am Ceram Soc 1980; 63(5-6): 241-8.

Fraga, S.; Pereira, G. K. R.; Freitas, M.; Kleverlaan, C. J.; Valandro, L. F.; May, L. G. Loading frequencies up to $20 \mathrm{~Hz}$ as an alternative to accelerate fatigue strength tests in a Y-TZP ceramic. J Mech Behav Biomed Mater 2016; 61: 79-86.

Garine, W. N. Measurement of the rotational misfit and implant-abutment gap of all ceramic abutments. Int J Oral Maxillofac Implants 2007; 22(6): 928-38.

Garvie, R. C.; Hannink, R. H.; Pascoe, R. T. Ceramic steel? Nature 1975; 258: 703 - 704.

Pereira, G. K. R.; Amaral, M.; Simoneti, R.; Rocha, G. C.; Cesar, P. F.; Valandro, L. F. Effect of grinding with diamond-disc and -bur on the mechanical behavior of a Y-TZP ceramic. J Mech Behav Biomed Mater 2014; 37: 133-140.

Gomes, E. A.; Assunção, W. G.; Rocha, E. P.; Santos, P. H. Cerâmicas odontológicas: o estado atual. Cerâmica 2008; 54(331): 319-325. 
Gonzaga, C. C.; Cesar, P. F.; Miranda, W. G.; Yoshimura, H. N. Slowcrack growth and reliability of dental ceramics. Dent Mater 2011; 27(4): 394-406.

Griggs, J. A. Recent advances in materials for all-ceramic restorations. Dent Clin N Am 2007; 51(3): 713-727.

Guazzato, M.; Quach, L.; Albakry, M.; Swain, M. V. Influence of surface and heat treatments on the flexural strength of Y-TZP dental ceramic. J Dent 2005; 33(1): 9-18.

Guess, P. C.; Bonfante, E. A.; Silva, N. R.; Coelho, P. G.; Thompson, V. P. Effect of core design and veneering technique on damage and reliability of YTZP-supported crowns. Dent Mater 2013; 29(3): 307-16.

Guilardi, L. F.; Pereira, G. K. R.; Gündel, A.; Rippe, M. P.; Valandro, L. F. Surface micromorphology, phase transformation, and mechanical reliability of ground and aged monolithic zirconia ceramic. J Mech Behav Biomed Mater 2017; 65: 849-856.

Gungor, M. B.; Yilmaz, H.; Nemli, S. K.; Bal, B. T.; Aydin, C. Effect of surface treatments on the biaxial flexural strength phase transformation, and surface roughness of bilayered porcelain/zirconia dental ceramics. J Prosthet Dent 2015; 113(6): 585-595.

Hannink, R. H. J.; Kelly, P. M.; Muddle, B. C. Transformation toughening in zirconiacontaining ceramics. J Am Ceram Soc 2000; 83(3): 461-87.

Harada, K.; Raigrodski, A. J.; Chung, K. H.; Flinn, B. D.; Dogan, S.; Mancl, L. A. A comparative evaluation of the translucency of zirconias and lithium disilicate for monolithic restorations. J Prosthet Dent 2016; 116(2): 257-63.

Hasegawa, H.; Hioki, T.; Kamigaito, O. Cubic-to-rhombohedral phase-transformation in zirconia by ion-implantation. J Mater Sci Lett 1985; 4(9): 1092-1094.

Hatanaka, G. R.; Polli, G. S.; Fais, L. M. G.; Reis, J. M. D. S. N.; Pinelli, L. A. P. Zirconia changes after grinding and regeneration firing. J Prosthet Dent 2017; 118(1): 61-68.

Heather, J. C.; Seong, W. J.; Pesun, I. J. Current ceramic materials and systems with clinical recommendations: a systematic review. J Prosthet Dent 2007; 98(5): 389-404.

Ho, C. J.; Liu, H. C.; Tuan, W. H. Effect of abrasive grinding on the strength of Y-TZP. J Eur Ceram Soc 2009; 29(12): 2665-2669.

Iseri, U.; Ozkurt, Z.; Kazazoglu, E.; Kuçukoglu, D. Influence of grinding procedures on the flexural strength of zirconia ceramics. Braz Dent J 2010; 21(6): 528-532.

ISO 13356. Implants for Surgery - Ceramic Materials Based on Yttria-stabilizes Tetragonal Zirconia (Y-TZP). International Organ Stand, 2008.

ISO 6872. Dentistry-Ceramic Materials. International Organ Stand, 2015. 
Jing, Z.; Zhang, K.; Yihong, L.; Zhijan, S. Effect of multistep processing technique on the formation of microdefects and residual stresses in zirconia dental restorations. J Prosthodont 2014; 23(3): 206-212.

Jirajariyavej, B.; Wanapirom, P.; Anunmana, C. Influence of implant abutment material and ceramic thickness on optical properties. J Prosthet Dent 2017. Available from <http://dx.doi.org/10.1016/j.prosdent.2017.05.015>.

Karakoca, S.; Yilmaz, H. Influence of surface treatments on surface roughness, phase transformation, and biaxial flexural strength of Y-TZP ceramics. J Biomed Mater Res B Appl Biomater 2009; 91(2): 930-937.

Kelly, J. R.; Benetti, P. Ceramic materials in dentistry: historical evolution and current practice. Aust Dent J 2011; 56(1): 84-96.

Khayat, W.; Chebib, N.; Finkelman, M.; Khayat, S.; Ali, A. Effect of grinding and polishing on roughness and strength of zirconia. J Prosthet Dent 2017. Available from <http://dx.doi.org/10.1016/j.prosdent.2017.04.003>.

Kim, J. W.; Covel, N. S.; Guess, P. C.; Rekow, E. D.; Zhang, R. Concerns of hydrothermal degradation in CAD/CAM zirconia. J Dent Res 2010; 89(1): 91-5.

Kisi, E. H.; Howard, C. J. Crystal structures of zirconia phases and their inter-relation. Key Eng Mater 1998; 153: 1-36.

Kobayashi, K.; Kuwajima, H.; Masaki, T. Phase change and mechanical properties of ZrO2Y2O3 solid electrolyte after ageing. Solid State Ion. 1981; 34: 489-495.

Kosmac, T.; Oblac, C.; Marion, L. The effects of dental grinding and sandblasting on ageing and fatigue behavior of dental zirconia (Y-TZP) ceramics. J Eur Ceram Soc 2008; 28(5): 108590.

Kosmac, T.; Oblak, C.; Jevnikar, P.; Funduk, N.; Marion, L. Strength and reliability of surface treated Y-TZP dental ceramics. J Biomed Mater Res 2000; 53(4): 304-313. 40)

Kou, W.; Molin, M.; Sjogren, G. Surface roughness of five different dental ceramic core materials after grinding and polishing. J Oral Rehab 2006; 33(2): 117-124.

Lee, K. R.; Choe, H. C.; Heo, Y. R.; Lee, J. J.; Son, M. K. Effect of different grinding burs on the physical properties of zirconia. J Adv Prosthodont 2016; 8(2): 137-43.

Li, R. W.; Chow, T. W.; Matinlinna, J. P. Ceramic dental biomaterials and CAD/CAM technology: State of the art. J Prosthet Dent 2014; 58(4): 208-216.

Linkevicius, T.; Vaitelis, J. The effect of zirconia or titanium as abutment material on soft peri-implant tissues: a systematic review and meta-analysis. Clin Oral Implants Res 2015; 26(11): 139-47. 
Lughi, V.; Sergo V. Low temperature degradation - aging - of zirconia: a critical review of the relevant aspects in dentistry. Dent Mater 2010; 26(8): 807-820.

Maerten, A.; Zaslansky, P.; Mochales, C.; Traykova, T.; Mueller, W. D.; Fratzl, P.; Fleck, C. Characterizing the transformation near indents and cracks in clinically used dental yttriastabilized zirconium oxide constructs. Dent Mater 2013; 29(2): 241-251.

Matsui, K.; Horikoshi, H.; Ohmichi, Y. Cubic formation and grain growth mechanisms in tetragonal zirconia polycrystal. J Am Ceram Soc 2003; 86(8): 1401-8.

Michida, S. M. A.; Kimpara, E. T.; Santos, C.; Souza, R. O. A.; Bottino, M. A.; Ozcan, M. Effect of air-abrasion regimens and fine diamond bur grinding on flexural strength, Weibull modulus and phase transformation of zirconium dioxide. J Appl Biomater Funct Mater 2015; 13(3): e266-e273.

Mitov, G.; Gessner, J.; Lohbauer, U.; Woll, K.; Muecklich, F.; Pospiech, P. Subcritical crack growth behavior and life data analysis of two types of dental Y-TZP ceramics. Dent Mater 2011; 27(7): 684-91.

Miyazaki, T.; Nakamura, T.; Matsumura, H.; Ban, S.; Kobayashi, T. Current status of zirconia restoration. J Prosthodont Res 2013; 57(4): 236-61.

Mochales, C.; Maerten, A.; Rack, A.; Cloetens, P.; Mueller, W. D.; Zaslansky, P. Monoclinic phase transformation of zirconia-based dental prostheses, induced by clinically practised surface manipulations. Acta Biomater 2011; 7(7): 2994-3002.

Moris, I. C. M. Análise biomecânica in vitro de pilares estéticos de zircônia personalizados e não-personalizados. Tese (Doutorado em Reabilitação Oral) - Faculdade de Odontologia de Ribeirão Preto, Universidade de São Paulo. Ribeirão Preto, 122p, 2015.

Nakamura, K.; Harada, A.; Kanno, T.; Inagaki, R.; Niwano, Y.; Milleding, P. The influence of low-temperature degradation and cyclic loading on the fracture resistance of monolithic zirconia crowns. J Mech Behav Biomed Mater 2015; 47: 49-56.

Nothdurft, F. P.; Merker, S.; Pospiech, P. R. Fracture behavior of implant-implant and implant-tooth-supported all-ceramic fixed dental prostheses utilizing zirconium dioxide implant abutments. Clin Oral Investig 2011; 15(1): 89-97.

Ozer, F.; Naden, A.; Turp, V.; Mante, F.; Sen, D.; Blatz, M. B. Effect of thickness and surface modifications on flexural strength of monolithic zirconia. J Prosthet Dent 2017. Available from <http://dx.doi.org/10.1016/j.prosdent.2017.08.007>.

Pallis, K.; Griggs, J. A.; Woody, R. D.; Guillen, G. E.; Miller, A. W. Fracture resistance of three all-ceramic restorative systems for posterior applications. J Prosthet Dent 2004; 91(6): 561-9.

Park, J. I.; Lee, Y.; Lee, J. H.; Kim, Y. L.; Bae, J. M; Cho, H. W. Comparison of fracture resistance and fit accuracy of customized zirconia abutments with prefabricated zirconia abutments in internal hexagonal implants. Clin Implant Dent Relat Res 2013; 15(5): 769-78. 
Park, S. E.; Da Silva, J. D.; Weber, H. P.; Ishikawa-Nagai, S. Optical phenomenon of periimplant soft tissue. Part I: Specthophotometric assessment of natural tooth gingiva and periimplant mucosa. Clin Oral Implants Res 2007; 18(5): 569-574.

Passos, S. P.; Linke, B.; Larjava, H.; French, D. Performance of zirconia abutments for implantsupported single-tooth crowns in esthetic areas: a retrospective study up to 12-year followup. Clin Oral Impl Res 2014; 27(1): 1-8.

Pereira, G. K. R.; Amaral, M.; Cesar, P. F.; Bottino, M. C.; Kleverlaan, C. J.; Valandro, L. F. Effect of low-temperature aging on the mechanical behavior of ground Y-TZP. J Mech Behav Biomed Mater 2015; 45: 183-192.

Pereira, G. K. R.; Fraga, S.; Montagner, A. F.; Soares, F. Z. M.; Kleverlaan, C. J.; Valandro, L. F. The effect of grinding on the mechanical behavior of Y-TZP ceramics: A systematic review and meta-analyses. J Mech Behav Biomed Mater 2016C; 63: 417-442.

Pereira, G. K. R.; Silvestri, T.; Amaral, M.; Rippe, M. P.; Kleverlaan, C. J.; Valandro, L. F. Fatigue limit of polycrystalline zirconium oxide ceramics: Effect of grinding and lowtemperature aging. J Mech Behav Biomed Mater 2016B; 61: 45-54.

Pereira, G. K. R.; Silvestri, T.; Camargo, R.; Rippe, M. P.; Amaral, M.; Kleverlann, C. J.; Valandro, L. F. Mechanical behavior of a Y-TZP ceramic for monolithic restorations: Effect of grinding and low-temperature aging. Mat Sci 2016A; 63: 70-77.G

Piconi, C.; Maccauro, G. Zirconia as a ceramic biomaterial. Biomaterials 1999; 20(1): 1-25.

Polli, G. S.; Hatanaka, G. R.; Abi-Rached, F. O.; Pinelli, L. A. P.; Goes, M. S.; Cesar, P. F.; Reis, J. M. S. N. Effect of grinding and resintering on the fatigue limit and surface characterization of a Y-TZP ceramic. Braz Dent J 2016; 27(4): 468-475.

Preis, V.; Schmalzbauer, M.; Bougeard, D.; Schneider-Feyrer, S.; Rosentritt, M. Surface properties of monolithic zirconia after dental adjustment treatments and in vitro wear simulation. J Dent 2015; 43(1): 133-139.

Quinn, G. D. NIST recommended practice guide: fractography of ceramic sandglasses. National Institute of Standards Technology 2007. p. 6-58.

Quinn, J. B.; Sundar, V.; Lloyd, I. K. Influence of microstructure and chemistry on the fracture toughness of dental ceramics. Dent Mater 2003; 19(7): 603-11.

Ramos, G. F.; Pereira, G. K. R.; Amaral, M.; Valandro, L. F.; Bottino, M. A. Effect of grinding and heat treatment on the mechanical behavior of zirconia ceramic. Braz Oral Res 2016; 30(1):e12. Available from <http://www.scielo.br/scielo.php?script=sci_arttext\&pid=S1806$83242016000100012 \& \operatorname{lng}=e n \& n r m=i s o>$.

Ruiz, L.; Ready, M. J. Effect of heat-treatment on grain size, phase assemblage, and mechanical properties of 3 mol\% Y- TZP. J Am Ceram Soc 1996; 79(9): 2331-2340. 
Ryan, D. P. O.; Fais, L. M. G.; Antonio, S. G.; Hatanaka, G. R.; Candido, L. M.; Pinelli, L. A. P. YTZP zirconia regeneration firing: Microstructural and crystallographic changes after grinding. Dent Mater J 2017; 36(4): 447-453.

Sabrah, A. H.; Cook, N. B.; Luangruangrong, P.; Hara, A. T.; Bottino, M. C. Full-contour Y-TZP ceramic surface roughness effect on synthetic hydroxyapatite wear. Dent Mater 2013; 29(6): 666-673.

Sailer, I.; Zembic, A.; Jung, R. E.; Hammerle, C. H.; Mattiola, A. Single-tooth implant reconstructions: esthetic factors influencing the decision between titanium and zirconia abutments in anterior regions. Eur J Esthet Dent 2007; 2(3): 296-310.

Sakuma, T.; Yoshizawa, Y. I.; Suto, H. The rhombohedral phase produced in partially stabilized zirconia. J Mater Sci Lett 1985; 4(1): 29-30.

Schiroli, G. Single-tooth implant restorations in the esthetic zone with Pure Form ceramic crowns: 3 case reports. Oral Implantol 2004; 30(6): 358-63.

Scott, H. G. Phase relationships in the zirconia-yttria system. J Mater Sci 1975; 10(9): 15271535.

Shembish, F. A.; Tong, H.; Kaizer, M.; Janal, M. N.; Thompson, V. P.; Opdam, N. J.; et al. Fatigue resistente of CAD/CAM resin composite molar crowns. Dent Mater 2016; 32(4): 499509.

Silva, L. H. D.; Lima, E.; Miranda, R. B. P.; Favero, S. S.; Lohbauer, U.; Cesar, P. F. Dental ceramics: a review of new materials and processing methods. Braz Oral Res 2017; 31(1): e58. Available from <http://www.scielo.br/scielo.php?script=sci_arttext\&pid=S18068324201700 500203\&lng=en\&nrm=iso $>$.

Standart test method for Dynamic Young's Modulus, Shear Modulus, and Poisson's Ratio by impulse excitation of vibration; designation: E 1876 - 07. ASTM International, 2007. p 15.

Subasi, M. G.; Demir, N.; Kara, O.; Ozturk, N.; Faruk, O. Mechanical properties of zirconia after different surface treatments and repeated firings. J Adv. Prosthodont 2014; 6(6): 462467.

Sundh, A.; Molin, M.; Sjögren, G. Fracture resistance of yttrium oxide partially-stabilized zirconia all-ceramic bridges after veneering and mechanical fatigue testing. Dent Mater 2005; 21(5): 476-82.

Sundh, A.; Sjögren, G. A study of the bending resistance of implant-supported reinforced alumina and machined zirconia abutments and copies. Dent Mater 2008; 24(5): 611-7.

Tanimoto, Y. Dental materials used for metal-free restorations: Recent advances and future challenges. J Prosthodont Res 2015; 59(4): 213-5. 
Tripodakis, A. P.; Strub, J. R.; Kappert, H. F.; Witkowski, S. Strength and mode of failure of single implant all-ceramic abutment restorations under static load. Int J Prosthodont 1995; 8(3): 265-72.

Vagkopoulou, T.; Koutayas, S. O.; Koidis, P.; Strub, J. R. Zirconia in dentistry: Part 1. Discovering the nature of an upcoming bioceramic. Eur J Esthet Dent 2009; 4(2): 130-51.

Varga, S.; Spalj, S.; Varga, M. P.; Milosevic, S. A.; Mestrovic, S.; Slaj, M. Maximum voluntary molar bite force in subjects with normal occlusion. Eur J Orthod 2011; 33(4): 427-33.

Varoni, E. M.; Moltrasio, G.; Gargano, M.; Ludwig, N.; Lodi, G.; Scaringi, R. Color analysis of periimplant soft tissues focusing on implant system: a case series. Implant Dent 2017; 26(2): 217-24

Vigolo, P.; Fonzi, F.; Majzoub, Z.; Cordioli, G. An in vitro evaluation of titanium, zirconia, and alumina procera abutments with hexagonal connection. Int J Oral Maxillofac Implants 2006; 21(4): 575-80.

Villefort, R. F.; Amaral, M.; Pereira, G. K. R.; Campos, T. M.; Zhang, Y.; Bottino, M. A.; Valandro, L. F.; de Melo, R. M. Effects of two grading techniques of zirconia material on the fatigue limit of full-contour 3-unit fixed dental prostheses. Dent Mater 2017; 33(4): e155e164.

Yildirim, M.; Fischer, H.; Marx, R.; Edelhoff, D. In vivo fracture resistance of implantsupported all-ceramic restorations. J Prosthet Dent 2003; 90(4): 325-31

Yin L. Property-process relations in simulated clinical abrasive adjusting of dental ceramics. J Mech Behav Biomed 2012; 16: 55-65.

Yousef, H.; Luke, A.; Ricci, J.; Weiner, S. Analysis of change in implant screws subject to occlusal loading: A preliminary analyses. Implant Dent 2005; 14(4): 378-382.

Zhang, Y.; Sailer, I.; Lawn, B. R. Fatigue of dental ceramics. J Dent 2013; 41(12): 1135-1147.

Zucuni, C. P.; Guilardi, L. F.; Fraga, S.; May, L. G.; Pereira, G. K. R.; Valandro, L. F. CAD/CAM machining vs pre-sintering in-lab fabrication techniques of Y-TZP ceramic specimens: Effects on their mechanical fatigue behavior. J Mech Behav Biomed Mater 2017B; 71: 201-208.

Zucuni, C. P.; Guilardi, L. F.; Rippe, M. P.; Pereira, G. K. R.; Valandro, L. F. Fatigue strength of yttria-stabilized zirconia polycrystals: Effects of grinding, polishing, glazing, and heat treatment. J Mech Behav Biomed Mater 2017A; 75: 512-520. 

Qpêndices 



\section{APÊNDICES}

APÊNDICE A - Dados originais da rugosidade superficial (Sa) do Grupo C

\begin{tabular}{ccccccc}
\hline $\begin{array}{c}\text { Corpo de } \\
\text { prova }\end{array}$ & $\mathbf{R 1}$ & $\mathbf{R 2}$ & $\mathbf{R 3}$ & $\mathbf{R 4}$ & $\mathbf{R 5}$ & Média \\
\hline $\mathbf{C 1}$ & 1,393 & 1,465 & 1,356 & 1,399 & 1,407 & 1,404 \\
\hline $\mathbf{C 2}$ & 1,561 & 1,491 & 1,629 & 1,505 & 1,324 & 1,502 \\
\hline $\mathbf{C 3}$ & 1,661 & 1,795 & 1,622 & 1,632 & 1,795 & 1,701 \\
\hline $\mathbf{C 4}$ & 1,855 & 1,575 & 1,596 & 1,576 & 1,935 & 1,7074 \\
\hline $\mathbf{C 5}$ & 3,672 & 1,997 & 1,727 & 1,821 & 3,321 & 2,5076 \\
\hline $\mathbf{C 6}$ & 1,414 & 1,512 & 1,494 & 1,504 & 1,525 & 1,4898 \\
\hline $\mathbf{C 7}$ & 2,103 & 1,966 & 1,775 & 1,672 & 1,685 & 1,8402 \\
\hline $\mathbf{C} 8$ & 2,429 & 1,736 & 1,929 & 2,009 & 2,117 & 2,044 \\
\hline $\mathbf{C 9}$ & 1,632 & 1,601 & 1,66 & 1,449 & 1,393 & 1,547 \\
\hline C10 & 1,669 & 1,721 & 1,617 & 1,561 & 1,508 & 1,6152 \\
\hline C11 & 1,551 & 1,611 & 1,527 & 1,456 & 1,578 & 1,5446 \\
\hline C12 & 1,656 & 1,654 & 2,188 & 0,916 & 1,606 & 1,604 \\
\hline C13 & 1,456 & 1,395 & 1,459 & 1,469 & 1,553 & 1,4664 \\
\hline C14 & 1,725 & 1,805 & 1,995 & 2,155 & 1,857 & 1,9074 \\
\hline C15 & 1,634 & 1,882 & 1,633 & 1,855 & 1,823 & 1,7654 \\
\hline C16 & 1,561 & 1,626 & 1,745 & 1,747 & 1,623 & 1,6604 \\
\hline C17 & 1,661 & 1,832 & 1,875 & 2,05 & 2,196 & 1,9228 \\
\hline C18 & 2,274 & 2,025 & 1,721 & 1,701 & 1,819 & 1,908 \\
\hline C19 & 1,667 & 1,588 & 1,521 & 1,542 & 1,728 & 1,6092 \\
\hline C20 & 1,665 & 1,626 & 1,579 & 1,728 & 1,66 & 1,6516 \\
\hline C21 & 1,279 & 1,624 & 1,645 & 2,078 & 1,821 & 1,6894 \\
\hline
\end{tabular}

APÊNDICE B - Dados originais da rugosidade superficial (Sa) do Grupo A

\begin{tabular}{|c|c|c|c|c|c|c|}
\hline $\begin{array}{c}\text { Corpo de } \\
\text { prova }\end{array}$ & R1 & $\mathbf{R 2}$ & R3 & R4 & R5 & Média \\
\hline A1 & 8,951 & 6,708 & 7,377 & 9,226 & 6,246 & 7,95 \\
\hline A2 & 6,06 & 5,959 & 6,064 & 6,09 & 6,195 & 6,0736 \\
\hline A3 & 6,574 & 7,183 & 4,928 & 6,521 & 6,757 & 6,3926 \\
\hline A4 & 6,653 & 8,346 & 7,371 & 7,392 & 6,423 & 7,237 \\
\hline A5 & 4,05 & 5,833 & 4,438 & 4,897 & 8,213 & 5,4862 \\
\hline A6 & 8,776 & 7,655 & 7,149 & 7,982 & 8,363 & 7,985 \\
\hline A7 & 6,648 & 6,381 & 6,317 & 7,008 & 4,926 & 6,256 \\
\hline A8 & 6,747 & 7,057 & 7,95 & 7,7 & 7,195 & 7,3298 \\
\hline A9 & 5,955 & 6,041 & 6,472 & 7,199 & 6,375 & 6,4084 \\
\hline A10 & 7,478 & 7,673 & 8,343 & 7,526 & 7,724 & 7,7488 \\
\hline A11 & 7,193 & 6,835 & 5,572 & 5,969 & 6,018 & 6,3174 \\
\hline A12 & 4,936 & 4,071 & 4,902 & 5,58 & 5,418 & 4,9814 \\
\hline A13 & 8,755 & 7,677 & 7,57 & 7,435 & 6,832 & 7,6538 \\
\hline A14 & 4,491 & 6,568 & 6,68 & 6,646 & 6,345 & 6,146 \\
\hline A15 & 6,987 & 7,566 & 7,173 & 7,014 & 7,158 & 7,1796 \\
\hline A16 & 5,668 & 8,005 & 7,94 & 8,011 & 8,706 & 7,666 \\
\hline A17 & 7,37 & 8,153 & 7,157 & 6,766 & 6,944 & 7,278 \\
\hline A18 & 6,413 & 2,783 & 5,918 & 5,936 & 6 & 5,41 \\
\hline A19 & 6,799 & 5,05 & 5,062 & 7,356 & 7,33 & 6,3194 \\
\hline A20 & 7,564 & 8,252 & 8,631 & 7,324 & 7,622 & 7,8786 \\
\hline A21 & 8,21 & 7,927 & 6,566 & 6,304 & 5,827 & 6,9668 \\
\hline
\end{tabular}


APÊNDICE C - Dados originais da rugosidade superficial (Sa) do Grupo B

\begin{tabular}{ccccccc}
\hline $\begin{array}{c}\text { Corpo de } \\
\text { prova }\end{array}$ & R1 & R2 & R3 & R4 & R5 & Média \\
\hline B1 & 5,261 & 5,202 & 5,244 & 5,687 & 4,855 & 5,2498 \\
\hline B2 & 5,008 & 5,362 & 5,515 & 5,636 & 5,221 & 5,3484 \\
\hline B3 & 6,475 & 6,456 & 7,322 & 7,559 & 8,013 & 7,165 \\
\hline B4 & 5,434 & 5,112 & 5,732 & 6,121 & 7,372 & 5,9542 \\
\hline B5 & 5,087 & 5,529 & 5,028 & 6,633 & 5,9 & 5,6354 \\
\hline B6 & 4,752 & 4,651 & 4,225 & 3,956 & 3,691 & 4,255 \\
\hline B7 & 4,804 & 5,759 & 5,998 & 6,701 & 6,887 & 6,0298 \\
\hline B8 & 6,872 & 6,406 & 5,996 & 6,787 & 6,713 & 6,5548 \\
\hline B9 & 8,346 & 9,791 & 8,997 & 7,493 & 7,146 & 8,3546 \\
\hline B10 & 1,881 & 3,147 & 4,118 & 4,092 & 4,021 & 3,4518 \\
\hline B11 & 4,19 & 3,725 & 3,682 & 4,693 & 4,064 & 4,0708 \\
\hline B12 & 6,898 & 5,444 & 6,002 & 5,852 & 5,228 & 5,8848 \\
\hline B13 & 3,303 & 4,971 & 5,164 & 5,219 & 5,107 & 4,7528 \\
\hline B14 & 7,029 & 5,02 & 4,434 & 7,242 & 6,808 & 6,1066 \\
\hline B15 & 5,639 & 5,599 & 5,793 & 5,769 & 5,646 & 5,6892 \\
\hline B16 & 5,447 & 5,165 & 6,222 & 5,004 & 5,259 & 5,4194 \\
\hline B17 & 3,646 & 3,445 & 3,385 & 4,232 & 4,655 & 3,8726 \\
\hline B18 & 5,396 & 4,926 & 4,501 & 4,778 & 5,346 & 4,9894 \\
\hline B19 & 3,871 & 4,09 & 3,789 & 3,92 & 4,116 & 3,9572 \\
\hline B20 & 4,778 & 4,994 & 4,578 & 5,267 & 5,029 & 4,9292 \\
\hline B21 & 4,459 & 4,739 & 3,861 & 4,133 & 4,652 & 4,3688 \\
\hline & & & & & &
\end{tabular}

APÊNDICE D - Dados originais do módulo de elasticidade dinâmico (GPa) do Grupo C

\begin{tabular}{|c|c|}
\hline Corpo de prova & MEflex \\
\hline C1 & 201,68 \\
\hline $\mathrm{C2}$ & 216,51 \\
\hline C3 & 188,73 \\
\hline C4 & 232,92 \\
\hline C5 & 212,80 \\
\hline C6 & 216,30 \\
\hline C7 & 223,84 \\
\hline C8 & 222,84 \\
\hline C9 & 219,02 \\
\hline C10 & 205,47 \\
\hline C11 & 167,38 \\
\hline C12 & 215,95 \\
\hline C13 & 224,92 \\
\hline C14 & 176,30 \\
\hline C15 & 200,42 \\
\hline C16 & 205,58 \\
\hline C17 & 193,94 \\
\hline C18 & 195,69 \\
\hline C19 & 170,41 \\
\hline $\mathrm{C20}$ & 195,60 \\
\hline $\mathrm{C} 21$ & 160,13 \\
\hline
\end{tabular}


APÊNDICE E - Dados originais do módulo de elasticidade dinâmico (GPa) do Grupo A

\begin{tabular}{cc}
\hline Corpo de prova & MEflex \\
\hline A1 & 202,91 \\
\hline A2 & 175,99 \\
\hline A3 & 193,03 \\
\hline A4 & 205,86 \\
\hline A5 & 134,19 \\
\hline A6 & 219,76 \\
\hline A7 & 212,74 \\
\hline A8 & 195,25 \\
\hline A9 & 211,69 \\
\hline A10 & 220,29 \\
\hline A11 & 199,00 \\
\hline A12 & 217,06 \\
\hline A13 & 201,14 \\
\hline A14 & 203,20 \\
\hline A15 & 202,47 \\
\hline A16 & 182,71 \\
\hline A17 & 197,06 \\
\hline A18 & 201,50 \\
\hline A19 & 207,56 \\
\hline A20 & 205,26 \\
\hline A21 & 192,57 \\
\hline & \\
\hline & \\
\hline & \\
\hline & \\
\hline & \\
\hline & \\
\hline & \\
\hline & \\
\hline
\end{tabular}

APÊNDICE F - Dados originais do módulo de elasticidade dinâmico (GPa) do Grupo B

\begin{tabular}{|c|c|}
\hline Corpo de prova & MEflex \\
\hline B1 & 235,82 \\
\hline B2 & 210,32 \\
\hline B3 & 219,32 \\
\hline B4 & 202,24 \\
\hline B5 & 227,72 \\
\hline B6 & 229,26 \\
\hline B7 & 205,03 \\
\hline B8 & 195,00 \\
\hline B9 & 219,60 \\
\hline B10 & 216,33 \\
\hline B11 & 220,83 \\
\hline B12 & 196,19 \\
\hline B13 & 238,83 \\
\hline B14 & 207,57 \\
\hline B15 & 207,64 \\
\hline B16 & 214,96 \\
\hline B17 & 234,34 \\
\hline B18 & 223,44 \\
\hline B19 & 212,63 \\
\hline B20 & 228,32 \\
\hline B21 & 215,18 \\
\hline
\end{tabular}


APÊNDICE G - Dados originais da resistência à flexão (MPa) do Grupo C

\begin{tabular}{cc}
\hline Corpo de prova & RF \\
\hline C1 & 1145,173 \\
\hline C2 & 1233,907 \\
\hline C3 & 940,5048 \\
\hline
\end{tabular}

APÊNDICE H - Dados originais da resistência à flexão (MPa) do Grupo A

\begin{tabular}{cc}
\hline Corpo de prova & RF \\
\hline A1 & 810,9714 \\
\hline A2 & 1282,223 \\
\hline A3 & 1434,296 \\
\hline
\end{tabular}

APÊNDICE I - Dados originais da resistência à flexão (MPa) do Grupo B

\begin{tabular}{cc}
\hline Corpo de prova & RF \\
\hline B1 & 1440,546 \\
\hline B2 & 1442,553 \\
\hline B3 & 1693,24 \\
\hline
\end{tabular}

APÊNDICE J - Força (N) aplicada nos diferentes patamares dos três carregamentos realizados para o Grupo C

\begin{tabular}{cccccccccccc}
\hline & $\mathbf{1}$ & $\mathbf{2}$ & $\mathbf{4}$ & $\mathbf{4}$ & $\mathbf{5}$ & $\mathbf{6}$ & $\mathbf{7}$ & $\mathbf{8}$ & $\mathbf{9}$ & $\mathbf{1 0}$ & $\mathbf{1 1}$ \\
\hline $\begin{array}{c}\text { Carregamento } \\
\text { leve }\end{array}$ & 83 & 94 & 104 & 115 & 125 & 136 & 146 & 157 & 167 & 178 & 188 \\
\hline $\begin{array}{c}\text { Carregamento } \\
\text { moderado }\end{array}$ & 83 & 104 & 125 & 146 & 167 & 188 & & & & \\
\hline $\begin{array}{c}\text { Carregamento } \\
\text { severo }\end{array}$ & 83 & 115 & 125 & 157 & 188 & & & & & \\
\hline
\end{tabular}

APÊNDICE K - Força (N) aplicada nos diferentes patamares dos três carregamentos realizados para o Grupo A

\begin{tabular}{cccccccccccc}
\hline & $\mathbf{1}$ & $\mathbf{2}$ & $\mathbf{4}$ & $\mathbf{4}$ & $\mathbf{5}$ & $\mathbf{6}$ & $\mathbf{7}$ & $\mathbf{8}$ & $\mathbf{9}$ & $\mathbf{1 0}$ & $\mathbf{1 1}$ \\
\hline $\begin{array}{c}\text { Carregamento } \\
\text { leve }\end{array}$ & 91 & 102 & 114 & 125 & 137 & 148 & 160 & 171 & 182 & 194 & 205 \\
\hline $\begin{array}{c}\text { Carregamento } \\
\text { moderado }\end{array}$ & 91 & 114 & 137 & 160 & 182 & 205 & & & & & \\
\hline $\begin{array}{c}\text { Carregamento } \\
\text { severo }\end{array}$ & 91 & 125 & 137 & 171 & 205 & & & & & & \\
\hline
\end{tabular}


APÊNDICE L - Força (N) aplicada nos diferentes patamares dos três carregamentos realizados para o Grupo B

\begin{tabular}{cccccccccccc}
\hline & $\mathbf{1}$ & $\mathbf{2}$ & $\mathbf{4}$ & $\mathbf{4}$ & $\mathbf{5}$ & $\mathbf{6}$ & $\mathbf{7}$ & $\mathbf{8}$ & $\mathbf{9}$ & $\mathbf{1 0}$ & $\mathbf{1 1}$ \\
\hline $\begin{array}{c}\text { Carregamento } \\
\text { leve }\end{array}$ & 118 & 132 & 147 & 162 & 177 & 191 & 206 & 221 & 236 & 250 & 265 \\
\hline $\begin{array}{c}\text { Carregamento } \\
\text { moderado }\end{array}$ & 118 & 147 & 177 & 206 & 236 & 265 & & & & \\
\hline $\begin{array}{c}\text { Carregamento } \\
\text { severo }\end{array}$ & 118 & 162 & 177 & 221 & 265 & & & & & \\
\hline
\end{tabular}

APÊNDICE M - Dados originais do Grupo C quando submetido à carregamento leve

\begin{tabular}{|c|c|c|c|c|c|c|c|c|c|c|c|c|}
\hline $\begin{array}{c}\text { Corpo de } \\
\text { prova }\end{array}$ & 1 & 2 & 3 & 4 & 5 & 6 & 7 & 8 & 9 & 10 & 11 & $\begin{array}{l}\mathrm{N}^{\circ} \text { total } \\
\text { de ciclos }\end{array}$ \\
\hline C1 & $S$ & $S$ & $S$ & $S$ & $\mathrm{~F}$ & - & - & - & - & - & - & 63044 \\
\hline $\mathrm{C2}$ & $S$ & $S$ & $S$ & $S$ & $S$ & $\mathrm{~F}$ & - & - & - & - & - & 74044 \\
\hline C3 & $S$ & $S$ & $S$ & $S$ & $S$ & $S$ & $S$ & $S$ & $\mathrm{~F}$ & - & - & 120157 \\
\hline C4 & $S$ & $\mathrm{~S}$ & $\mathrm{~F}$ & - & - & - & - & - & - & - & - & 34104 \\
\hline C5 & $S$ & $S$ & $\mathrm{~F}$ & - & - & - & - & - & - & - & - & 31960 \\
\hline C6 & $S$ & $S$ & $S$ & $S$ & $\mathrm{~F}$ & - & - & - & - & - & - & 59069 \\
\hline
\end{tabular}

S: a amostra sobreviveu a este patamar

F: a amostra fraturou neste patamar

APÊNDICE N - Dados originais do Grupo C quando submetido à carregamento moderado

\begin{tabular}{cccccccc}
\hline $\begin{array}{c}\text { Corpo } \\
\text { de prova }\end{array}$ & $\mathbf{1}$ & $\mathbf{2}$ & $\mathbf{3}$ & $\mathbf{4}$ & $\mathbf{5}$ & $\mathbf{6}$ & $\begin{array}{c}\mathbf{N}^{\circ} \text { total } \\
\text { de ciclos }\end{array}$ \\
\hline C7 & S & F & - & - & - & - & 14596 \\
\hline C8 & S & S & S & S & F & - & 57834 \\
\hline C9 & S & F & - & - & - & - & 15724 \\
\hline C10 & S & S & S & S & S & S & 86400 \\
\hline C11 & S & S & F & - & - & - & 29169 \\
\hline C12 & S & S & S & S & F & - & 57679 \\
\hline
\end{tabular}

S: a amostra sobreviveu a este patamar

F: a amostra fraturou neste patamar 
APÊNDICE O - Dados originais do Grupo C quando submetido à carregamento severo

\begin{tabular}{ccccccc}
\hline $\begin{array}{c}\text { Corpo } \\
\text { de prova }\end{array}$ & $\mathbf{1}$ & $\mathbf{2}$ & $\mathbf{3}$ & $\mathbf{4}$ & $\mathbf{5}$ & $\begin{array}{c}\mathbf{N}^{\circ} \text { total } \\
\text { de ciclos }\end{array}$ \\
\hline C13 & S & S & S & F & - & 50547 \\
\hline C14 & S & S & S & F & - & 45603 \\
\hline C15 & S & S & S & F & - & 43987 \\
\hline C16 & S & S & F & - & - & 30042 \\
\hline C17 & S & S & F & - & - & 39612 \\
\hline C18 & S & S & F & - & - & 37192 \\
\hline
\end{tabular}

S: a amostra sobreviveu a este patamar

F: a amostra fraturou neste patamar

APÊNDICE P - Dados originais do Grupo A quando submetido à carregamento leve

\begin{tabular}{|c|c|c|c|c|c|c|c|c|c|c|c|c|}
\hline $\begin{array}{l}\text { Corpo de } \\
\text { prova }\end{array}$ & 1 & 2 & 3 & 4 & 5 & 6 & 7 & 8 & 9 & 10 & 11 & $\begin{array}{l}N^{\circ} \text { total } \\
\text { de ciclos }\end{array}$ \\
\hline A1 & $\mathrm{F}$ & - & - & - & - & - & - & - & - & - & - & 3171 \\
\hline A2 & $\mathrm{S}$ & $S$ & $S$ & $S$ & $S$ & $S$ & $\mathrm{~F}$ & - & - & - & - & 89389 \\
\hline A3 & $\mathrm{F}$ & - & - & - & - & - & - & - & - & - & - & 1500 \\
\hline A4 & $S$ & $S$ & $S$ & $\mathrm{~F}$ & - & - & - & - & - & - & - & 45639 \\
\hline A5 & $\mathrm{F}$ & - & - & - & - & - & - & - & - & - & - & 3562 \\
\hline A6 & $\mathrm{S}$ & $S$ & $\mathrm{~S}$ & $\mathrm{~S}$ & $\mathrm{~S}$ & $\mathrm{~S}$ & $\mathrm{~F}$ & - & - & - & - & 86661 \\
\hline
\end{tabular}

S: a amostra sobreviveu a este patamar

F: a amostra fraturou neste patamar

APÊNDICE Q - Dados originais do Grupo A quando submetido à carregamento moderado

\begin{tabular}{cccccccc}
$\begin{array}{c}\text { Corpo de } \\
\text { prova }\end{array}$ & $\mathbf{1}$ & $\mathbf{2}$ & $\mathbf{3}$ & $\mathbf{4}$ & $\mathbf{5}$ & $\mathbf{6}$ & $\begin{array}{c}\mathbf{N}^{\circ} \text { total } \\
\text { de ciclos }\end{array}$ \\
\hline A7 & S & S & S & F & - & - & 43284 \\
\hline A8 & S & F & - & - & - & - & 27947 \\
\hline A9 & S & S & S & F & - & - & 43341 \\
\hline A10 & S & S & S & F & - & - & 55182 \\
\hline A11 & S & S & S & F & - & - & 43485 \\
\hline A12 & S & S & S & S & S & F & 72706 \\
\hline
\end{tabular}

S: a amostra sobreviveu a este patamar

F: a amostra fraturou neste patamar

APÊNDICE R - Dados originais do Grupo A quando submetido à carregamento severo

\begin{tabular}{ccccccc}
\hline $\begin{array}{c}\text { Corpo de } \\
\text { prova }\end{array}$ & $\mathbf{1}$ & $\mathbf{2}$ & $\mathbf{3}$ & $\mathbf{4}$ & $\mathbf{5}$ & $\begin{array}{c}\mathbf{N}^{\circ} \text { total } \\
\text { de ciclos }\end{array}$ \\
\hline A13 & S & S & F & - & - & 30994 \\
\hline A14 & S & F & - & - & - & 17062 \\
\hline A15 & F & - & - & - & - & 12820 \\
\hline A16 & S & S & S & F & - & 43909 \\
\hline A17 & S & F & - & - & - & 14520 \\
\hline A18 & S & S & S & F & - & 43998 \\
\hline
\end{tabular}

S: a amostra sobreviveu a este patamar

F: a amostra fraturou neste patamar 
APÊNDICE S - Dados originais do Grupo B quando submetido à carregamento leve

\begin{tabular}{ccccccccccccc}
\hline $\begin{array}{c}\text { Corpo } \\
\text { de prova }\end{array}$ & $\mathbf{1}$ & $\mathbf{2}$ & $\mathbf{3}$ & $\mathbf{4}$ & $\mathbf{5}$ & $\mathbf{6}$ & $\mathbf{7}$ & $\mathbf{8}$ & $\mathbf{9}$ & $\mathbf{1 0}$ & $\mathbf{1 1}$ & $\begin{array}{c}\mathbf{N}^{\circ} \text { total } \\
\text { de ciclos }\end{array}$ \\
\hline B1 & S & S & S & F & - & - & - & - & - & - & - & 49271 \\
\hline B2 & S & S & S & S & S & F & - & - & - & - & - & 72778 \\
\hline B3 & S & S & S & S & S & S & F & - & - & - & - & 87800 \\
\hline B4 & S & S & S & S & S & S & S & S & F & - & - & 117351 \\
\hline B5 & S & S & S & S & S & S & F & - & - & - & - & 87830 \\
\hline B6 & S & S & S & S & S & S & F & - & - & - & - & 89204 \\
\hline
\end{tabular}

S: a amostra sobreviveu a este patamar

F: a amostra fraturou neste patamar

APÊNDICE T - Dados originais do Grupo B quando submetido à carregamento moderado

\begin{tabular}{cccccccc}
$\begin{array}{c}\text { Corpo } \\
\text { de prova }\end{array}$ & $\mathbf{1}$ & $\mathbf{2}$ & $\mathbf{3}$ & $\mathbf{4}$ & $\mathbf{5}$ & $\mathbf{6}$ & $\begin{array}{c}\mathbf{N}^{\circ} \text { total } \\
\text { de ciclos }\end{array}$ \\
\hline B7 & S & S & S & F & - & - & 43586 \\
\hline B8 & F & - & - & - & - & - & 1020 \\
\hline B9 & S & F & - & - & - & - & 19254 \\
\hline B10 & S & S & S & S & F & - & 60936 \\
\hline B11 & S & S & F & - & - & - & 29292 \\
\hline B12 & S & F & - & - & - & - & 15630 \\
\hline
\end{tabular}

S: a amostra sobreviveu a este patamar

F: a amostra fraturou neste patamar

APÊNDICE U - Dados originais do Grupo B quando submetido à carregamento severo

\begin{tabular}{ccccccc}
\hline $\begin{array}{c}\text { Corpo de } \\
\text { prova }\end{array}$ & $\mathbf{1}$ & $\mathbf{2}$ & $\mathbf{3}$ & $\mathbf{4}$ & $\mathbf{5}$ & $\begin{array}{c}\mathbf{N}^{\circ} \text { total } \\
\text { de ciclos }\end{array}$ \\
\hline B13 & S & F & - & - & - & 18435 \\
\hline B14 & S & S & S & F & - & 43249 \\
\hline B15 & S & S & F & - & - & 29120 \\
\hline B16 & S & S & S & F & - & 43240 \\
\hline B17 & S & S & S & F & - & 43374 \\
\hline B18 & S & S & S & S & F & 57942 \\
\hline
\end{tabular}

